\title{
Production of high value amine intermediates via biocatalytic cascades in continuous flow
}

Ashley P. Mattey, ${ }^{1}$ Grayson J. Ford ${ }^{1}$ Joan Citoler, ${ }^{1}$ Christopher Baldwin, ${ }^{1}$ James R. Marshall, ${ }^{1}$ Ryan B. Palmer, ${ }^{1}$ Matthew Thompson, ${ }^{2}$ Nicholas J. Turner, ${ }^{1}$ Sebastian C. Cosgrove,,${ }^{1,3^{*}}$ Sabine L. Flitsch ${ }^{*}$

${ }^{1}$ Manchester Institute of Biotechnology (MIB) \& School of Chemistry, The University of Manchester, 131 Princess Street, Manchester, M1 7DN, United Kingdom

²EnginZyme AB, Tomtebodevägen 617165 , Stockholm, Sweden.

${ }^{3}$ Lennard-Jones Laboratory, School of Chemical and Physical Sciences, Keele University, Keele, Staffordshire ST5 5BG, United Kingdom

Corresponding author email: sabine.flitsch@manchester.ac.uk; s.cosgrove@keele.ac.uk

\begin{abstract}
A key aim of biocatalysis is to mimic the ability of eukaryotic cells to carry out compartmentalized multistep cascades in a controlled and selective way. As biocatalytic cascades get longer and more complex, reactions become unattainable under typical batch conditions. Here a continuous flow multipoint injection reactor was combined with switching valves to overcome batch incompatibility, thus allowing for successful biocatalytic reaction cascades. As proof-of-principle, several reactive carbonyl intermediates were generated in situ using galactose oxidase and engineered choline oxidases, then passed directly to a series of packed-bed modules containing different aminating biocatalysts which accordingly produced a range of structurally distinct amines. The method was expanded to employ a batch incompatible sequential amination cascade via an oxidase-transaminase-imine reductase sequence, introducing different amine reagents at each step without cross reactivity. The combined approaches allowed for the biocatalytic synthesis of the natural product alkaloid precursor 40methylnorbelladine. The flow biocatalysis platform shown here significantly increases the scope of novel biocatalytic cascades, removing previous limitations due to reaction and reagent batch incompatibility.
\end{abstract}

\section{Main}

Multi-step synthesis in biocatalysis has been made more efficient through the utilization of enzymatic cascades. No longer are reactions limited by intermediate isolation, thus significantly reducing time and waste. ${ }^{1,2}$ The design of multienzyme systems has provided convenient syntheses of a number of high value compounds and are now seen as the method of choice in implementing biocatalytic reactions. ${ }^{3,4}$ Computer-aided synthesis planning (CASP) is also poised to revolutionize biocatalytic synthesis planning. ${ }^{5}$ Nevertheless, while biocatalytic cascades are increasingly considered as the method of choice for more complex syntheses, there are still limitations to one-pot systems due to incompatible enzyme/substrate combinations.

Flow chemistry has seen rapid development in recent years, with the potential to improve $\sim 50 \%$ of chemical processes. ${ }^{6}$ Small scale flow systems can more easily be translated into larger scale production with minimal optimization, a luxury not afforded in batch processes. ${ }^{7,8}$ Another advantage is that continuous flow systems can be composed of different modules (different reactor types), which can enable the combination of a broad range of chemistries that are incompatible under batch conditions (Figure 1). ${ }^{9}$ Further to this, the utilization of continuous flow systems facilitates the integration of several reaction steps resulting in telescoped synthetic sequences. ${ }^{10}$

Issues that arise with analytical biotransformations not being translatable to scale or different biocatalytic reaction types being incompatible, has led to the emergence of continuous flow biocatalysis as a favorable option to alleviate these issues. ${ }^{11}$ Operating under a continuous regime allows for greater control of reaction conditions as well as providing opportunities for inline analysis and purification, as well as automation. ${ }^{12,13}$ Most flow biocatalysis systems utilize immobilized enzymes, which vastly improve reusability and often increases thermal stability and solvent tolerance. ${ }^{14-16}$ The combination of immobilization and continuous flow reactors means that enzymes can be 
compartmentalized and segregated, allowing access to previously incompatible reactions in sequential reactor modules. Herein, efforts to exploit the power of biosynthetic cascades with a continuous, compartmentalization approach containing multiple reactor types and a combination of free and immobilized enzyme are described. In this work the issues of cross reactivity and reaction incompatibility in linear enzymatic cascades are addressed whilst also showing compartmentalized flow systems can be used to overcome metabolic flux issues associated with in vitro cascades. ${ }^{17}$ This allows the expansion of the scope of biocatalytic cascades available through exploitation of previously incompatible systems (Figure 1). The aim was to adopt a modular approach using standard laboratory equipment to generate versatile systems which enable access to a broad range of chemistries in a sustainable manner.

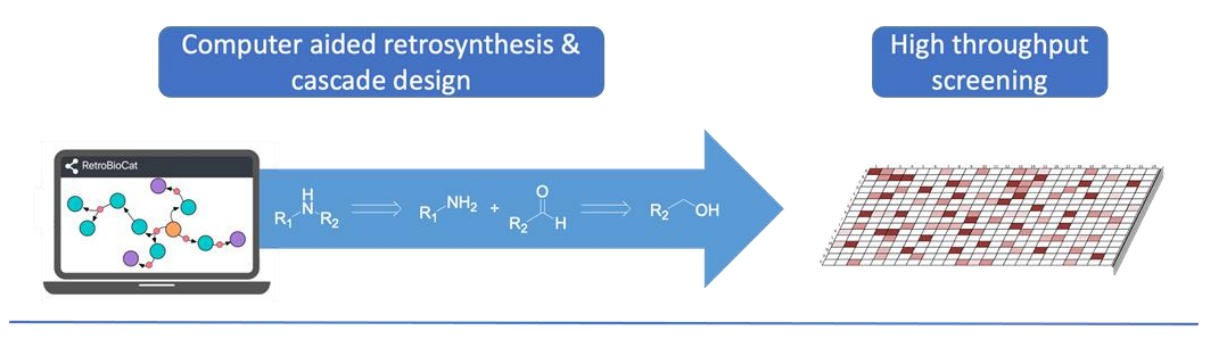

Scaling in continuous flow

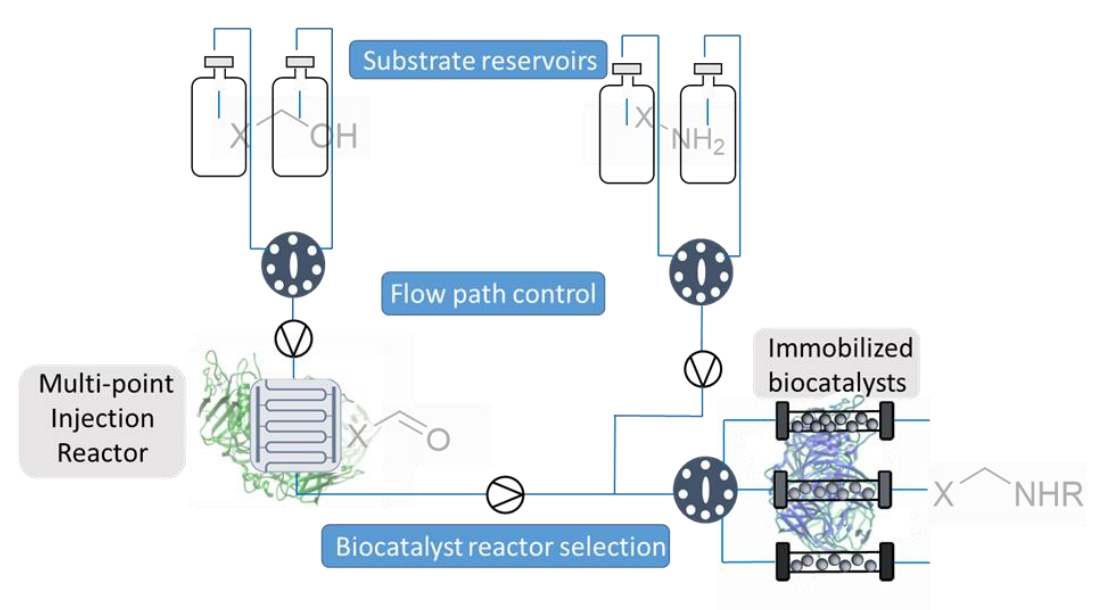

Figure 1. Computer-aided synthesis planning and high-throughput screening have placed biocatalysis at a position for mass adoption. Advanced compartmentalized continuous flow systems can be used to overcome incompatible enzyme combinations/chemistries can deliver the lab-based technological advancement necessary to fully realize this transformation.

The reaction cascades described here start with the generation of aldehydes from stable and commercially available alcohol starting materials. As aldehydes are versatile yet unstable intermediates, it was thought a continuous flow system that generated this group in situ at high concentrations and subsequently allowed for a range of further enzymatic modification.

Biocatalytic oxidations are fundamental in transitioning to a bio-based economy, in particular the use of oxidases which carry out selective oxidation using molecular oxygen as the sole oxidant. ${ }^{18,19}$ To overcome potential limitations of oxygen concentration, a previously described multipoint injection reactor (MPIR) was employed; it was shown to greatly improve the productivity of oxidase biocatalysts by negating low aqueous oxygen availability through in situ biocatalytic generation from hydrogen peroxide (Table 1). ${ }^{20-22}$ An engineered choline oxidase $\left(\mathrm{AcCO}_{6}\right)$ was initially chosen as an ideal biocatalyst to test in the MPIR due to its broad substrate scope and as it 
has been applied in biocatalytic cascades. ${ }^{23,24}$ Using the MPIR, AcCO6 productivity was vastly improved for the oxidation of a number of aromatic and aliphatic primary alcohols with a 57.7 fold improvement in space time yield and 3.7 fold improvement in productivity in the oxidation of phenylethanol (see Supporting Information). The biooxidations were further optimized to ensure no over-oxidation to the corresponding acid was observed, an issue associated with batch reactions and a previous flow report for this enzyme. ${ }^{14}$

Following the successful implementation of the MPIR for the generation of aldehydes, the system was expanded by carrying out subsequent continuous bio-reductive aminations. Amines are important molecules in synthetic chemistry, with a significant proportion of the reactions performed by medicinal chemists reported to be associated with amino-group chemistry. ${ }^{25}$ Biocatalytic amine synthesis has been advanced by transaminases and imine reductases/reductive aminases (IREDs/RedAms), with the use of aminating biocatalysts providing selective and sustainable options for the synthesis of chiral amines. ${ }^{26,27}$ One of the most frequently applied aminating enzymes in flow is transaminase. ${ }^{28,29}$ Therefore, the transaminase from Bacillus megaterium (BmTA) was immobilized and loaded it into a packed-bed reactor. ${ }^{23,30}$ This was connected to the output of the MPIR (with inline mixing via a micro static mixer), generating an MPIR-packed bed system (MPBS). Pleasingly, full conversion to the corresponding primary amine 2 was achieved at steady state and maintained for four hours (STY: $1.58 \mathrm{~g} \mathrm{~L}^{-1} \mathrm{~h}$ $1)$.

For the generation of secondary amines such as $\mathbf{3}$ from aldehyde 1, RedAm and glucose dehydrogenase (GDH) combinations can be used. ${ }^{14,31,32}$ Here, the reductive aminase from Ajellomyces dermatitidis (AdRedAm, $200 \mathrm{mg}$, $10 \mathrm{wt} \%$ ) and the GDH from Bacillus megaterium (BsGDH, $10 \mathrm{mg}, 10 \mathrm{wt} \%$ ) were immobilized and both loaded into a packed bed reactor. Pleasingly, this also gave full conversion of the in situ generated hydrocinnamaldehyde $\mathbf{1}$ to the corresponding $N$-allyl amine 3 at steady state which was maintained for four hours (STY: $2.1 \mathrm{~g} \mathrm{~L}^{-1} \mathrm{~h}^{-1}$ ) (Table 1).

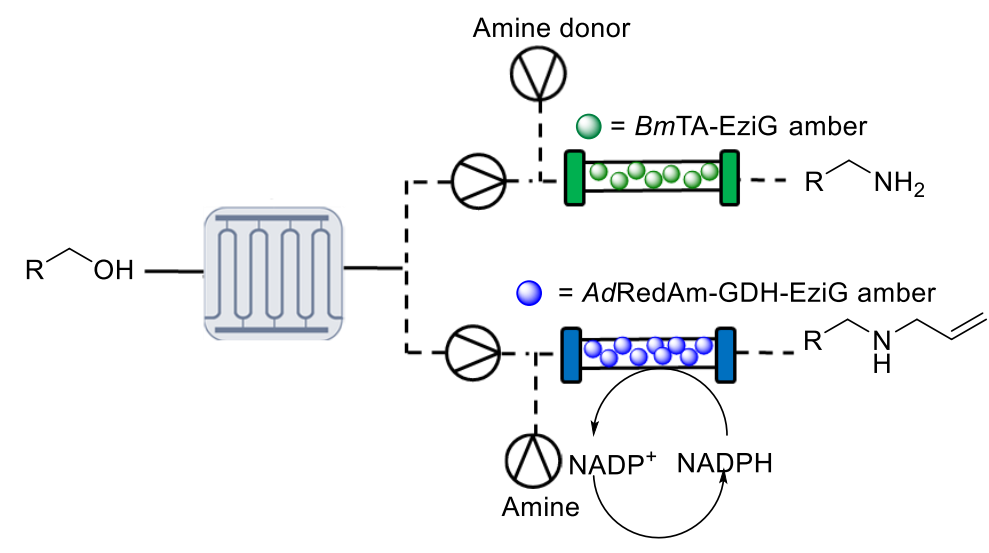

Entry Aldehyde $\mathbf{T}_{\text {res }}(\min )$ Conv

Table 1: Schematic representation of the MPIR-packed bed continuous flow system for the biocatalytic synthesis of amines from alcohols. *Steady state conversions determined by GC-FID and compared to chemical standards. 
Following the optimization of $\mathrm{AcCO}_{6}$-RedAm cascade in continuous flow, the combination of previously batch incompatible enzyme systems was investigated. Galactose oxidase (GOase), a copper-dependent alcohol oxidase, has been shown to be a useful tool in biocatalysis with a number of variants displaying a broad substrate scope. ${ }^{33-}$ 35 Using GOase instead of choline oxidase would lead to a panel of benzylic amines as shown in Scheme 1. However, due to the reactive copper center in GOase, amines can inhibit the biocatalyst meaning one-pot batch reactions are not feasible with aminating enzymes. Indeed, when the cascades were carried out in batch, performance as expected was poor, with no observable conversion to the corresponding amines (see Supporting Information).

To overcome these issues the use of compartmentalized MPBS was investigated. Pleasingly, extremely efficient cascades were observed with $>95 \%$ conversion achieved in the reductive amination of five benzaldehydes 4 (generated in situ by GOase in the MPIR, Scheme 1)), using the transaminase from Vibrio fluvialis (VfTA) and $A d$ RedAm to generate the primary $\mathbf{5}$ and secondary amines $\mathbf{6}$, respectively. Importantly, due to immobilization of the enzymes, several substrates could be screened using the same columns. This approach efficiently surveyed the activity of $V f$ TA and $A d$ RedAm in the reductive amination of the benzaldehyes 4a-e (20 mM: five or 10 eq. amine). A total system residence time of $<38$ mins was enough to obtain $>90 \%$ conversion in all instances. A panel of 10 primary 5a-e/secondary amines 6a-e $(10 \mathrm{mM})$ were generated merely by changing the flow path and the initial benzyl alcohol, an approach far less time consuming than the preparation of individual batch reactions and enzyme preparations. To further increase efficiency and automation, three-way switching valves (including a retrofitted HPLC waste valve) were added to the system (Scheme 1); this enabled exquisite control of the flow path without the laborious need of changing lines or columns. Using this approach, the system could be quickly switched between 'RedAm and 'TA' flow paths without intermittent washing steps, thus vastly improving efficiency. The same approach was also used for substrate feeding to the MPIR again greatly improving the efficiency of the system. Due to the relatively unexplored space of GOase-bioamination, these cascades represent the first of continuous biocatalyst substrate screening. This streamlined flow system will complement current high throughput biocatalytic screening methods ${ }^{36}$ and ultimately facilitate automation for biocatalytic cascade discovery in a highly efficient manner.

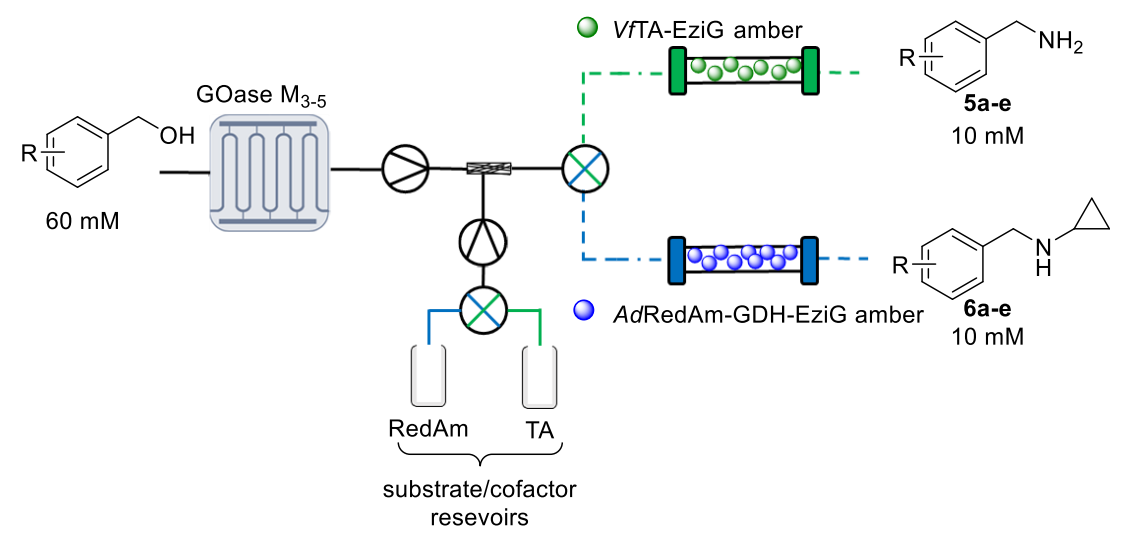




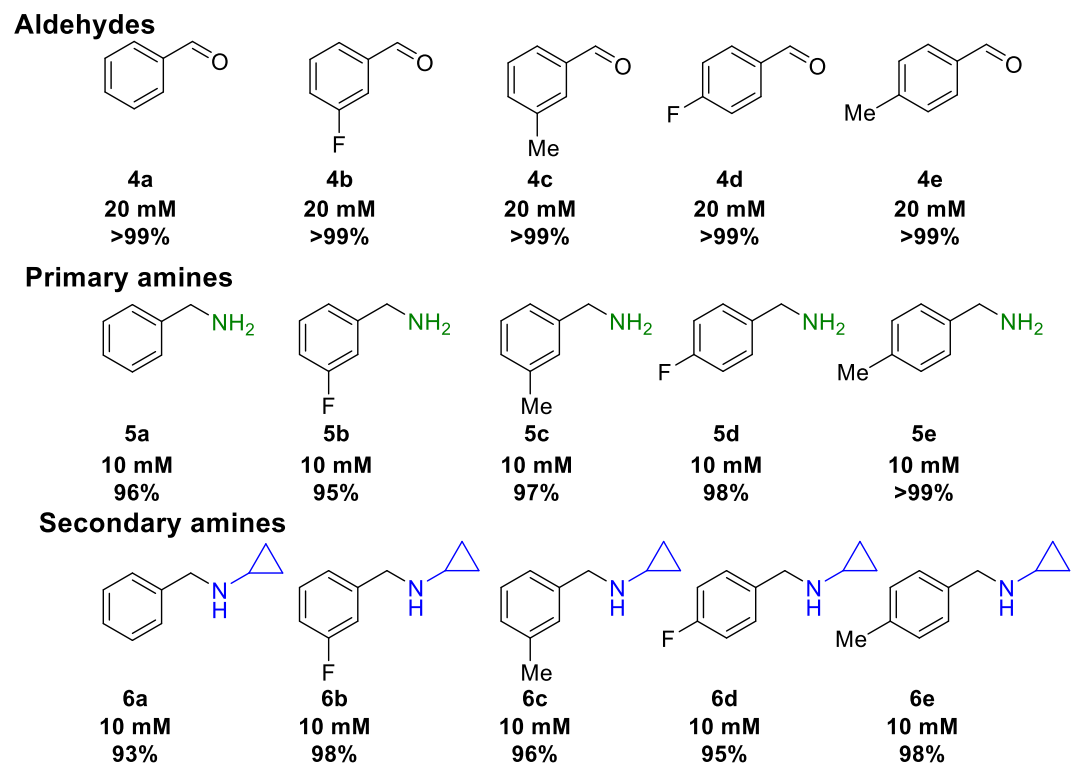

Scheme 1: GOase $\mathrm{M}_{3-5}$ and $A d \mathrm{RedAm} / V f \mathrm{TA}$ were applied in the MPBS continuous flow system and used for cascade screening. Steady state conversions determined by GC-FID analysis.

Following the successful implementation of the oxidase-bioamination cascades, the wide scope of the system was demonstrated with in situ amine generation in a TA-RedAm cascade (Table 2). Combinations of TA and RedAm/IRED in batch are not compatible because both enzymes use amine substrates with potential for cross reactivity. Hence, the in situ generation of primary amines by TAs for use in subsequent reductive aminations by RedAm/IRED has yet to be explored. For the initial flow bioamination cascade, BmTA and AdRedAm (with $B s \mathrm{GDH}$ ) were immobilized on EziG amber support (200 mg $10 \mathrm{wt} \%$ ) and placed in separate packed bed reactors, to prevent the previously mentioned potential for cross amination issues. Initially, a solution containing butanal (40 $\mathrm{mM})$, racemic alanine $(400 \mathrm{mM})$ and PLP $(1 \mathrm{mM})$ was passed through the TA module, achieving full conversion to butylamine 7 at steady state with a residence time of 12 minutes. The effluent of this reaction was mixed via a microstatic mixer (see Supporting Information) with another solution containing cyclohexanone (10 mM), NADP ${ }^{+}$ $(1 \mathrm{mM})$ and glucose $(50 \mathrm{mM})$. Initial results with $A d R e d A m$ showed $\sim 20 \%$ conversion at steady state, with four equivalents of amine 7 necessary ( $20 \mathrm{mM}$ butylamine 7, and $5 \mathrm{mM}$ ketone in RedAm module). To further improve the productivity of this reaction a more suitable RedAm was selected from a metagenomics panel. ${ }^{37}$ For the generation of $N$-butylcylohexlyamine 10, IR-79 was selected and immobilized on the EziG amber support (100 mg, $10 \mathrm{wt} \%$ ), with $85 \%$ conversion to the secondary amine $\mathbf{1 0}$ observed and maintained for three hours at steady state (Table 2). This represented a total system residence time of $21 \mathrm{mins}$ (STY: $1.87 \mathrm{~g} \mathrm{~L}^{-1} \mathrm{~h}^{-1}$ ), and only required two equivalents of butylamine 7 (20 mM butylamine and $10 \mathrm{mM}$ ketone in RedAm module). This approach was expanded to generate $\mathrm{N}$-(2-phenyl)ethyl cyclohexylamine 11 using another metagenomic RedAm (IR-23), again only requiring two equivalents of amine with a system residence time of 24 mins (STY: $2.53 \mathrm{~g} \mathrm{~L}^{-1} \mathrm{~h}^{-1}$ ). A third approach was then used to generate $N$-benzylcyclohexylamine 12 with the transaminase from Pseudomonas putida $(P p T A)^{38}$ mediated transamination of benzaldehyde followed by reductive amination with cyclohexanone using IR79. Pleasingly $95 \%$ conversion to $\mathbf{1 2}$ was achieved and maintained for four hours with a system residence time of 24 mins (STY: $2.24 \mathrm{~g} \mathrm{~L}^{-1} \mathrm{~h}^{-1}$ ). Again, the implementation of several switching valves allowed rapid change of flow path and enabled the generation of three RedAm products $(\mathbf{1 0}, \mathbf{1 1}, \mathbf{1 2})$ without isolation or purification of any intermediates. 


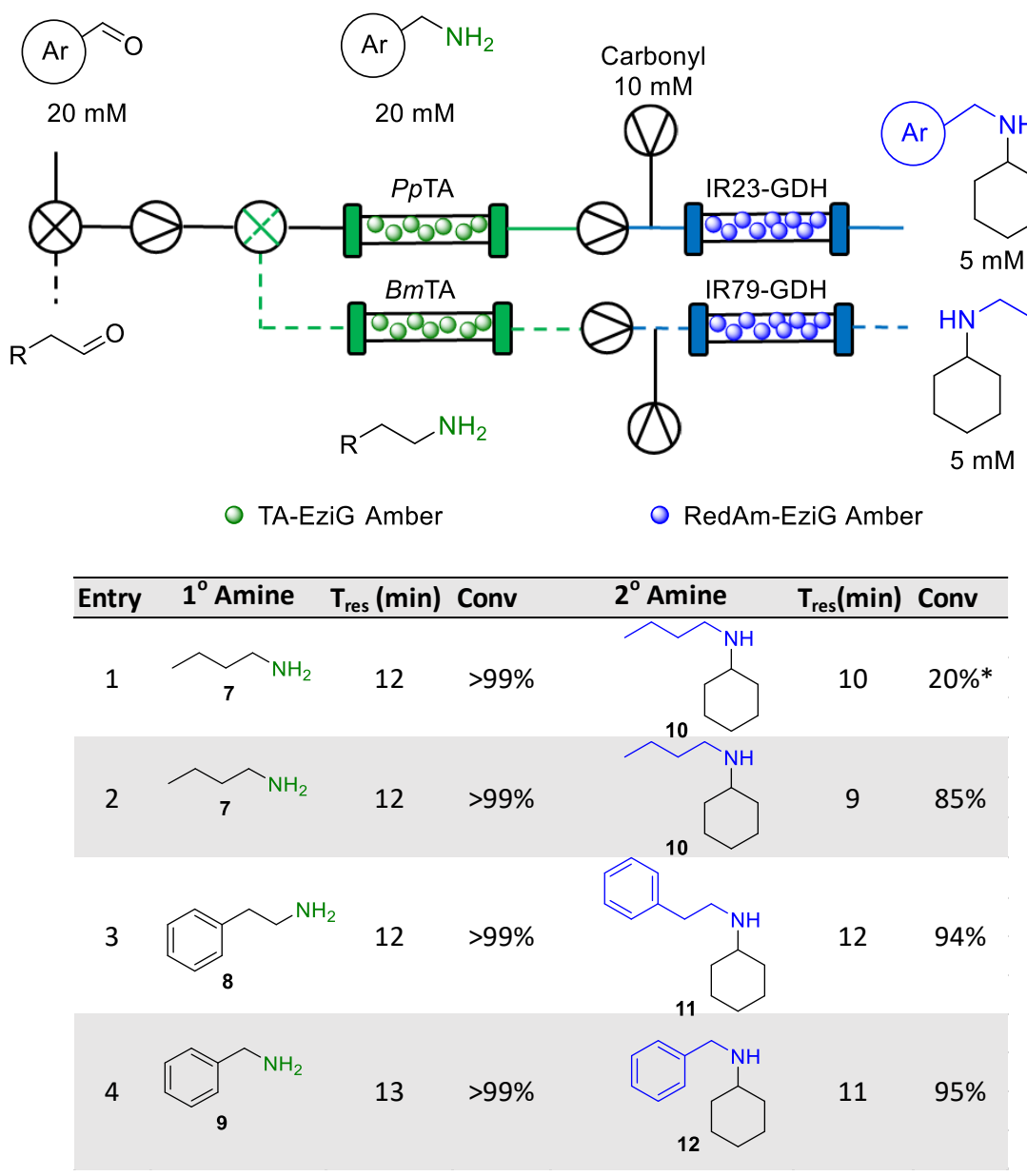

Table 2: Transaminase-RedAm cascades were applied in a multi packed-bed reactor system with switching valves enabling efficient control of flow path. Conversions to primary and secondary amines were calculate by comparison of GC-FID spectra with product standards. *Reductive amination carried out by AdRedAm.

De novo designed biocatalytic cascades are often limited to 2-4 steps due to incompatibility issues as discussed above, which become more limiting as the number of steps increases. After demonstrating that MPBS can overcome these issues, a compartmentalized six-enzyme cascade highlighting that multiple reactor technologies can be combined to enable previously inaccessible reaction sequences was targeted. A synthetic sequence that was able to convert primary alcohols into amines via an oxidase-TA sequence, which could then be used as the amine substrate for a RedAm reaction was envisaged (Table 3). Using the compartmentalized MPBS, $\mathrm{AcCO}_{6}$ efficiently oxidized phenylethanol $(120 \mathrm{mM})$. The resulting aldehyde 14 was mixed with racemic alanine $(400 \mathrm{mM})$ and PLP $(1 \mathrm{mM})$ via a microstatic mixer, which then passed through immobilized BmTA forming 2-phenylethylamine 8. The effluent from this reaction was mixed with a RedAm line (glucose $(50 \mathrm{mM}), \mathrm{NADP}^{+}(1 \mathrm{mM})$, cyclohexanone $\left.(10 \mathrm{mM})\right)$ and passed through immobilized IR-79 to quantitatively generate $\mathbf{1 1}$ under continuous conditions. Pleasingly, amine donors were generated in two biocatalytic steps from the alcohols, which then fed directly into the RedAm reactors that successfully utilized the in situ generated amine substrates. All three examples reached steady state conversions of $>90 \%$ 

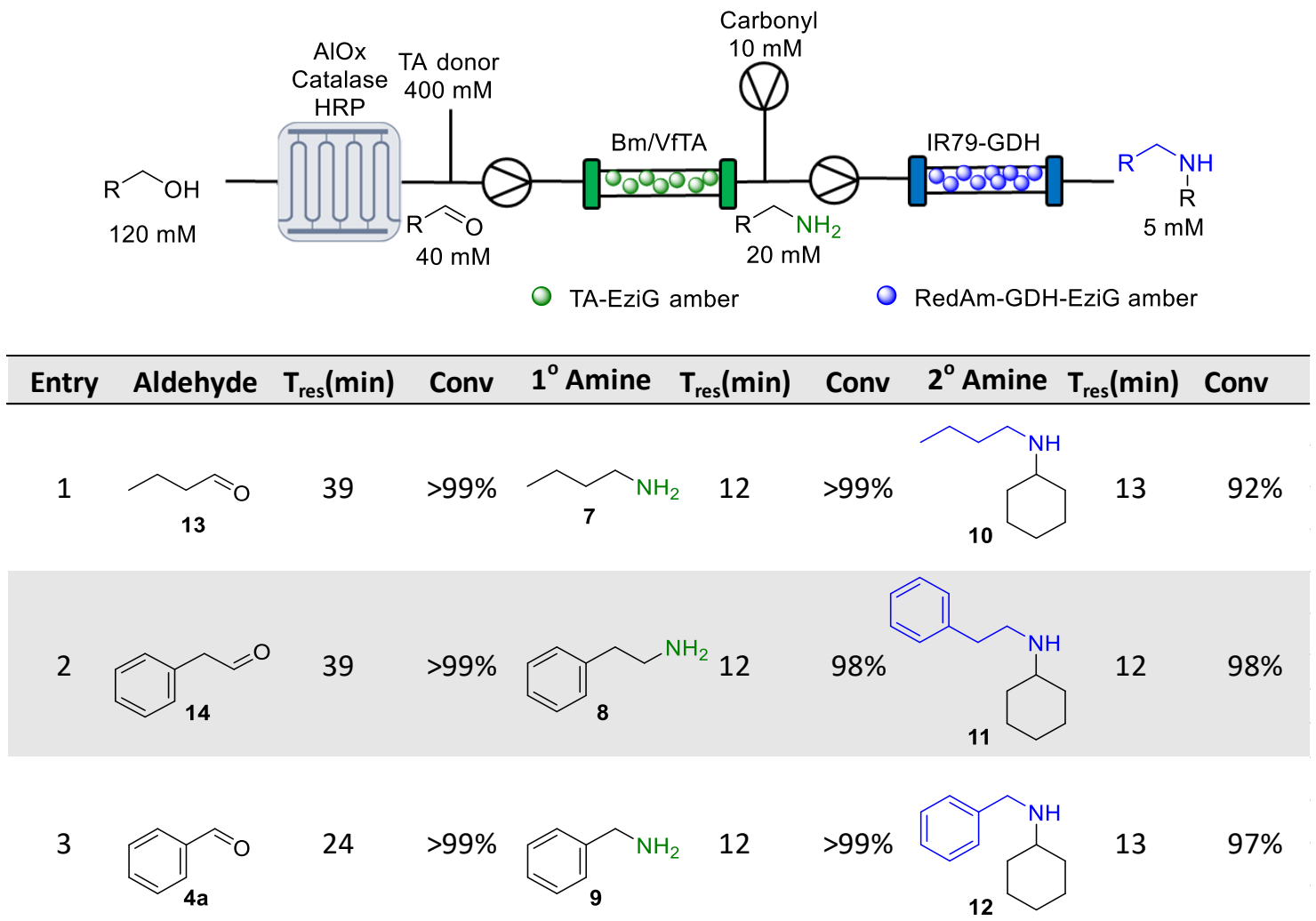

Table 3: A six enzyme continuous cascade used for the synthesis of asymmetric amines. Conversion was determined by GC-FID.

To highlight the benefits of this system in target synthesis, a continuous biocatalytic synthesis of 4Omethylnorbelladine 17 via an Oxidase-RedAm cascade was designed. ${ }^{5}$ 4O-Methylnorbelladine is an important precursor in the synthesis of a number of pharmacologically active alkaloid scaffolds, such as the dementia drug galantamine. ${ }^{39,40}$ For this cascade, it was thought tyramine $\mathbf{1 6}$ could be generated via a continuous oxidase-TA cascade. Choline oxidase activity was tested against tyrinol in the MPIR. The resulting biogenic aldehyde is a key intermediate in the biosynthesis of benzylisoquinoline alkaloids and often requires multistep syntheses. ${ }^{41,42}$ Despite the biooxidation proving highly efficient $\left(120 \mathrm{mM}\right.$ substrate loading; >90\% conversion; STY: $8.37 \mathrm{~g} \mathrm{~L}^{-1} \mathrm{~h}^{-1}$; productivity: $5.1 \mathrm{~g}_{\text {product }} \mathrm{g}_{\text {enzyme }}{ }^{-1}$ ) tyramine was commercially available at a lower cost than the alcohol so this step was not necessary.

For the reductive amination of isovanillin and tyramine 16, a previously described high throughput colorimetric assay was used to identify potential RedAms ${ }^{43}$ From this screen IR-80 was selected and the reaction validated with an analytical scale biotransformation. The product $\mathbf{1 7}$ was found to be insoluble in aqueous buffer and proved difficult to analyze by HPLC. As an alternative, the crude biotransformation was filtered, and the residue suspended in DMSO/MeOH for MALDI analysis with an observed $\mathrm{m} / \mathrm{z}$ of 274.2 corresponding to the protonated adduct of the product 17 (see Supporting Information). Encouraged by this result, IR-80 was immobilized on EziG amber $(150 \mathrm{mg}, 10 \mathrm{wt} \%)$ for translation into continuous flow (Scheme 2). To implement a cascade for this synthesis a GOase $\mathrm{M}_{3-5}\left(5 \mathrm{mg} \mathrm{mL}^{-1}\right)$ mediated biooxidation of isovanilyl alcohol $15(30 \mathrm{mM})$ was carried out in the MPIR. The effluent was mixed with the RedAm feed (tyramine $16(50 \mathrm{mM}), \mathrm{NADP}^{+}(0.1 \mathrm{mM})$ and glucose $\left.(50 \mathrm{mM})\right)$ which was flowed through an IR-80 module to quantitatively generate $\mathbf{1 7}$ for four hours with a system residence time of $36 \min$ (STY: $2.26 \mathrm{~g} \mathrm{~L}^{-1} \mathrm{~h}^{-1}$ ). Filtration of the effluent allowed recovery of the excess tyramine and provided a simple purification method for the isolation of 17. 


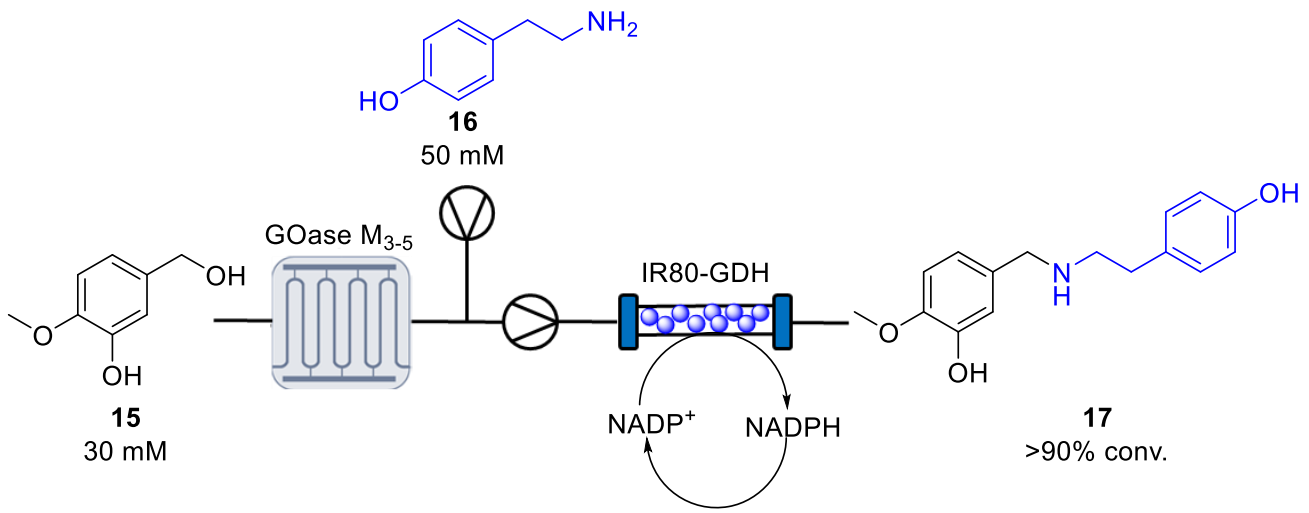

Scheme 2: Continuous oxidase-RedAm cascade for the synthesis of 4O-methylnorbelladaine 17.

In summary, for the first time it has been shown that previously incompatible enzyme cascades can be run continuously, greatly improving the metrics (up to 58-fold for STY and 4 fold for enzyme productivity) when compared to the equivalent batch reactions. This system is extremely versatile with several enzyme combinations tested that enabled the generation of a range of amine intermediates. The reactors were also extended to demonstrate proof of concept, high throughput reaction screening in continuous flow. A continuous synthesis of the biologically relevant molecule 4O-methylnorbelladine was also successfully demonstrated. This continuous approach, in combination with automated high throughput biocatalyst screening, ${ }^{36}$ and computer aided synthesis planning, ${ }^{5}$ paves the way for fully autonomous biocatalytic synthesis.

\section{Acknowledgements}

This work was supported by IBioIC, Prozomix Ltd. and Bioshape Ltd., RCUK (BB/ L013762/1; BB/M027791/1; BB/M02903411; BB/ M028836/1) and ERC (788231-ProgrES-ERC-2017-ADG). SCC acknowledges the UK Catalysis Hub and Keele University for funding. Thanks go to Dr James Galman for providing samples of PpTA. Also to Rehana Sung for assisting in the acquisition of mass spec data

\section{Data availability}

Data supporting the findings of this study are available within the paper and its supporting information, or from the corresponding author upon reasonable request. Biological materials are available from commercial sources as described in the manuscript and supplementary data, or available for research use, from the corresponding author upon reasonable request.

\section{REFERENCES}

1. Gandomkar, S., Żądło-Dobrowolska, A. \& Kroutil, W. Extending Designed Linear Biocatalytic Cascades for Organic Synthesis. ChemCatChem 11, 225-243 (2019).

2. Huffman, M. A. et al. Design of an in vitro biocatalytic cascade for the manufacture of islatravir. Science 366, 1255-1259 (2019).

3. Schrittwieser, J. H., Velikogne, S., Hall, M. \& Kroutil, W. Artificial Biocatalytic Linear Cascades for Preparation of Organic Molecules. Chem. Rev. 118, 270-348 (2018).

4. $\quad$ France, S. P., Hepworth, L. J., Turner, N. J. \& Flitsch, S. L. Constructing Biocatalytic Cascades: In Vitro and in Vivo Approaches to de Novo Multi-Enzyme Pathways. ACS Catal. 7, 710-724 (2017).

5. Finnigan, W., Hepworth, L., Turner, N. \& Flitsch, S. RetroBioCat: Computer-Aided Synthesis Planning for Biocatalytic Reactions and Cascades. Nat. Catal. (2021) doi:10.1038/s41929-020-00556-Z.

6. Tamborini, L., Fernandes, P., Paradisi, F. \& Molinari, F. Flow Bioreactors as Complementary Tools for Biocatalytic Process Intensification. Trends Biotechnol. 36, 73-88 (2018).

7. Geyer, K., Codée, J. D. C. \& Seeberger, P. H. Microreactors as tools for synthetic Chemists - The chemists' round-bottomed flask of the 21st century? Chem. Eur. J. 12, 8434-8442 (2006). 
8. Wegner, J., Ceylan, S. \& Kirschning, A. Ten key issues in modern flow chemistry. Chem. Commun. 37, 4583-4592 (2011).

9. De Risi, C. et al. Recent advances in continuous-flow organocatalysis for process intensification. React. Chem. Eng. 5, 1017-1052 (2020).

10. Pastre, J. C. et al. Integrated Batch and Continuous Flow Process for the Synthesis of Goniothalamin. ACS Omega 5, 18472-18483 (2020).

11. Britton, J., Weiss, G. A. \& Britton, J. Continuous flow biocatalysis. Chem. Soc. Rev. 47, 5891-5918 (2018).

12. Paradisi, F. Flow biocatalysis. Catalysts 10, 645 (2020).

13. Plutschack, M. B., Pieber, B., Gilmore, K. \& Seeberger, P. H. The Hitchhiker's Guide to Flow Chemistry. Chem. Rev. 117, 11796-11893 (2017).

14. Thompson, M. P. et al. A generic platform for the immobilisation of engineered biocatalysts. Tetrahedron 75, 327-334 (2019).

15. Thompson, M. P., Peñafiel, I., Cosgrove, S. C. \& Turner, N. J. Biocatalysis Using Immobilized Enzymes in Continuous Flow for the Synthesis of Fine Chemicals. Org. Process Res. Dev. 23, 9-18 (2019).

16. Böhmer, W., Volkov, A., Engelmark Cassimjee, K. \& Mutti, F. G. Continuous Flow Bioamination of Ketones in Organic Solvents at Controlled Water Activity using Immobilized $\omega$-Transaminases. Adv. Synth. Catal. 362, 1858-1867 (2020).

17. Cutlan, R., De Rose, S., Isupov, M. N., Littlechild, J. A. \& Harmer, N. J. Using enzyme cascades in biocatalysis: Highlight on transaminases and carboxylic acid reductases. Biochim. Biophys. Acta - Proteins Proteomics 1868, 140322 (2020).

18. Sheldon, R. A. Catalytic Oxidations in a Bio-Based Economy. Front. Chem. 8, 132 (2020).

19. Dong, J. J. et al. Biocatalytic Oxidation Reactions: A Chemist's Perspective. Angew. Chem. Int. Ed. 57, 9238-9261 (2018).

20. Cosgrove, S. C. et al. Biocatalytic Oxidation in Continuous Flow for the Generation of Carbohydrate Dialdehydes. ACS Catal. 9, 11658-11662 (2019).

21. Chapman, M. R., Cosgrove, S. C., Turner, N. J., Kapur, N. \& Blacker, A. J. Highly Productive Oxidative Biocatalysis in Continuous Flow by Enhancing the Aqueous Equilibrium Solubility of Oxygen. Angew. Chem. Int. Ed. 57, 10535-10539 (2018).

22. Toftgaard Pedersen, A. et al. Process Requirements of Galactose Oxidase Catalyzed Oxidation of Alcohols. Org. Process Res. Dev. 19, 1580-1589 (2015).

23. Ramsden, J. I. et al. Biocatalytic N-Alkylation of Amines Using Either Primary Alcohols or Carboxylic Acids via Reductive Aminase Cascades. J. Am. Chem. Soc. 141, 1201-1206 (2019).

24. Heath, R. S. et al. An Engineered Alcohol Oxidase for the Oxidation of Primary Alcohols. ChemBioChem 20, 276-281 (2019).

25. Roughley, S. D. \& Jordan, A. M. The medicinal chemist's toolbox: An analysis of reactions used in the pursuit of drug candidates. J. Med. Chem. 54, 3451-3479 (2011).

26. Mangas-Sanchez, J. et al. Imine reductases (IREDs). Curr. Opin. Chem. Biol. 37, 19-25 (2017).

27. Kelly, S. A., Mix, S., Moody, T. S. \& Gilmore, B. F. Transaminases for industrial biocatalysis: novel enzyme discovery. Appl. Microbiol. Biotechnol. 104, 4781-4794 (2020).

28. Contente, M. L., Dall'Oglio, F., Tamborini, L., Molinari, F. \& Paradisi, F. Highly Efficient Oxidation of Amines to Aldehydes with Flow-based Biocatalysis. ChemCatChem 9, 3843-3848 (2017).

29. Contente, M. L. \& Paradisi, F. Self-sustaining closed-loop multienzyme-mediated conversion of amines into alcohols in continuous reactions. Nat. Catal. 1, 452-459 (2018). 
30. Aumala, V. et al. Biocatalytic Production of Amino Carbohydrates through Oxidoreductase and Transaminase Cascades. ChemSusChem (2019) doi:10.1002/cssc.201802580.

31. Finnigan, W., Citoler, J., Cosgrove, S. C. \& Turner, N. J. Rapid model-based optimisation of a two-enzyme system for continuous reductive amination in flow. Org. Process Res. Dev. 24, 1969-1977 (2020).

32. Mangas-Sanchez, J. et al. Asymmetric synthesis of primary amines catalyzed by thermotolerant fungal reductive aminases. Chem. Sci. 11, 5052-5057 (2020).

33. Birmingham, W. R. \& Turner, N. J. A Single Enzyme Oxidative 'cascade' via a Dual-Functional Galactose Oxidase. ACS Catal. 8, 4025-4032 (2018).

34. Rannes, J. B. et al. Glycoprotein labeling using engineered variants of galactose oxidase obtained by directed evolution. J. Am. Chem. Soc. 133, 8436-8439 (2011).

35. Ford, G. J. et al. Synthesis of protected 3-aminopiperidine and 3-aminoazepane derivatives using enzyme cascades. Chem. Commun. (Camb). (2020) doi:10.1039/d0cc02976a.

36. Holland-Moritz, D. A. et al. Mass Activated Droplet Sorting (MADS) Enables High-Throughput Screening of Enzymatic Reactions at Nanoliter Scale. Angew. Chem. Int. Ed. 59, 4470-4477 (2020).

37. Montgomery, S. L. et al. Characterization of imine reductases in reductive amination for the exploration of structure-activity relationships. Sci. Adv. 6, eaay9320 (2020).

38. Galman, J. L. et al. Characterization of a Putrescine Transaminase From Pseudomonas putida and its Application to the Synthesis of Benzylamine Derivatives. Front. Bioeng. Biotechnol. 6, (2018).

39. Kilgore, M. B. et al. Cloning and characterization of a norbelladine 4'-o-methyltransferase involved in the biosynthesis of the Alzheimer's drug galanthamine in Narcissus sp. aff. pseudonarcissus. PLoS One 9, e103223 (2014).

40. Desgagné-Penix, I. Biosynthesis of alkaloids in Amaryllidaceae plants: a review. Phytochemistry Reviews (2020) doi:10.1007/s11101-020-09678-5.

41. Samanani, N., Liscombe, D. K. \& Facchini, P. J. Molecular cloning and characterization of norcoclaurine synthase, an catalyzing the first committed step in benzylisoquinoline alkaloid biosynthesis. Plant J. 40, 302-313 (2004).

42. Contente, M. L. \& Paradisi, F. Transaminase-Catalyzed Continuous Synthesis of Biogenic Aldehydes. ChemBioChem 20, 2830-2833 (2019).

43. Marshall, J. R. et al. Screening and characterization of a diverse panel of metagenomic imine reductases for biocatalytic reductive amination. Nat. Chem. (2020) doi:10.1038/s41557-020-00606-w. 


\section{SUPPORTING INFORMATION}

\section{Production of high value asymmetric amine intermediates via biocatalytic cascades in continuous flow}

Ashley P. Mattey, ${ }^{1}$ Grayson J. Ford ${ }^{1}$ Joan Citoler, ${ }^{1}$ Christopher Baldwin, ${ }^{1}$ James R. Marshall, ${ }^{1}$ Matthew Thompson, ${ }^{2}$ Nicholas J. Turner, ${ }^{1}$ Sebastian C. Cosgrove, ${ }^{1,3^{*}}$ Sabine L. Flitsch ${ }^{1 *}$

${ }^{1}$ Manchester Institute of Biotechnology (MIB) \& School of Chemistry, The University of Manchester, 131 Princess Street, Manchester, M1 7DN, United Kingdom

2EnginZyme AB, Teknikringen 38A, SE-114 28 Stockholm, Sweden.

${ }^{3}$ Lennard-Jones Laboratory, School of Chemical and Physical Sciences, Keele University, Keele, Staffordshire ST5 5BG, United Kingdom

\section{Materials}

All chemicals were purchased from Sigma Aldrich unless stated otherwise. EziG ${ }^{\mathrm{TM}}$ amber was provided by Enginzyme. NADP ${ }^{+}$was provided by Prozomix Itd.

\section{Metagenomic IRED sequences ${ }^{1}$}

>p-IR23, CfIRED (Cystobacter ferrugineus, A0A1L9AVJ5_9DELT) (24)

MGSSHHHHHHSSGLVPRGSHMKPGISVLGTGRMGSALVGAFLKQGYNVAVWNRTKSKCA P LAALGARVATTVRDAVADAEVVVVNVNDYVTSEALLRQDDVTKGLRGKLIVQLTSGSPRQ AREMAAWARQHELQYLDGAIMGTPNFIGEPGGTILYSGPGALFEKYKPVLLVLGGNSLHV GSDVGHASALDSALLSFLWGSMFGVLQAVSVCEAEGLPLGAYMEYVQATKPMVDGAVTD F VKRIQTGRFAGDEKTLATVEAHHGALRHLIELCEEHGIHHAVPAAFGQLFQAALQAGHAQ DDFAVLNKFMK*

>p-IR79 (Streptomyces chattanoogensis, A0A0N0XYF8_9ACTN)

MGSSHHHHHHSSGLVPRGSHMTDNKVGSSHDTAGTRPLTLLGLGAMGAALGHAWLAAGP LTVWNRTPGRAEPLAAQGAQVAGTAAEAVAANRLVVVCLLNDDTLGETLDGVDLAGKDLV NLTTSTPGQARVRAEWARERGARFLDGGIMAVPPMIGAPGSGASVFYSGSRALFDAHAEA LAVPAGTAYVGEDPGFAALHDVALLSAMYGMFAGVAHAFALIRKEEIPPKDFAPLLSGWL TAMTSSVHQAAAQLESGDYTKNVVSNLAMQVAGSETLLGTAEEQGVSAELLTPYLALMER RLAEGHGDEDTTGLIDLLVRRTGR*

>p-IR80 (Synechococcus elongatus, A0A0H3K567_SYNP6)

MGSSHHHHHHSSGLVPRGSHMVGEQETRMRCGLIGTGLLGTAIAERLLTVGQLLTVWNRT AERSQPLVALGATIAPTPAALLADCEVCLLLLSDAEAIAATLLTEESRSQLVGKTIIQMG TISPAESRAIADQIAAAGGQYLEAPVLGSLPEARNGTLIVMVGAEPAVFEQWRSLLCHLS PEPEWIGPIGTAATLKLALNQLIGSLTSAFGGSLALLQRSGLAVEPFMAILRQSALYAPT FDKKLSRLLSHQYDNPNFPTTHLAKDLRLFRETAADLGITTDAVEGVESIVQKAIAQGWG DQDYSALYEAINPDSN* 


\section{Biocatalyst production}

$\mathrm{AcCO}_{6}, \mathrm{GOase} \mathrm{M}_{3-5}$ and $A d \mathrm{RedAm}$ were provided by Prozomix Itd. in the form of freeze dried lysate.

\section{Enzyme expression}

All IREDs and TAs were expressed by transforming E. coli BL21 (DE3) chemically competent cells with plasmids containing the gene sequences of interest. The transformed cells were grown overnight at $37^{\circ} \mathrm{C}$ and $200 \mathrm{rpm}$ in $50 \mathrm{~mL}$ falcon tubes containing $20 \mathrm{~mL}$ of LB medium ( $1 \%$ tryptone, $0.5 \%$ yeast extract, $1 \% \mathrm{NaCl}$ ) with kanamycin or ampicillin, depending on the plasmid. The following day, $2 \mathrm{~L}$ baffled flasks supplemented with $600 \mathrm{~mL}$ LB medium and antibiotic and were inoculated with the overnight cultures $(1: 100 \mathrm{v} / \mathrm{v})$. At OD $0.6-0.8$, the cells were inoculated with IPTG to a final concertation of $0.5 \mathrm{mM}$ and incubated overnight at $20^{\circ} \mathrm{C}$ and $200 \mathrm{rpm}$. Cells were harvested by centrifugation at $4000 \mathrm{rpm}$ for $20 \mathrm{~min}$ and stored at -20 ${ }^{\circ} \mathrm{C}$ for further use.

\section{Lysate preparation}

Cell pellets were resuspended in Tris- $\mathrm{HCl}$ buffer $(25 \mathrm{mM}, \mathrm{pH} \mathrm{7})$ at a concentration of 200 $\mathrm{mgcww} / \mathrm{mL}$. Subsequently, cells were lysed by ultra-sonication (20 s ON, 20s OFF, 20 cycles) using a Soniprep 150 (MSE UK Ltd.) and centrifuged at 18,000 rpm for $30 \mathrm{~min}$ to remove the cell debris. Supernatant was snap-frozen in liquid $\mathrm{N}_{2}$ and stored at $-80^{\circ} \mathrm{C}$ for further use.

\begin{tabular}{cc}
\hline Biocatalyst & \%Expression \\
\hline AcCO $_{6}$ & 10 \\
${\text { GOase } \mathrm{M}_{3-5}}$ & 7 \\
BmTA & 9 \\
Pp TA & 10 \\
Ad RedAm & 12 \\
IR-80 & 9 \\
IR-79 & 10 \\
IR-23 & 9
\end{tabular}

Table S1: \%Expression of each biocatalyst was calculated by purifying a specific amount of freeze dried lysate and measuring amount of purified protein by nanodrop/BCA assay.

\section{Enzyme immobilization}

Specific amounts of freeze dried lysate was suspended in immobilization buffer (Tris- $\mathrm{HCl}(20$ $\mathrm{mM}), \mathrm{NaCl}(300 \mathrm{mM})$, imidazole $(25 \mathrm{mM}), \mathrm{pH} 7)$ to give a final concentration of $10 \mathrm{mg} \mathrm{mL}^{-1}$. Amounts of EziG amber beads were initially washed with immobilization buffer on an orbital shaker for 10 mins. After this, the beads were left to settle and the supernatant discarded. Biocatalyst lysate was then added to the beads and mixed via an orbital shaker for $1 \mathrm{~h}$. The beads were left to settle, then an aliquot of the supernatant was taken prior to removal for SDS-PAGE and absorbance measurements to calculate biocatalyst loading on the support. The remaining beads were washed with Tris- $\mathrm{HCl}$ buffer $(25 \mathrm{mM}, \mathrm{pH} 7, \mathrm{NaCl}(300 \mathrm{mM}))$ to remove any weakly bound protein. 


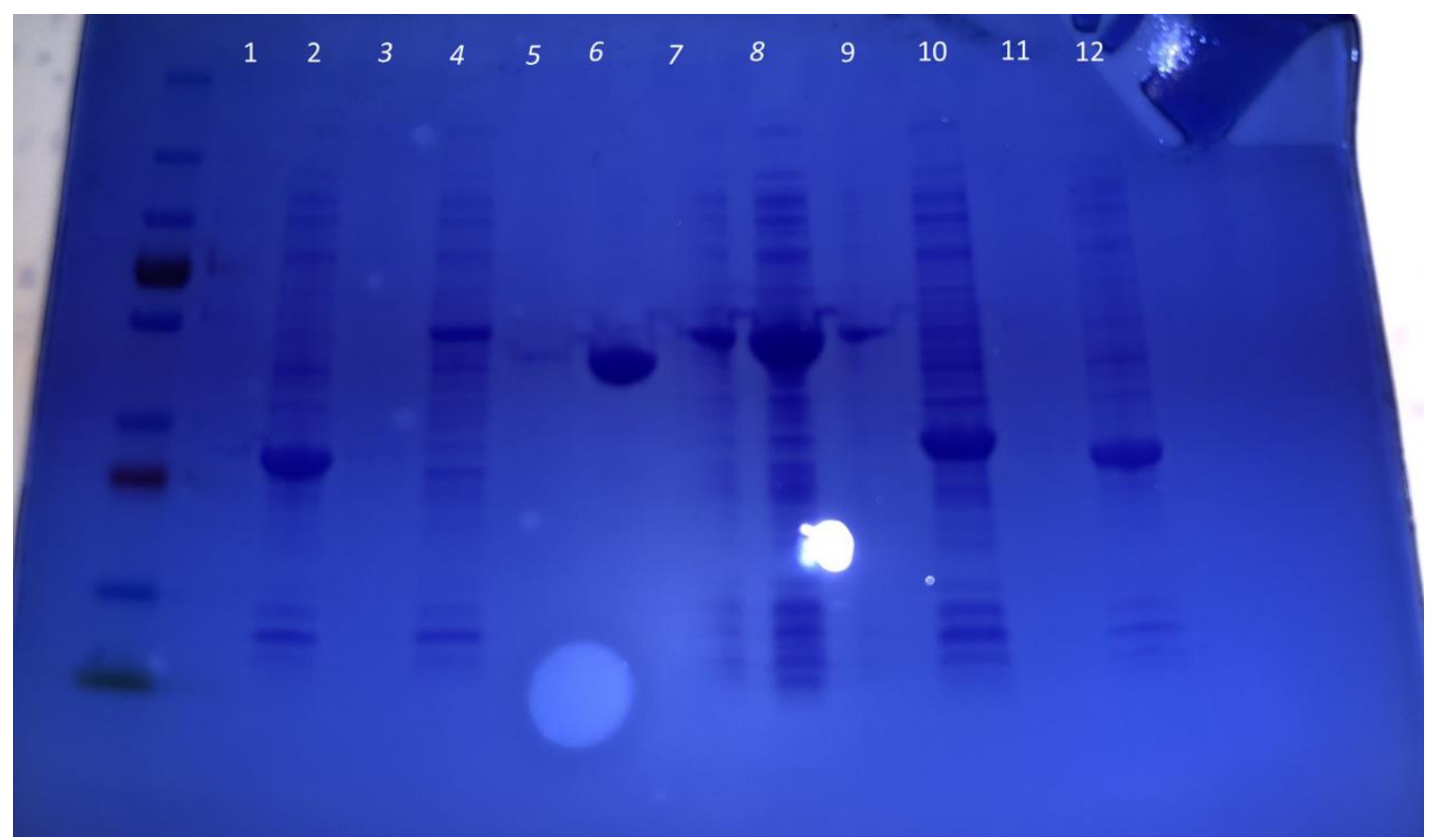

Figure S1: SDS Gel of aliquots from pre and post immobilisation samples (1: IR23 post, 2: IR23 pre, 3: BmTA post, 4:BmTA pre, 5: VfTA post, 6: VfTA pre, 7:PpTA post, 8: PpTA pre, 9: IR79 post, 10: IR79 pre, 11: IR80 post, 12: IR80 pre).

\section{Continuous flow reactions}

Continuous flow reactions were performed using the following equipment: Eldex Optos series pumps model 2SM (flow rate $0.003-5.000 \mathrm{~mL} \mathrm{~min}^{-1}$ ) and PTFE tubing (I.D 1/16") were purchased from Cole Parmer (Cambridge, UK). Asia flow chemistry 2 module syringe pump (flow rate $0.001-10.000 \mathrm{~mL} \mathrm{~min}^{-1}$ ) was purchased from Syrris, each module was equipped with a $500 \mathrm{uL}$ and $1 \mathrm{~mL}$ syringe. Stainless steel and PEEK fittings were purchased from Swagelok (Manchester, UK). A Gilson FC204 110/220V fraction collector was purchased from Gilson (Dunstable, UK). An SSI flow-through back-pressure regulator (5-75 psi) was purchased from Sigma-Aldrich (Gillingham, UK). The Perspex multi-point injection reactor, as described previously, ${ }^{2}$ was produced by Prof Nik Kapur at the iPRD (University of Leeds, UK). Omnifit manual three-way switching valves were purchased from Fisher scientific UK. Kinesis microstatic mixers (for 1/16" tubing) were purchased from Fisher scientific UK.

\section{Analytical methods}

GC-FID

HP-1 (agilent) column $\left(30 \mathrm{~m} \times 0.32 \mathrm{~mm} \times 0.25 \mu \mathrm{m}\right.$ Method: $40{ }^{\circ} \mathrm{C}$ to $325^{\circ} \mathrm{C}$ at $30{ }^{\circ} \mathrm{C} \mathrm{min}^{-1}$, injector $250^{\circ} \mathrm{C}$, detector $250^{\circ} \mathrm{C}$ )

NMR

${ }^{1} \mathrm{H}-\mathrm{NMR}$ and ${ }^{13} \mathrm{C}-\mathrm{NMR}$ spectra were recorded on a Bruker-400 instrument at $293.8 \mathrm{~K}$.

MALDI-ToF

Crude reaction mixtures $(0.5 \mu \mathrm{L})$ were spotted on target plates, then mixed with THAP matrix $\left(0.5 \mu \mathrm{L}, 10 \mathrm{mg} \mathrm{mL}^{-1}\right.$ solution in acetone) and dried in ambient temperature. The product was analysed in positive mode on a Bruker Ultraflex MALDI-ToF instrument.

\section{Metrics}

Space-time yield (STY): For a continuous flow reaction, STY is calculated based on the reactor volume, as the amount of product per unit of time per unit of reactor volume (e.g. $\left.\mathrm{g} \mathrm{L}^{-1} \mathrm{~h}^{-1}\right)$. 
STY was calculated by summing the amounts of product obtained in each of the time points at steady state and dividing them by the total amount of time at steady state and the reactor volume.

Biocatalyst productivity is defined as the amount of product per unit of biocatalyst (e.g. groduct $g_{\text {enzyme }}{ }^{-1}$ ). Biocatalyst productivity was calculated by summing the amounts of product obtained in each of the time points at steady stage and dividing them by the amount of enzyme used during steady state.

\section{Multipoint injection reactor: Choline oxidase optimization}

Optimized conditions: the reaction mixture was made into three separate solutions, solution one (Choline oxidase $\mathrm{AcCO}_{6}$ lysate $\left(20 \mathrm{mg} \mathrm{mL}^{-1}\right)$, catalase $\left.\left(0.1 \mathrm{mg} \mathrm{mL}^{-1}\right)\right)$, solution two (phenylethanol $\left.(60 \mathrm{mM}), \mathrm{H}_{2} \mathrm{O}_{2}(60 \mathrm{mM})\right)$ and solution three $\left(\mathrm{H}_{2} \mathrm{O}_{2}(240 \mathrm{mM})\right.$, antifoam $(0.01 \%))$. Solutions one two and three were pumped at equal flow rates of $22 \mu \mathrm{L} \mathrm{min}{ }^{-1}$ giving a flow rate in the reactor of $66 \mu \mathrm{L} \mathrm{min}^{-1}$, affording a $t_{\text {res }}$ of 39 minutes. The effluent was collected in $2.6 \mathrm{~mL}$ volumes every 39 minutes via the fraction collector, corresponding to individual reactor volumes. Each fraction was extracted into ethyl acetate to stop the reaction, and analyzed via GC-FID.

\section{Multipoint injection reactor: GOase $\mathbf{M}_{3-5}$}

Optimized conditions: The reaction mixture was made into three separate solutions, solution one (GOase $\mathrm{M}_{3-5}$ lysate $\left(10 \mathrm{mg} \mathrm{mL}^{-1}\right)$, $\mathrm{HRP}\left(0.1 \mathrm{mg} \mathrm{mL}^{-1}\right)$, catalase $\left.\left(0.1 \mathrm{mg} \mathrm{mL}^{-1}\right)\right)$, solution two (3-F-BenOl $\left.(60 \mathrm{mM}), \mathrm{H}_{2} \mathrm{O}_{2}(60 \mathrm{mM})\right)$ and solution three $\left(\mathrm{H}_{2} \mathrm{O}_{2}(240 \mathrm{mM})\right.$, antifoam $(0.01 \%))$. The three solutions were pumped at equal flow rates of $36 \mu \mathrm{L} \mathrm{min}{ }^{-1}$, giving a flow rate in the reactor of $108 \mu \mathrm{L} \mathrm{min}{ }^{-1}$, affording a $t_{\text {res }}$ of 24 minutes.

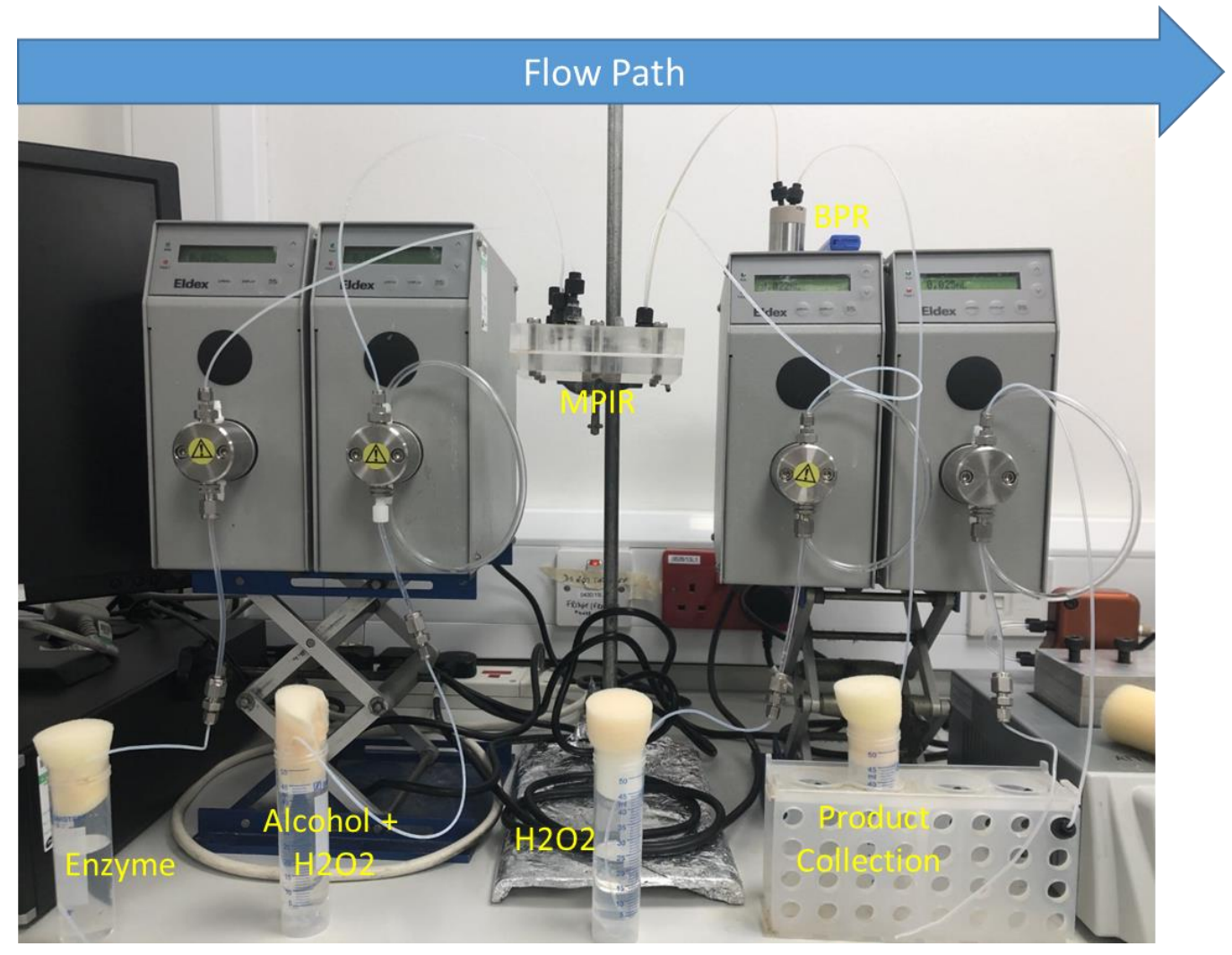

Figure S2: Lab set up of multipoint injection reactor to carry out in flow bio-oxidations. 


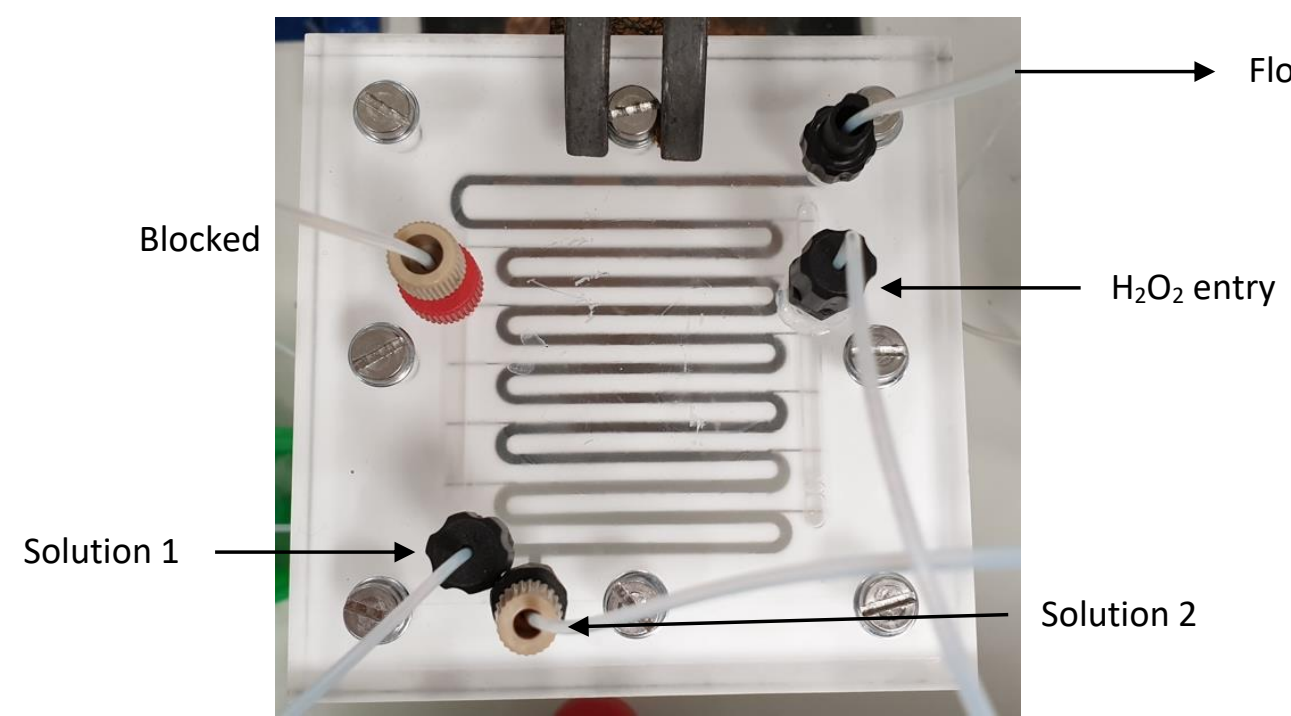

Figure S3: Picture of multipoint injection reactor (total vol. $2.6 \mathrm{~mL}$ ), with different entry points illustrated.

Table S2: Results of choline oxidase flow optimization reactions.

\begin{tabular}{ccccc|}
\hline \multirow{2}{*}{ H2O2 Eq. Residence time $(\boldsymbol{m i n})$} & pH & \multicolumn{2}{c|}{ Conversion } \\
& & & Aldehyde & Acid \\
\hline 2 & 24 & 8 & 20 & 5 \\
3 & 24 & 8 & 26 & 9 \\
& 24 & 8 & 33 & 13 \\
4 & 39 & 8 & 65 & 4 \\
& 39 & 7 & 94 & 0 \\
\hline
\end{tabular}

${ }^{a}$ conditions: $\mathrm{AcCO}_{6}\left(20 \mathrm{mg} \mathrm{mL}^{-1}\right)$, Phenylethanol (60 mM), $\mathrm{H}_{2} \mathrm{O}_{2}, \mathrm{KPi}$ buffer (100 mM, pH 7.4), antifoam $(0.01 \%)^{\text {b }}$ steady state conversion determined by GC-FID analysis.

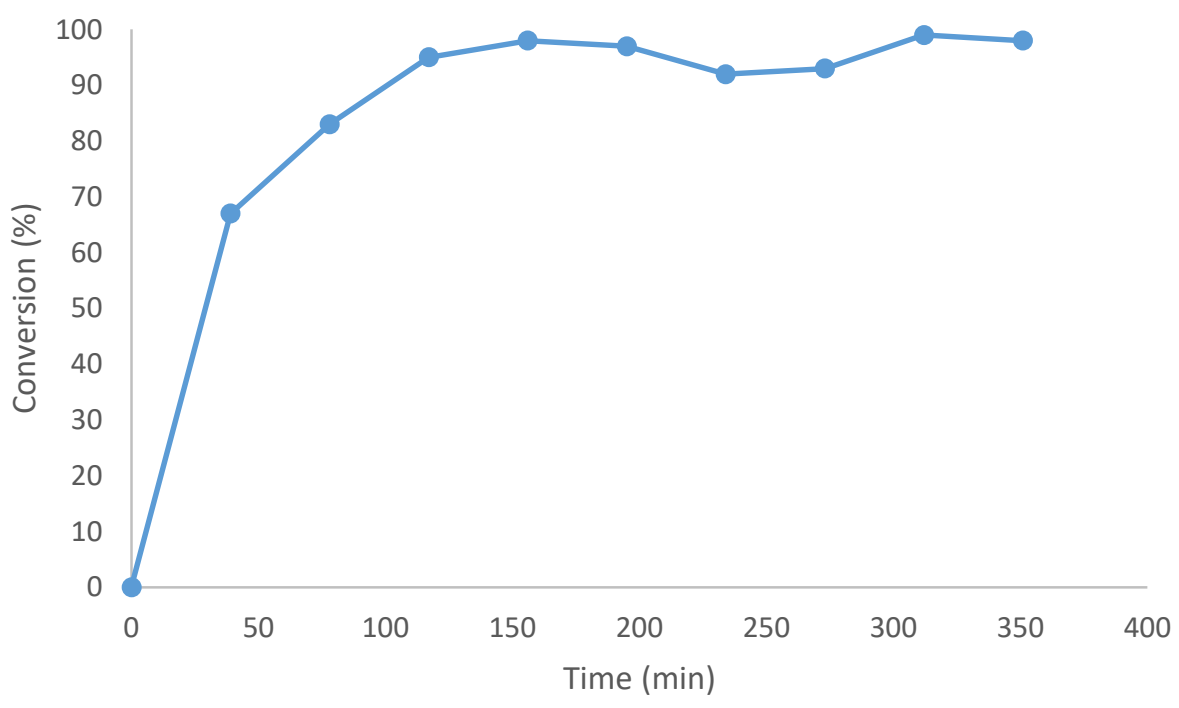

Figure S4: Continuous bio-oxidation of phenylethanol by $\mathrm{AcCO}_{6}$ in the MPIR under optimized conditions. 


\section{Batch scale up of $\mathrm{AcCO}_{6}$ bio-oxidation of phenylethanol}

To compare the metrics of batch and flow for bio-oxidations with $\mathrm{AcCO}_{6}$ a $35 \mathrm{~mL}$ scale biotransformation was prepared. The following reactants and reagents were added to a $50 \mathrm{~mL}$ flask to a total volume of $35 \mathrm{~mL}: \mathrm{AcCO}_{6}\left(25 \mathrm{mg} \mathrm{mL}^{-1}\right)$, catalase $\left(0.1 \mathrm{mg} \mathrm{mL}^{-1}\right)$, phenylethanol (100 mM), KPi buffer (100 mM, pH 7.4, 10\% DMSO). The flask was incubated at $30{ }^{\circ} \mathrm{C}$ for 16 h. After this a $500 \mu \mathrm{L}$ aliquot was taken and extracted into ethyl acetate and conversion to the corresponding aldehyde was determined by GC-FID analysis.

\section{One pot batch GOase-TA/IRED (Free enzyme) reactions}

A reaction containing GOase $\left(2 \mathrm{mg} \mathrm{mL}^{-1}\right), \mathrm{HRP}$ and catalase (both $\left.0.1 \mathrm{mg} \mathrm{mL}^{-1}\right), 3 \mathrm{~F}-\mathrm{BenOI}(20$ $\mathrm{mM}), \operatorname{AdRedAm}\left(2 \mathrm{mg} \mathrm{mL}^{-1}\right), B s \mathrm{GDH}\left(0.1 \mathrm{mg} \mathrm{mL}^{-1}\right) \mathrm{NADP}^{+}(0.5 \mathrm{mM})$, glucose $(50 \mathrm{mM})$, cyclopropylamine $(100 \mathrm{mM})$ and $\mathrm{CuSO}_{4}(0.05 \mathrm{mM})$ in NaPi buffer $(100 \mathrm{mM}, \mathrm{pH} 7.4)$ was analysed via GC-FID, with no conversion observed.

A reaction containing GOase $\left(2 \mathrm{mg} \mathrm{mL}^{-1}\right), \mathrm{HRP}$ and catalase (both $\left.0.1 \mathrm{mg} \mathrm{mL}^{-1}\right), 3 \mathrm{~F}-\mathrm{BenOI}(20$ $\mathrm{mM}), \operatorname{VfTA}\left(1 \mathrm{mg} \mathrm{mL}^{-1}\right)$, alanine $(200 \mathrm{mM})$ and $\mathrm{CuSO}_{4}(0.05 \mathrm{mM})$ in NaPi buffer $(100 \mathrm{mM}, \mathrm{pH}$ 7.4) was analysed via GC-FID, with no conversion observed.

\section{Single step continuous biotransformations in packed bed reactors}

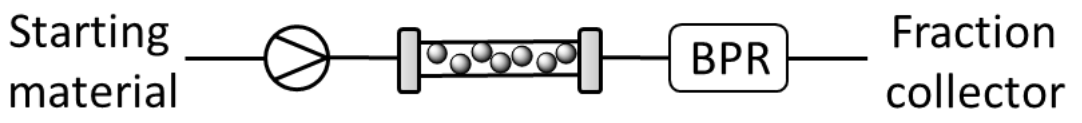

Figure S5: Schematic representation of single enzymatic transformation in continuous flow.

\section{Packed bed continuous reactions: Metagenomic IREDs}

Initially, three RedAms were selected from a metagenomic panel ${ }^{1}$ and co-immobilized with $B s G D H$ then packed into glass columns for continuous flow reactions. Fractions were collected every 24 mins (equating to approximately two reactor volumes) and ran for $4 \mathrm{~h}$. All RedAm flow reactions were carried out in KPi buffer $(100 \mathrm{mM}, \mathrm{pH} 7.5)$ to ensure compatibility with other reaction buffers.

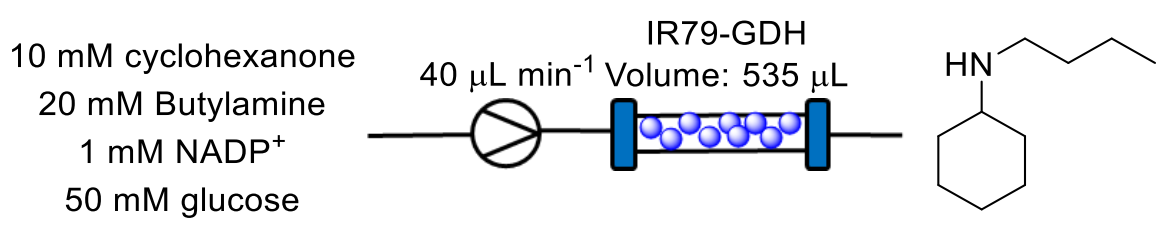




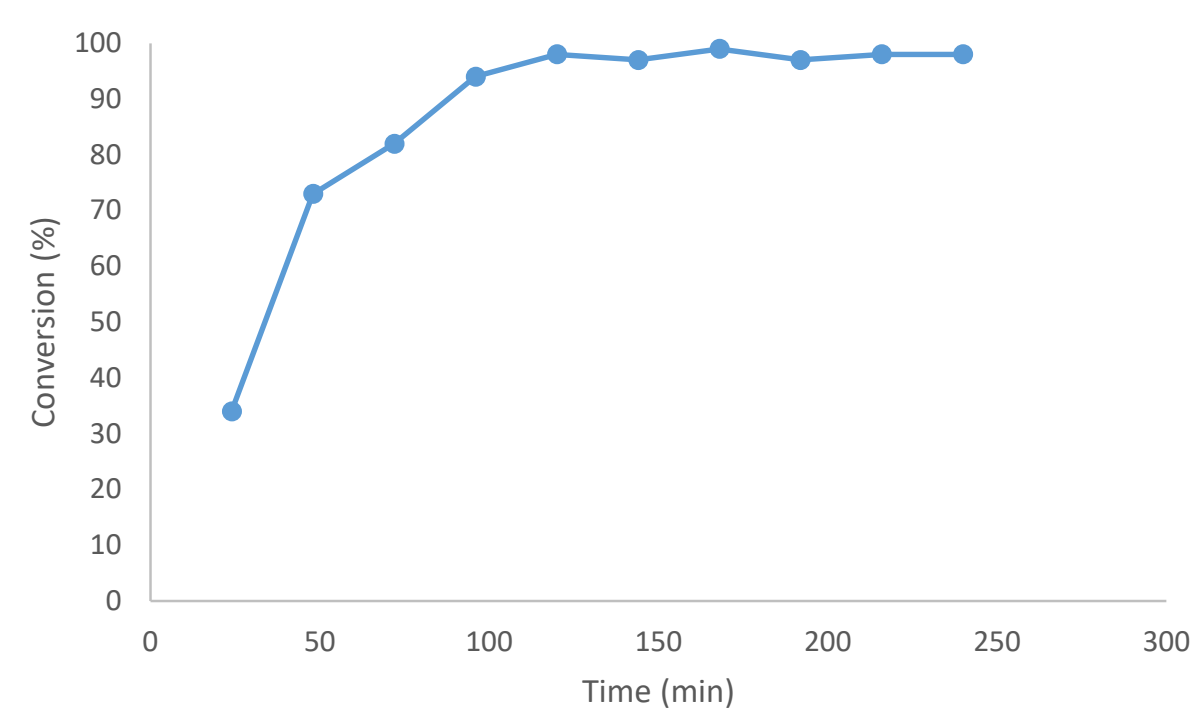

Figure S6: Continuous production of $N$-butylcyclohexanamine with co-immobilized IR-79 and $B s G D H$.
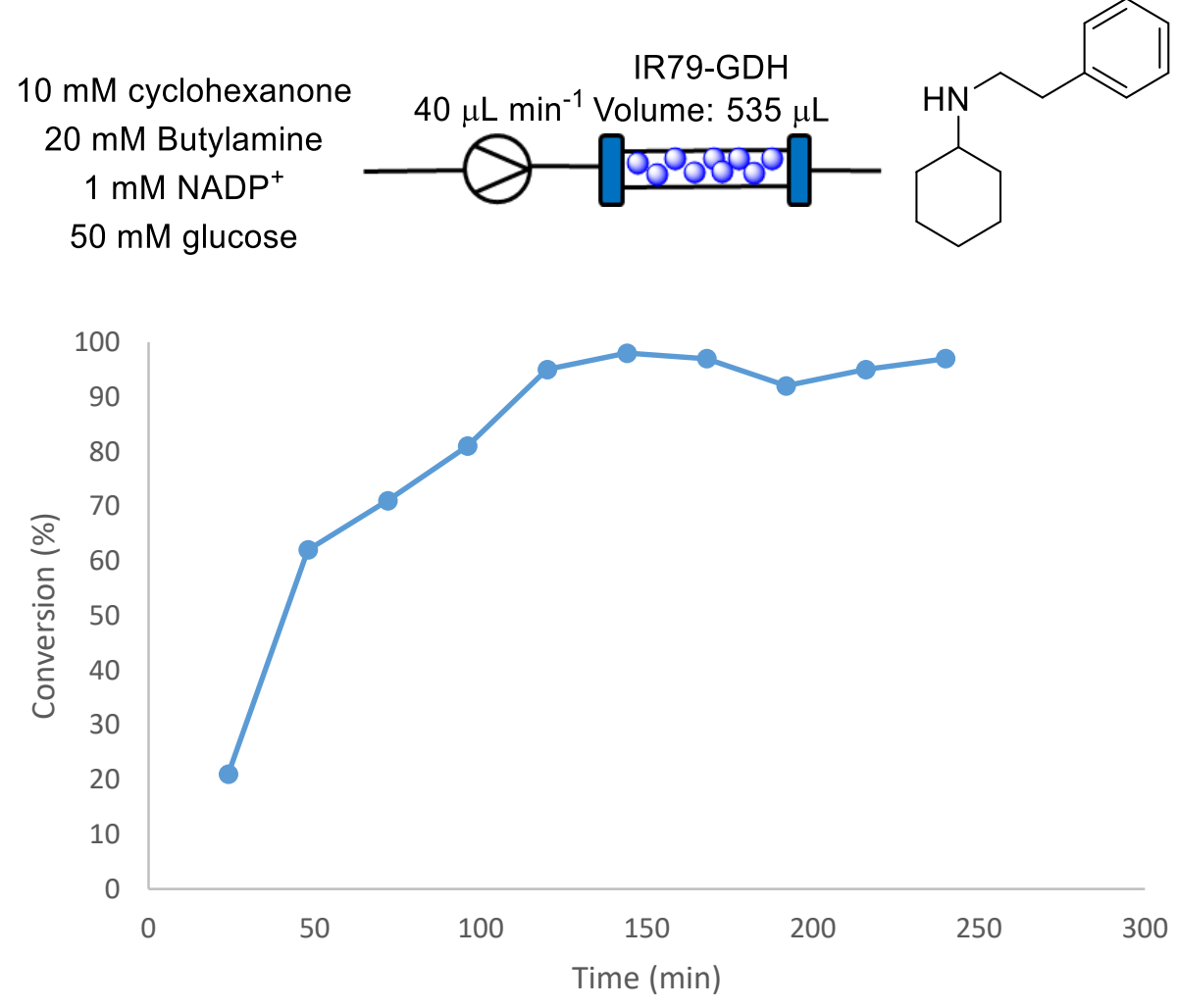

Figure S7: Continuous production of $\mathrm{N}$-phenyethylcyclohexanamine with co-immobilized IR23 and BsGDH.

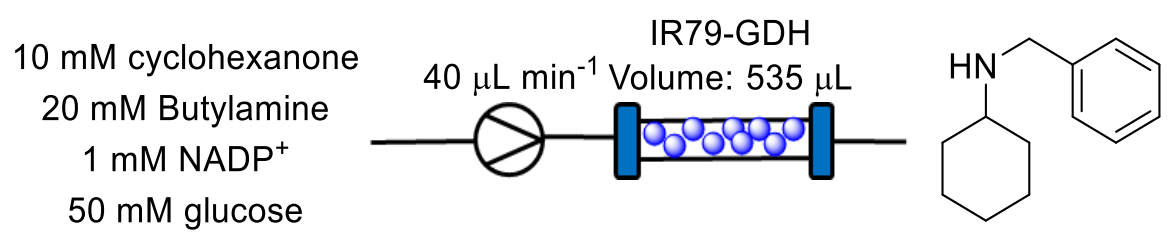




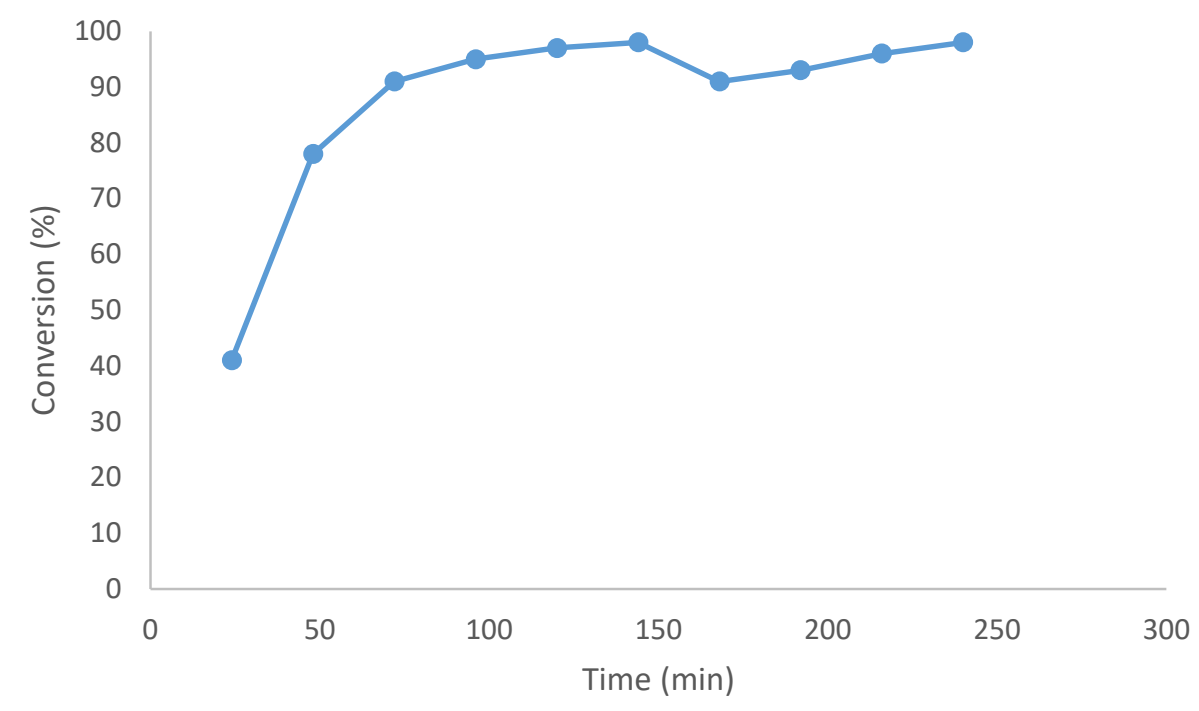

Figure S8: Continuous production of $\mathrm{N}$-benzylcyclohexanamine with co-immobilized IR-79 and BsGDH.

\section{MPIR-Packed bed continuous reactions}

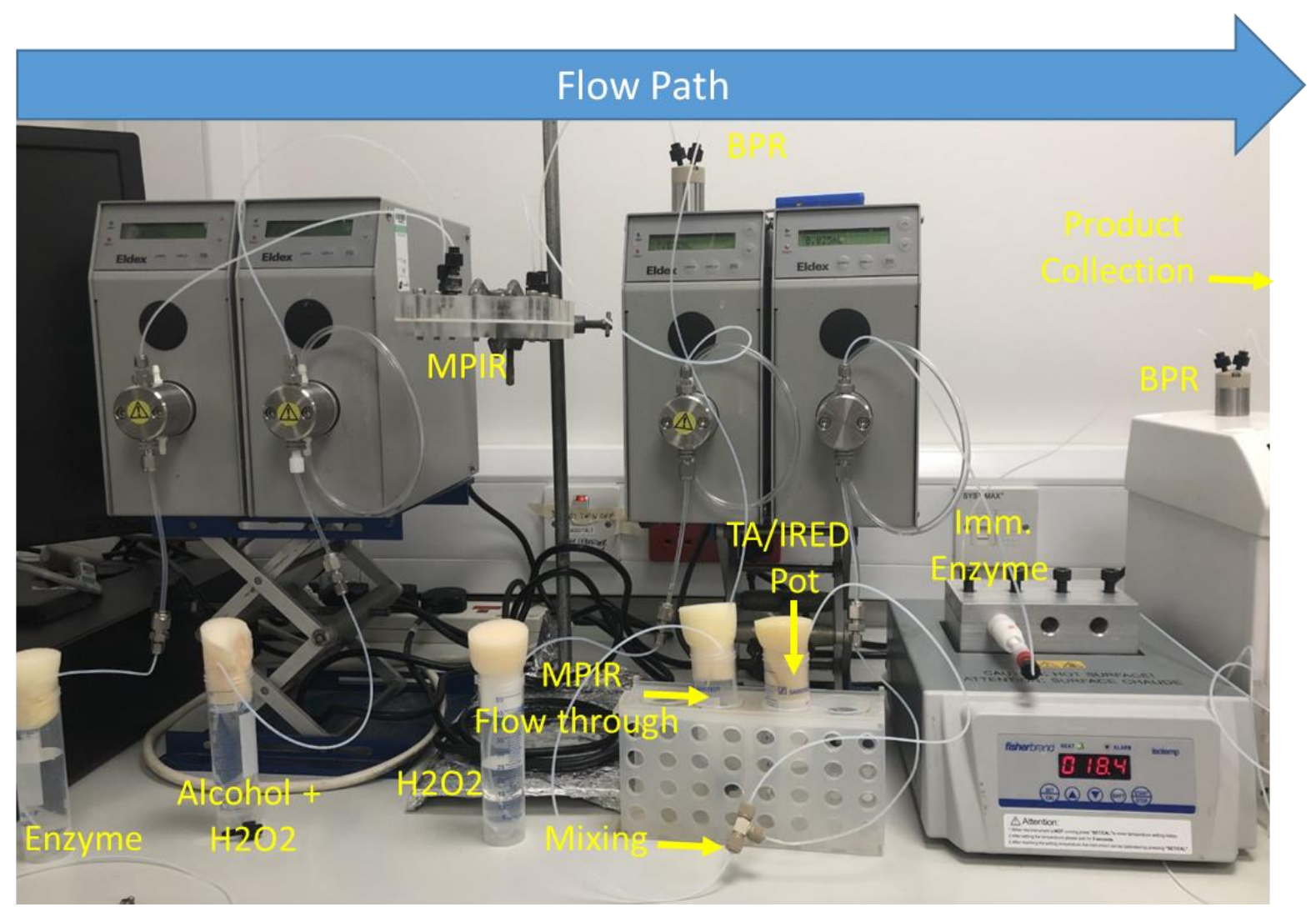

Figure S9: Flow set up for MPIR-packed bed continuous flow reactions.

MPIR-packed bed systems were set up as shown in Figure 9. The initial bio-oxidation in the MPIR was run for 90 mins to ensure the system had reached steady state. The flow through was then collected until a reservoir of aldehyde was formed. A Syrris Asia flow chemistry syringe pump with two modules was then used to pump the flow through from the MPIR and 
an RedAm substrate reservoir (amine (100 mM, 5 eq.), NADP ${ }^{+}(1 \mathrm{mM})$, glucose $(50 \mathrm{mM})$ ). These lines were mixed via a Kinesis microstatic mixer and then passed through the immobilized RedAm (Alternatively an Eldex pump with a static mixer pre-fitted can be used). The same approach was adopted when using immobilized transaminases where the TA substrate reservoir (rac-Alanine $(200 \mathrm{mM})$, PLP $(1 \mathrm{mM}))$. AcCO6 MPIR reactions were run in KPi buffer (100 mM, pH 7), whilst the RedAm and TA substrate reservoirs were made up in $\mathrm{KPi}$ (100 mM, pH 7.5). The GOase-IRED/TA system was run in NaPi buffer (100 mM, pH 7.5). Fractions were basified, extracted into ethyl acetate and analysed by GC-FID.
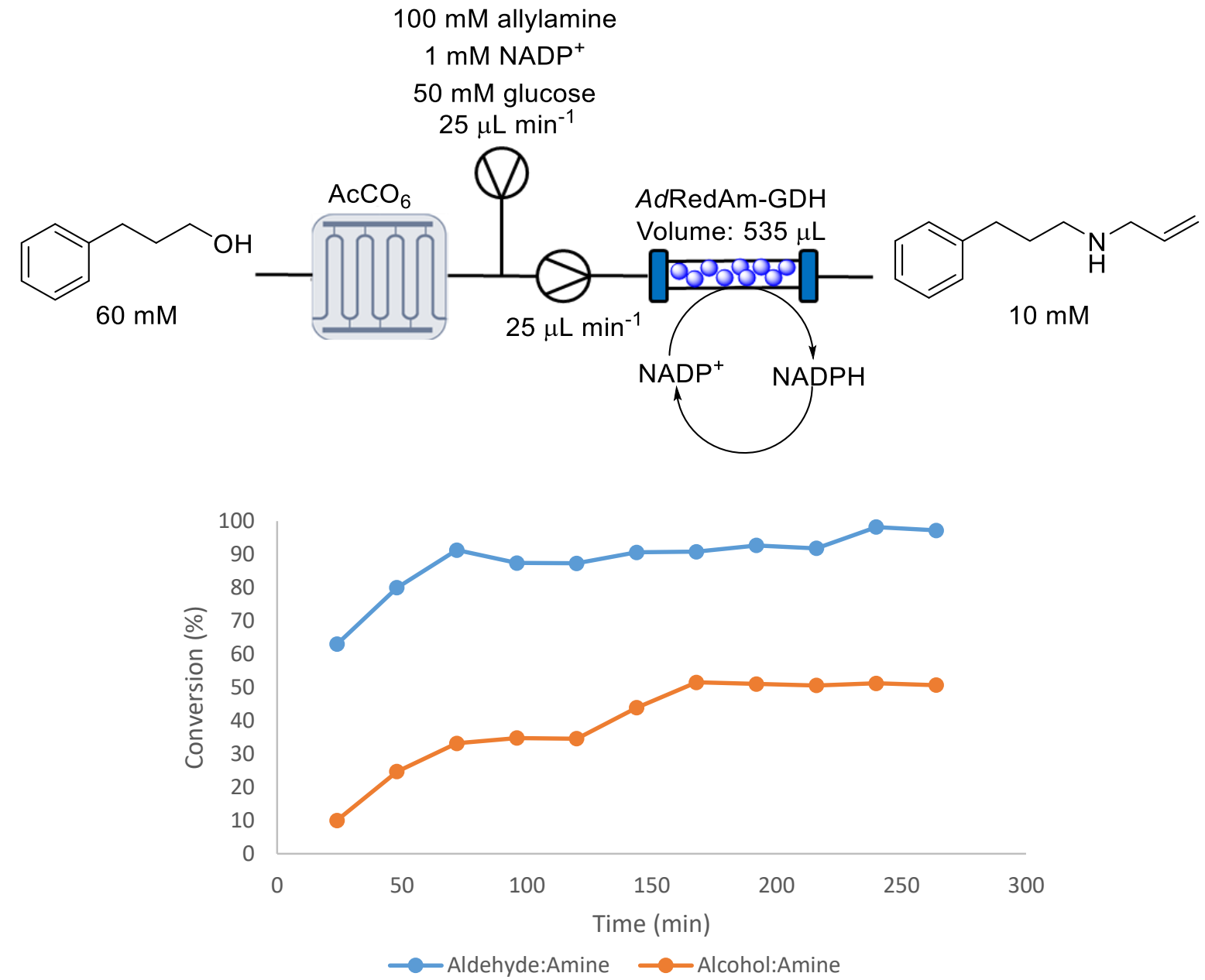

Figure S10: $\mathrm{AcCO}_{6}-\mathrm{AdRedAm} \mathrm{MPIR-packed} \mathrm{bed} \mathrm{system} \mathrm{for} \mathrm{the} \mathrm{continuous} \mathrm{production} \mathrm{of}$ hydrocinammylallylamine. Fractions were basified, extracted into ethyl acetate and dried over anhydrous $\mathrm{MgSO}_{4}$ prior to GC-FID analysis. 


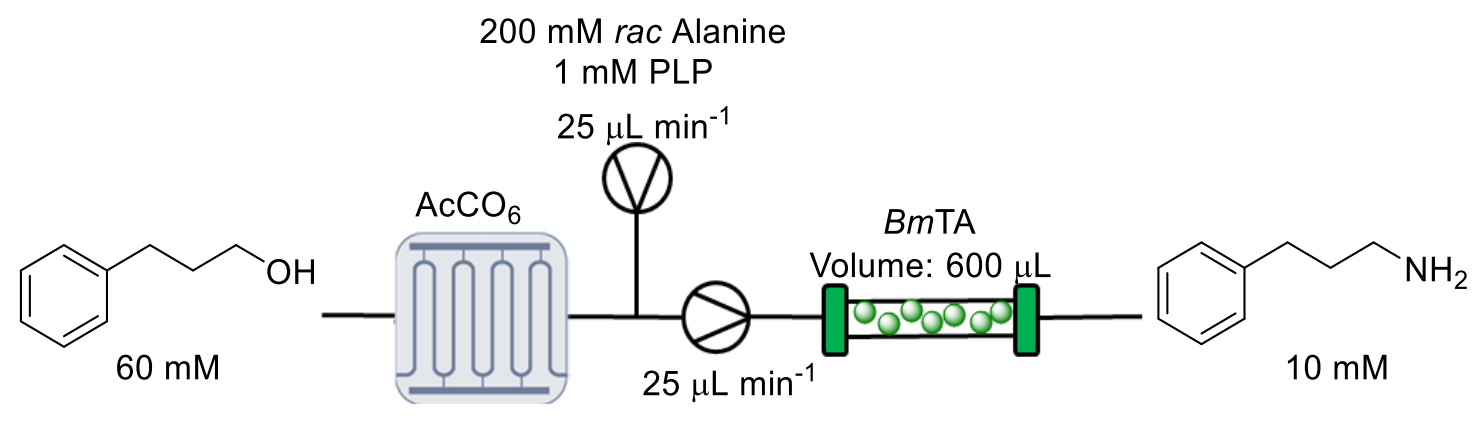

Figure S11: $\mathrm{AcCO}_{6}-\mathrm{BmTA}$ MPIR-packed bed system for the continuous production of hydrocinammylamine.

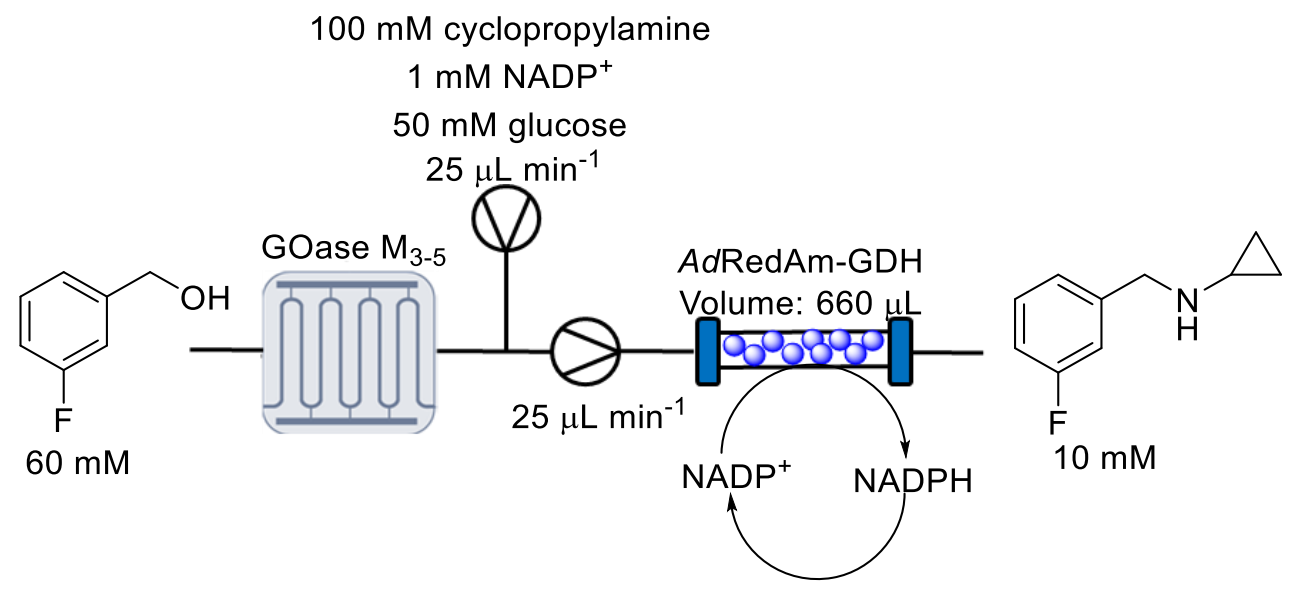

Figure S12: GOase $M_{3-5}-A d R e d A m$ MPIR-packed bed system for the continuous production of $N$-(3-fluorobenzyl)cyclopropanamine.

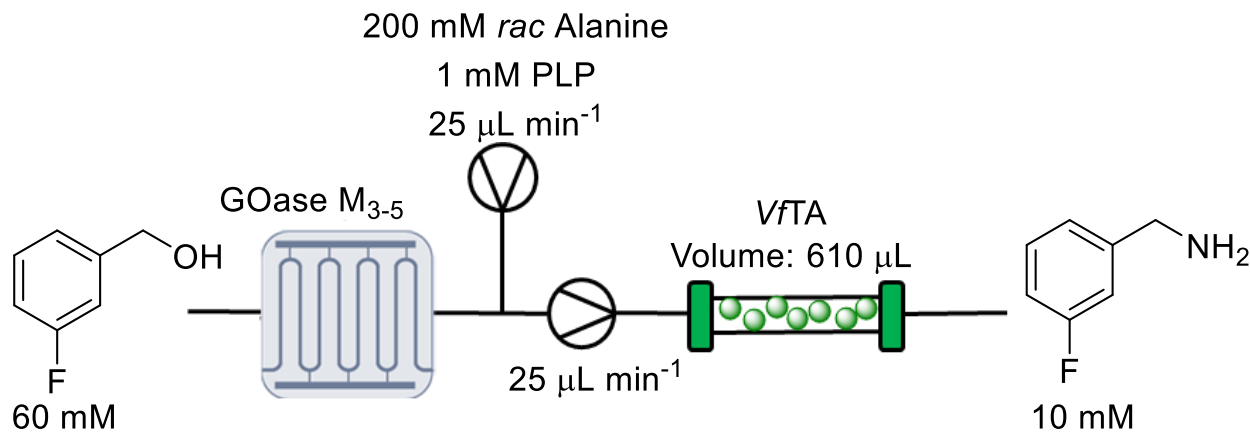

Figure S13: GOase $\mathrm{M}_{3-5}-A d R e d A m$ MPIR-packed bed system for the continuous production of (3-fluorophenyl)methanamine. 
MPIR-Packed bed (with added switching valves) continuous reactions

A.

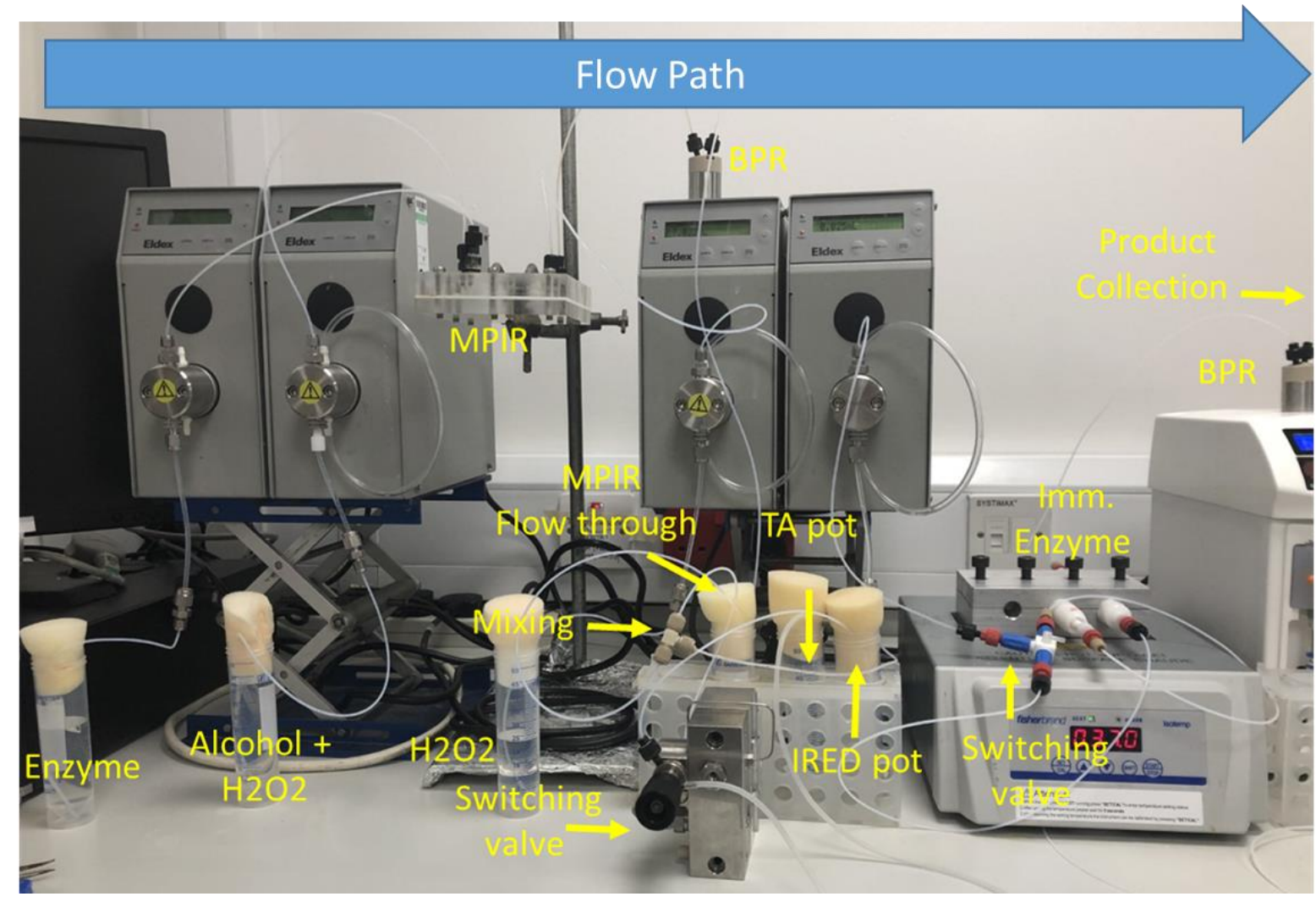

B.
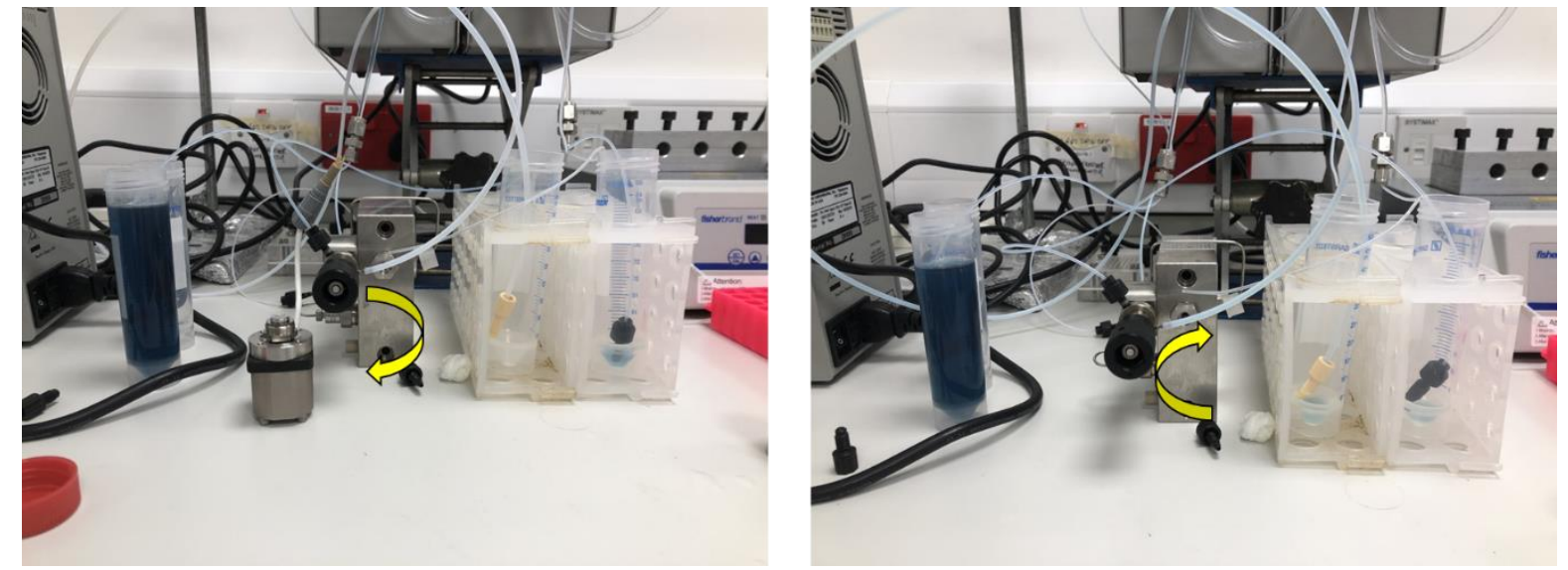

Figure S14: A. Lab set up for MPIR-Packed bed continuous flow reactions with added switching valves to improve efficiency. B. Retrofitted manual HPLC waste valve showing control of flow path. 
Screening MPIR-Packed bed systems were set up as pictured above: The initial bio-oxidation in the MPIR was run for 90 minutes to ensure the system had reached steady state, and the effluent discarded. The reaction mixture was collected until a reservoir of aldehyde solution was formed. An Eldex pump (with a pre-fitted static mixer) was then pumped the effluent from the MPIR and a RedAm substrate reservoir (amine substrate (100 mM-5eq.), NADP ${ }^{+}(1 \mathrm{mM})$, glucose $(50 \mathrm{mM}))$ or a TA substrate reservoir (rac-alanine $(200 \mathrm{mM})$, PLP $(1 \mathrm{mM}))$ that were placed before a retrofitted HPLC waste valve. The flow path was controlled by turning the waste valve to pump from either substrate reservoir. The solution was passed through an Omnifit three way switching valve to control the flow path to the immobilized RedAm or TA. GOase-RedAmTA systems were all run in NaPi buffer (100 mM, pH 7.5). Fractions were basified, extracted into ethyl acetate and analysed by GC-FID. Alternatively the HPLC waste valve can be fitted before the MPIR with benzyl alcohol substrate reservoirs that enable choice of alcohol substrate.

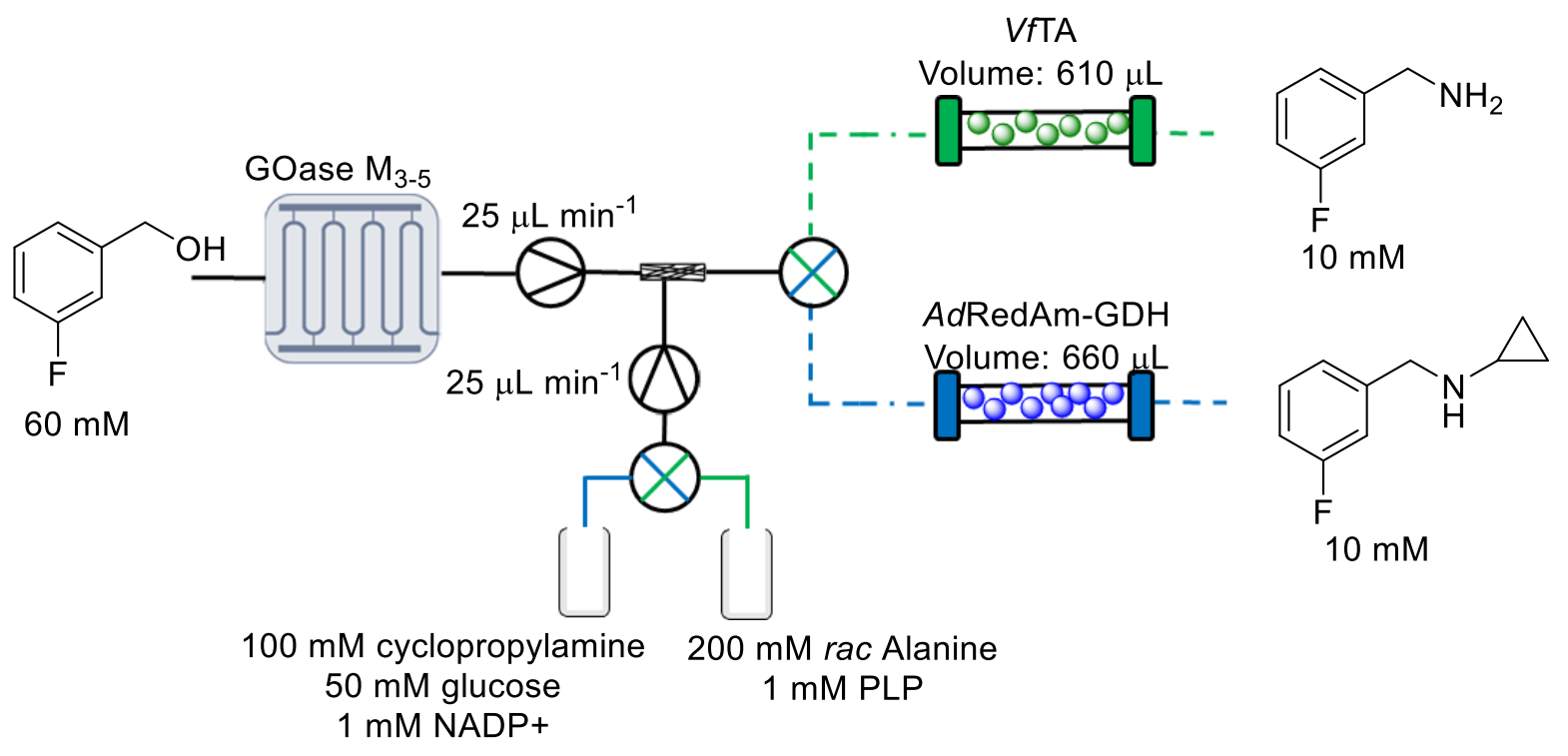

Figure S15: GOase-AdRedAm/BmTA MPIR-packed bed system with the addition of two switching valves allows for change of flow path.

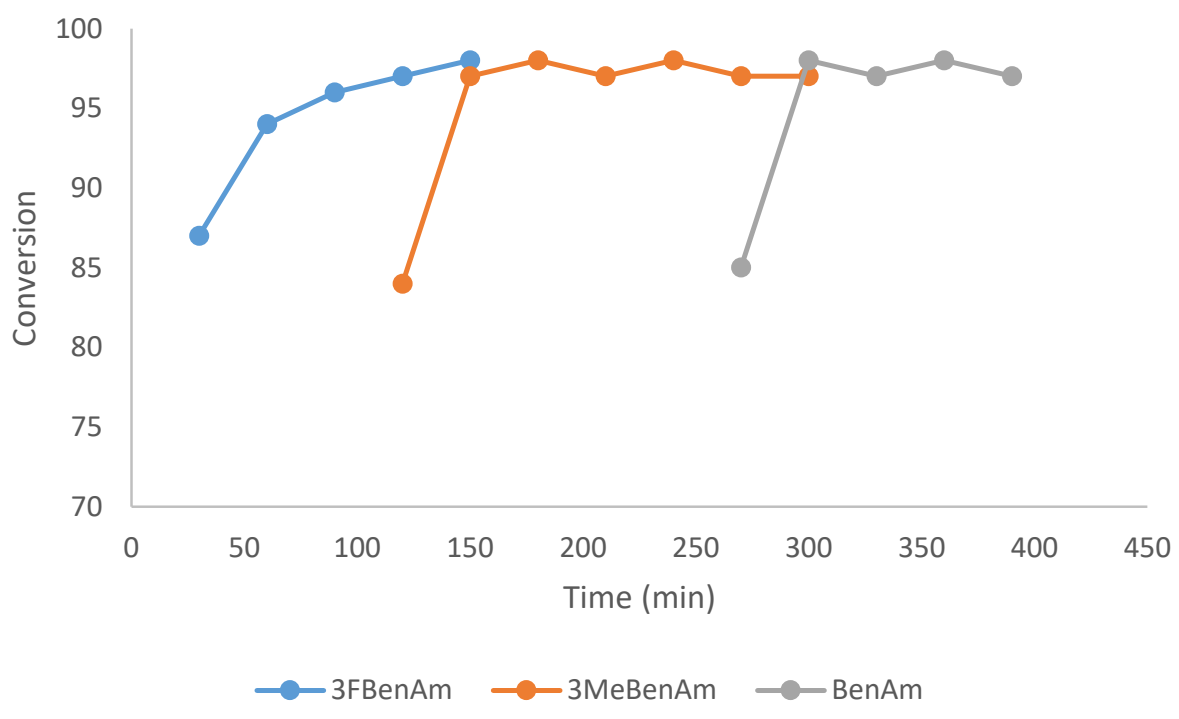


Figure S16: Adding switching valves to the MPIR-packed bed system enabled in flow biocatalyst screening with generation of three substituted benzylamines without intermittent washing steps. Fractions were collected, basified and extracted into ethyl acetate and analysed by GC-FID.

\section{Packed bed- Packed bed continuous reactions}

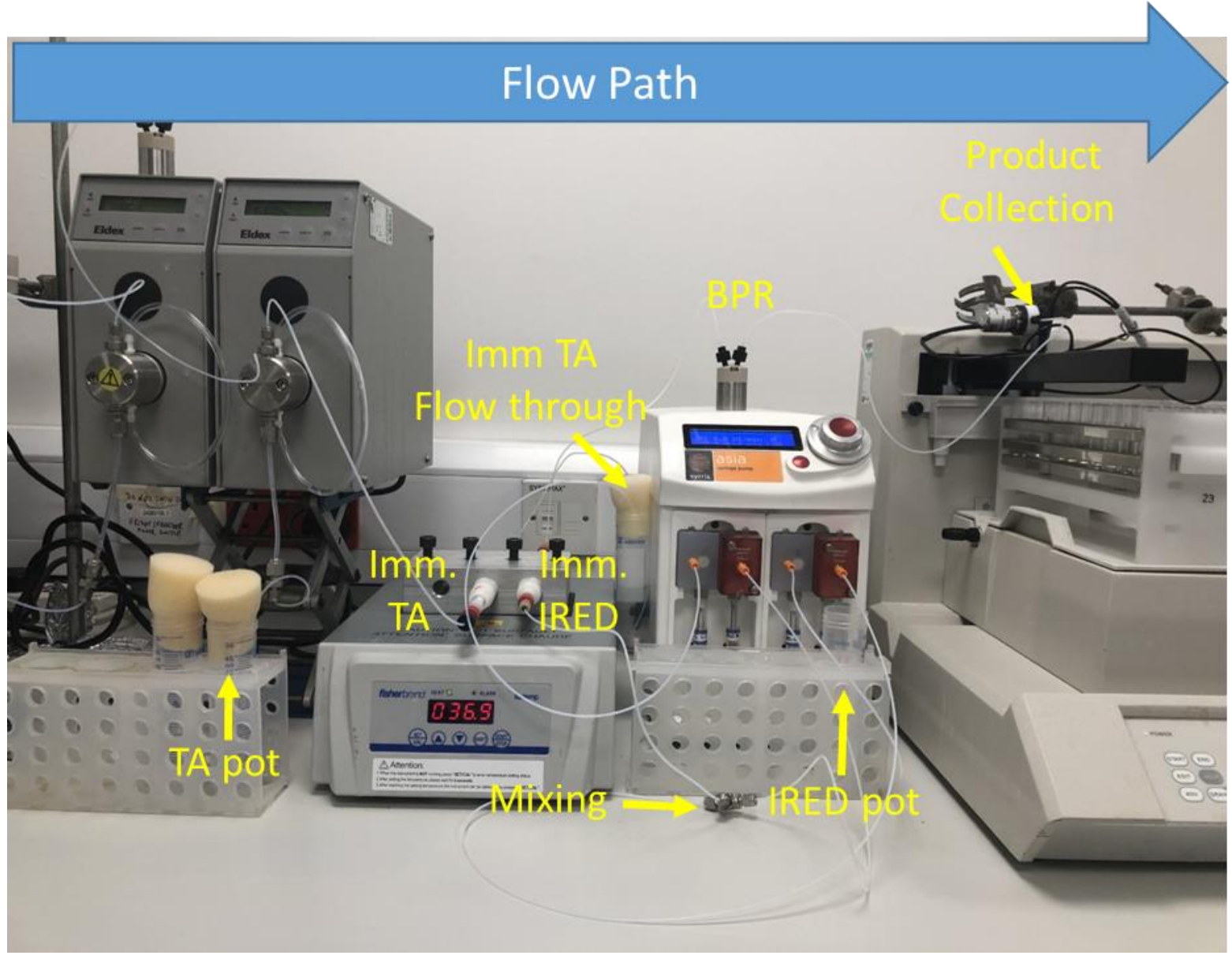

Figure S17: Lab set up for packed bed packed bed continuous flow reactions.

Packed bed-packed bed systems were set up as pictured above: A TA substrate reservoir (aldehyde $(20 \mathrm{mM})$, PLP $(1 \mathrm{mM})$ and rac-alanine $(200 \mathrm{mM}))$ was flowed through an immobilized TA. The system was left for 1 hour to reach steady state then the effluent was collected until a reservoir was formed. A Syrris Asia flow chemistry syringe pump with two modules was then used to pump the flow through from the TA module and a RedAm substrate reservoir (carbonyl $(10 \mathrm{mM}), \mathrm{NADP}^{+}(1 \mathrm{mM})$, glucose $\left.(50 \mathrm{mM})\right)$. These lines were mixed via a Kinesis microstatic mixer or $\mathrm{T}$ junction and then passed through the immobilized RedAm to a fraction collector. Fractions were basified, extracted into ethyl acetate and analysed via GCFID. 


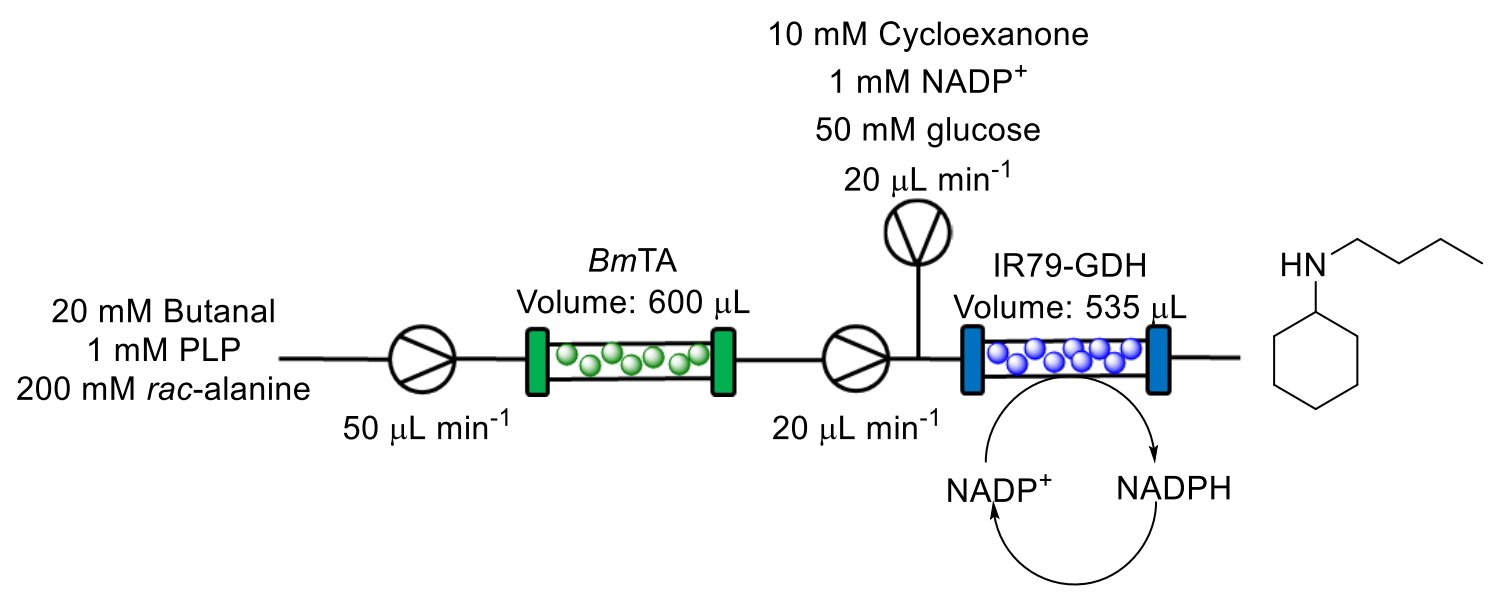

Figure S18: BmTA-IR79 packed bed-packed bed system for the continuous production of $\mathrm{N}$ butylcyclohexanamine.

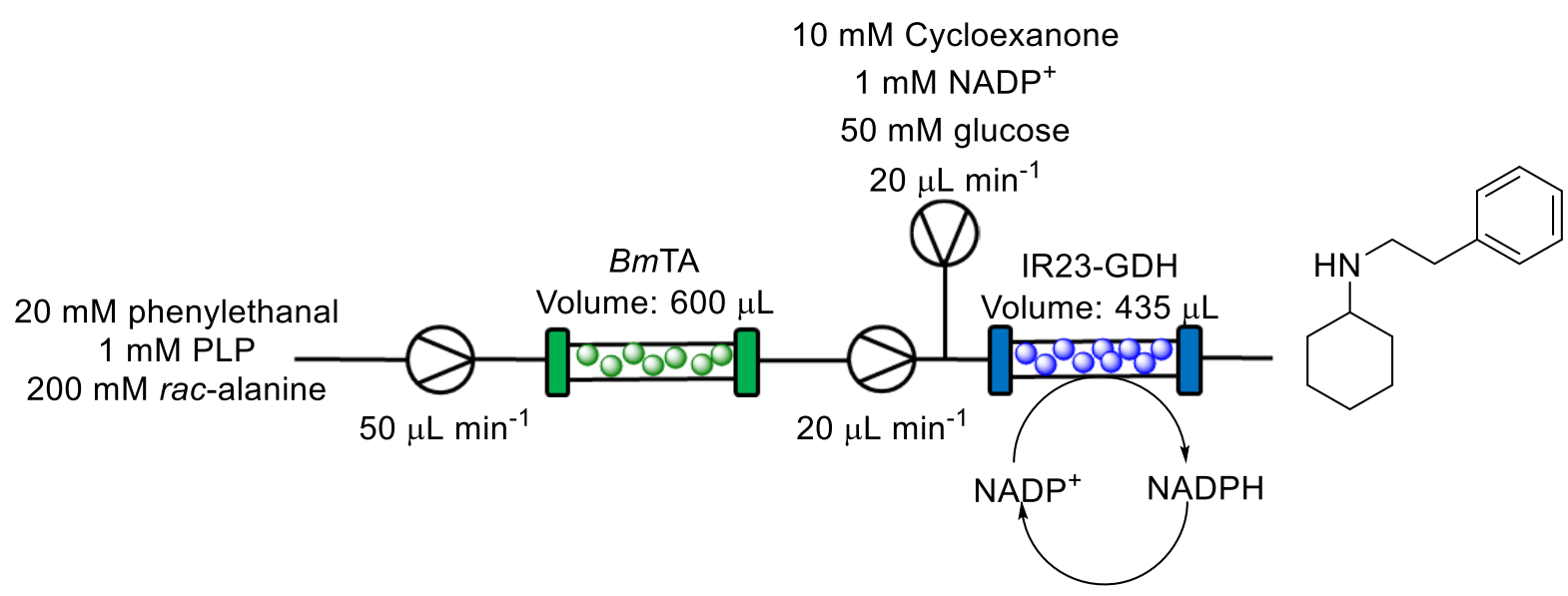

Figure S19: BmTA-IR23 packed bed-packed bed system for the continuous production of $N$ phenylethylcyclohexanamine.

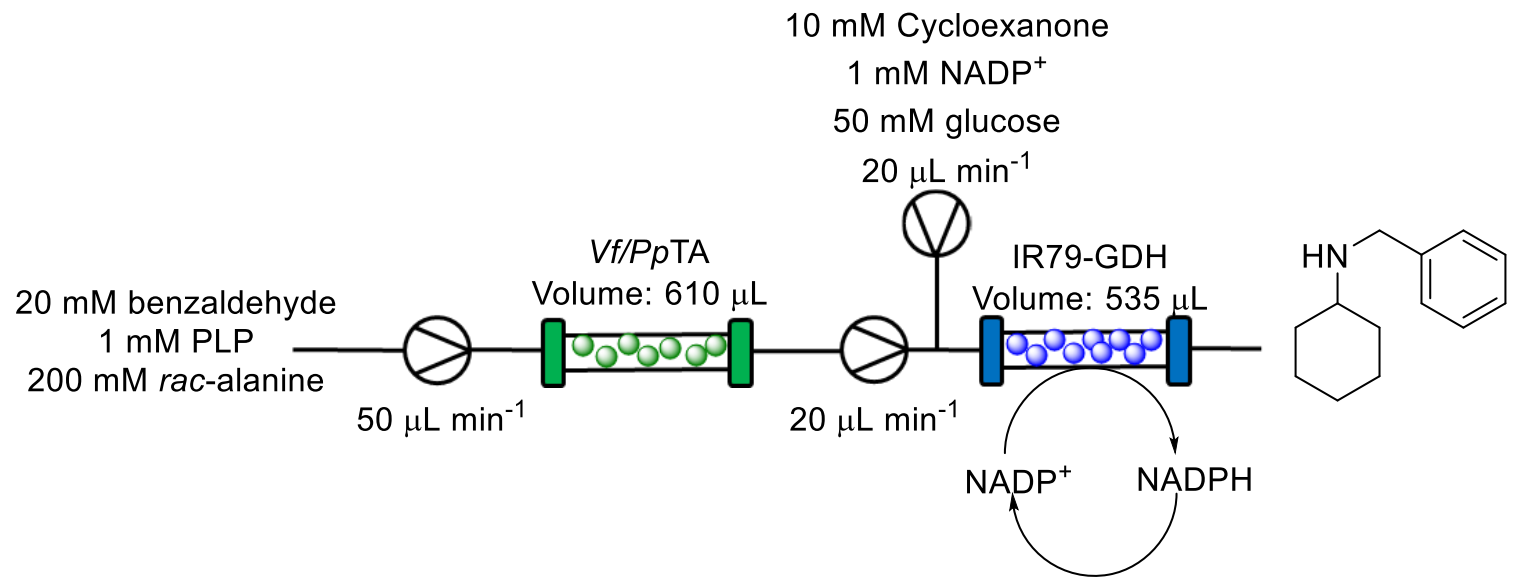

Figure S20: Vf or PpTA-IR79 packed bed-packed bed system for the continuous production of $N$-benzylycyclohexanamine. 
Packed bed- packed bed (added switching valves) continuous reactions
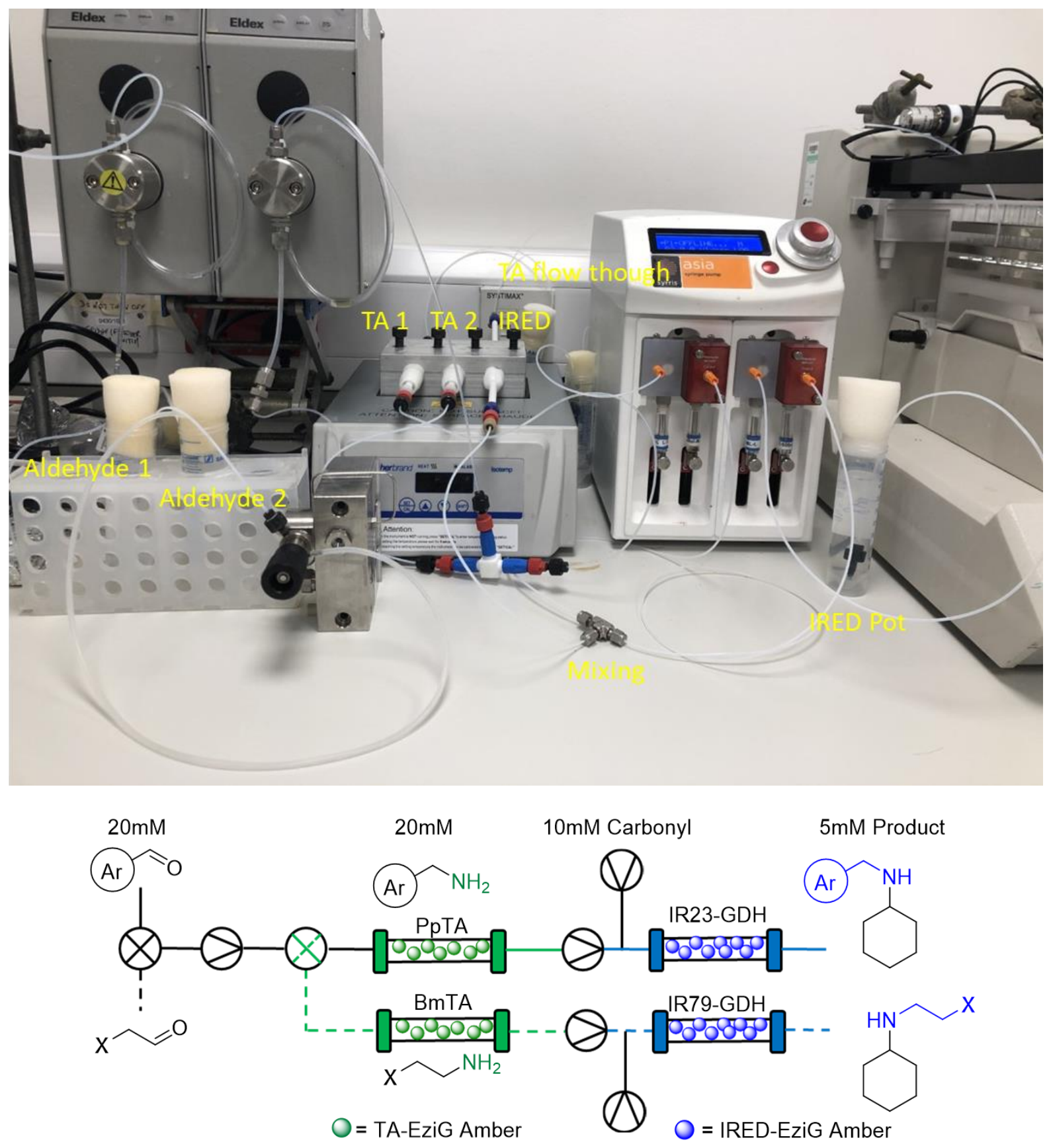

Figure S21: TA-RedAm packed-packed bed system with added switching valves enables rapid change of flow path and efficient synthesis of multiple products in one system. 


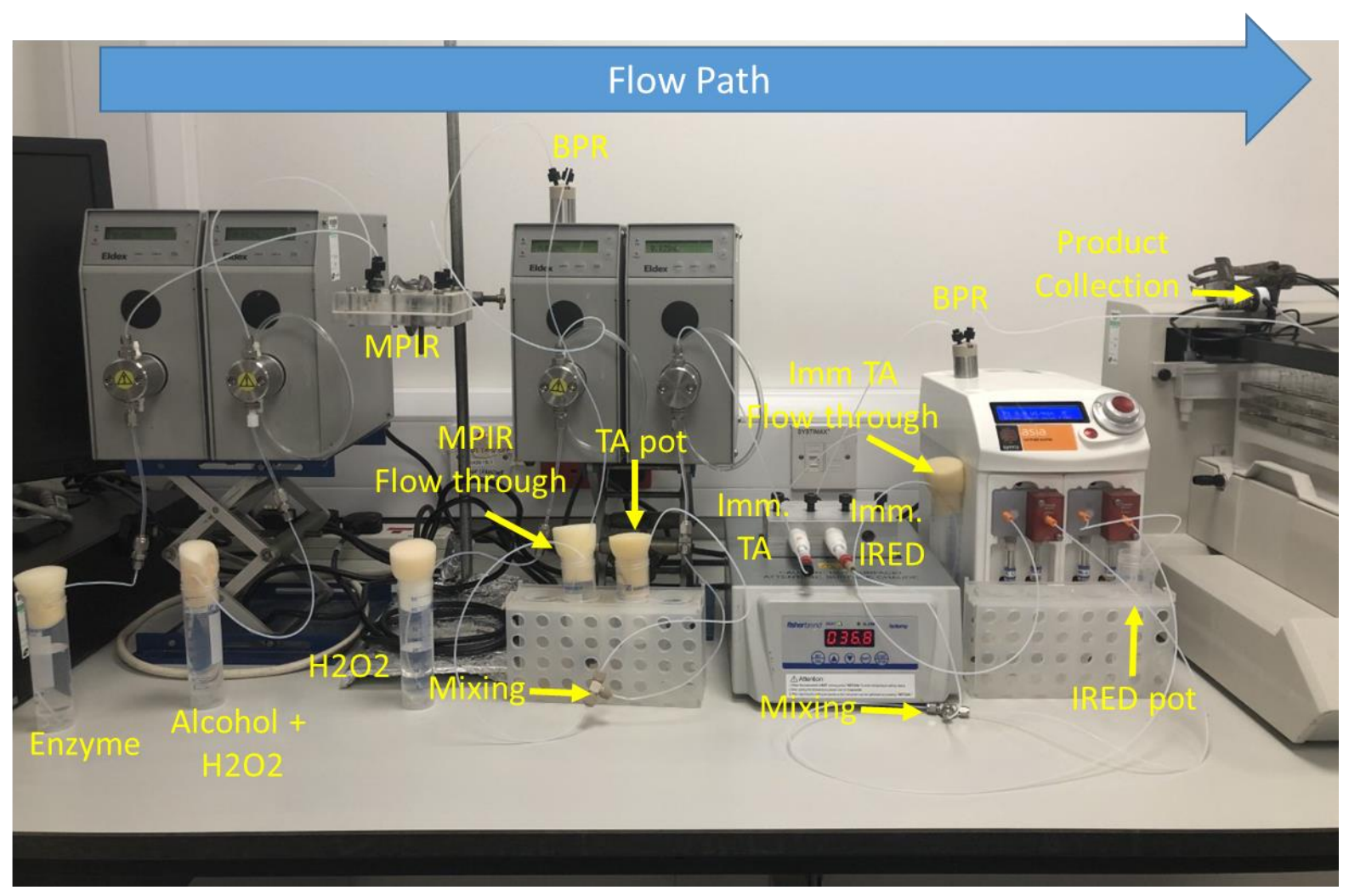

Figure S22: Lab set up for MPIR-packed bed-packed bed continuous flow reactions.

The MPIR and a MPIR-packed bed-packed bed systems were set up as pictured above: The initial bio-oxidation in the MPIR was run for 90 minutes to ensure the system had reached steady state, and the effluent discarded. The reaction mixture was collected until a reservoir of aldehyde solution was formed. A T-junction was fitted before an Eldex pump with a line from the MPIR flow and a line from a TA substrate reservoir (alanine $(400 \mathrm{mM})$, PLP $(1 \mathrm{mM}))$. This was passed through an immobilised transaminase and was run for 60 minutes to ensure steady state was reached. A Syrris Asia flow chemistry syringe pump with two modules was then used to pump the flow through from the TA reaction and a RedAm substrate reservoir (carbonyl $(10 \mathrm{mM}), \mathrm{NADP}^{+}(1 \mathrm{mM})$, glucose $\left.(50 \mathrm{mM})\right)$. These lines were mixed via a Kinesis microstatic mixer and passed through the immobilized RedAm. AcCO6 MPIR reactions were run in KPi buffer (100 mM, pH 7), whilst the RedAm and TA substrate reservoirs were made up in KPi buffer (100 mM, pH 7.5). The GOase-RedAm/TA system was run in NaPi buffer (100 $\mathrm{mM}, \mathrm{pH}$ 7.5). Fractions were basified, extracted into ethyl acetate and analysed by GC-FID.

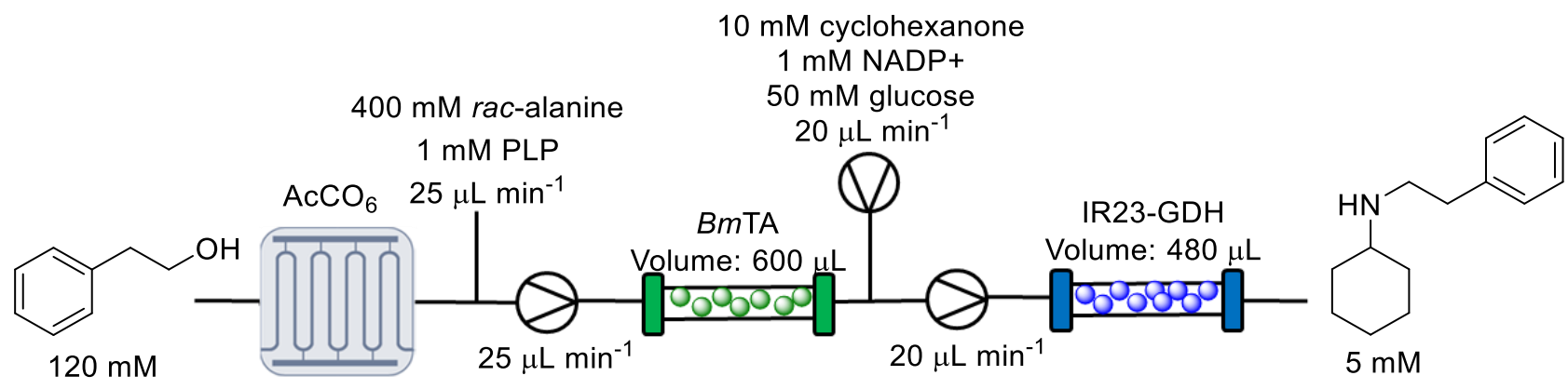


Figure S23: $\mathrm{AcCO}_{6}-\mathrm{BmTA}$-IR23 MPIR-packed bed-packed bed system for the continuous production of $\mathrm{N}$-phenylethylcyclohexanamine.

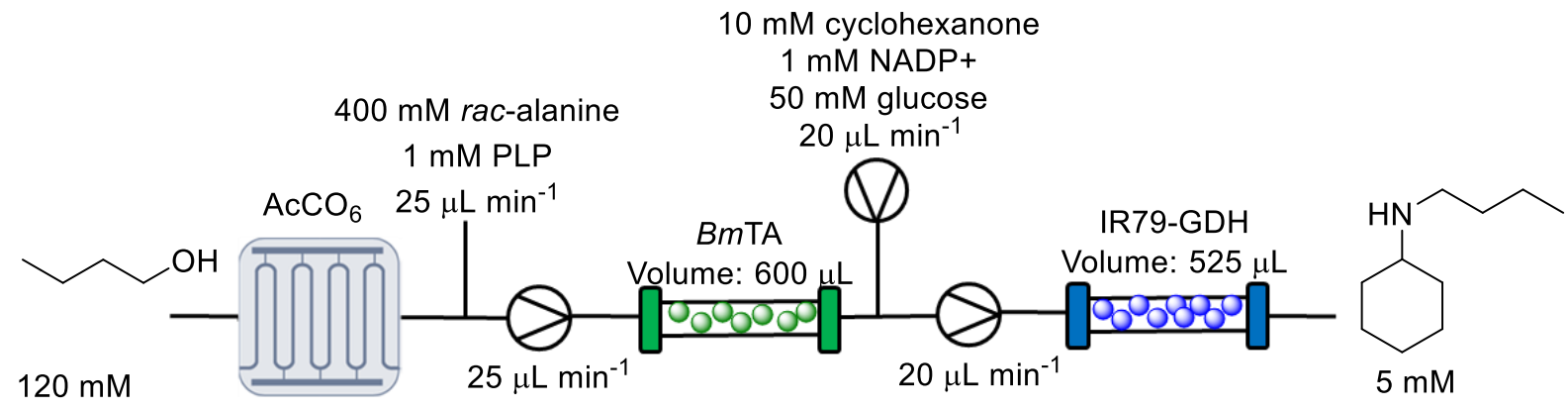

Figure S24: $\mathrm{AcCO}_{6}-\mathrm{BmTA}$-IR79 MPIR-packed bed-packed bed system for the continuous production of $\mathrm{N}$-butylcyclohexanamine.

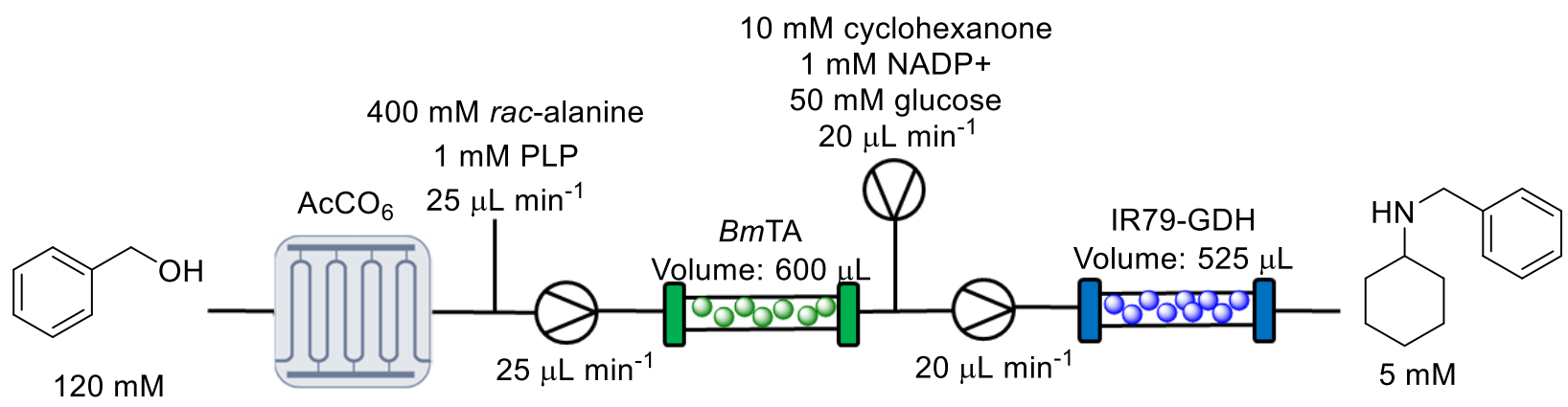

Figure S25: GOase-BmTA-IR79 MPIR-packed bed-packed bed system for the continuous production of $\mathrm{N}$-benzylcyclohexanamine.

In flow enzymatic synthesis of 40 -Methylnorbelladine 
A previously described high throughput colorimetric screen was used to identify potential RedAms capable of carrying out reductive amination with isovanilin and tyramine to generate 40-Me norbelladine. ${ }^{3}$

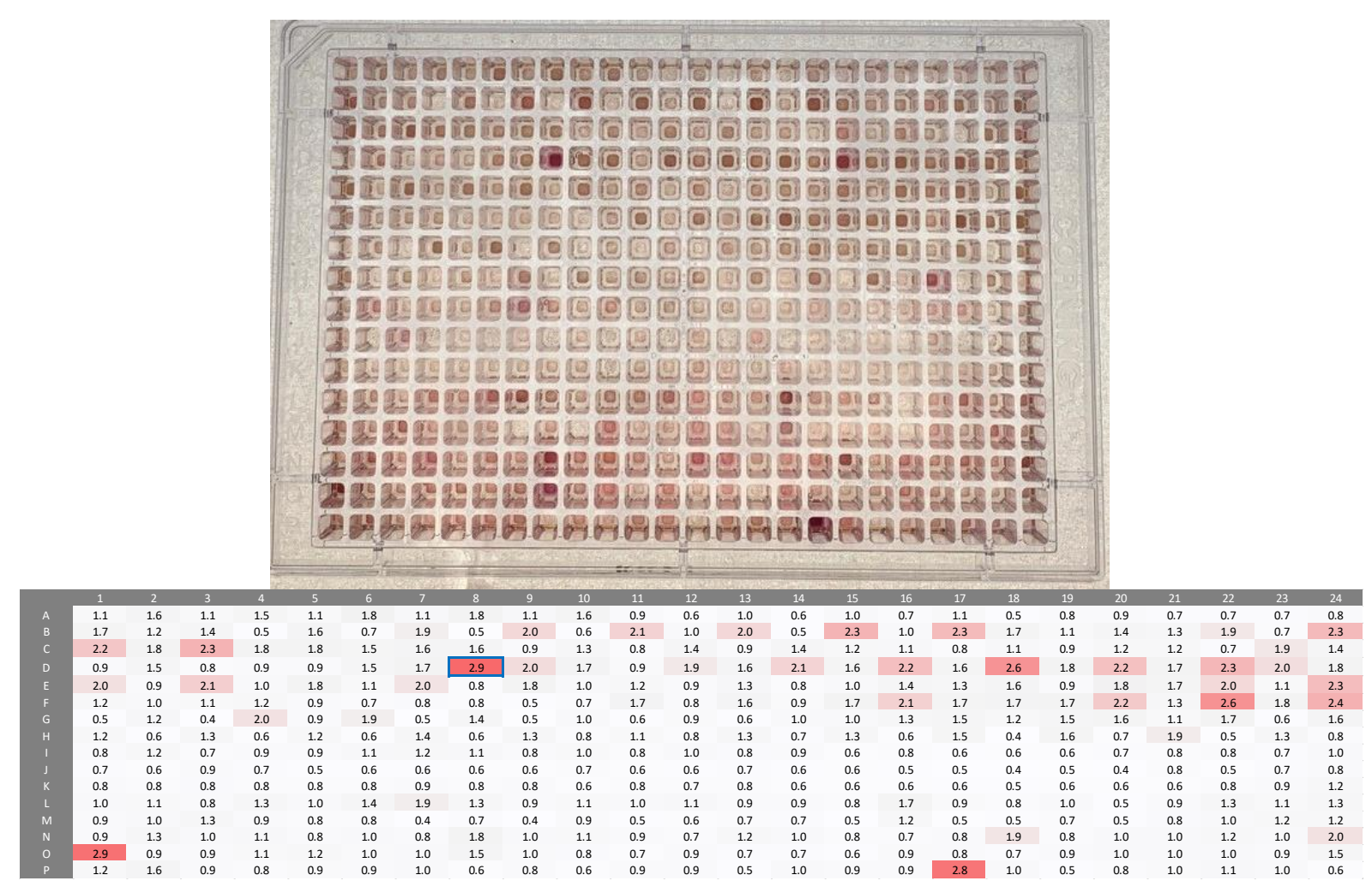

Figure S26: Top: picture of IREDy-2-go screen after 24 hours incubation. Bottom: absorbance recorded from plates with IR-80 highlighted in blue.

\section{4-OMe norbelladine batch reaction}

Analyitical scale $(500 \mu \mathrm{L}) \mathrm{IR}-80$ reactions were carried out in NaPi buffer $(100 \mathrm{mM}, \mathrm{pH} 7.5$, $20 \% \mathrm{v} / \mathrm{v} \mathrm{DMSO})$ and contained: IR-80 (10 mg mL $\mathrm{m}^{-1}$, lysate), isovanillin $(5 \mathrm{mM})$, tyramine (25 $\mathrm{mM}), \mathrm{NADP}^{+}(0.5 \mathrm{mM})$, glucose $(50 \mathrm{mM})$ and $\mathrm{BsGDH}\left(1 \mathrm{mg} \mathrm{mL}^{-1}\right)$. The reaction was incubated at $30^{\circ} \mathrm{C}$ overnight with $200 \mathrm{rpm}$ shaking. Biotransformations were filtered using $10 \mathrm{kDa} \mathrm{MWCO}$ Vivapsin column. The filtrate was removed and the residue suspended in $\mathrm{H}_{2} \mathrm{O}$ and filtered again. The remaining residue was then suspended in $\mathrm{MeOH} / \mathrm{DMSO}$, filtered and then analysed by MALDI-ToF.<smiles>COc1ccc(CNCCc2ccc(O)cc2)cc1O</smiles>

Exact Mass: 273.14

$\left[\mathrm{M}+\mathrm{H}^{+}\right] 274.14$ 


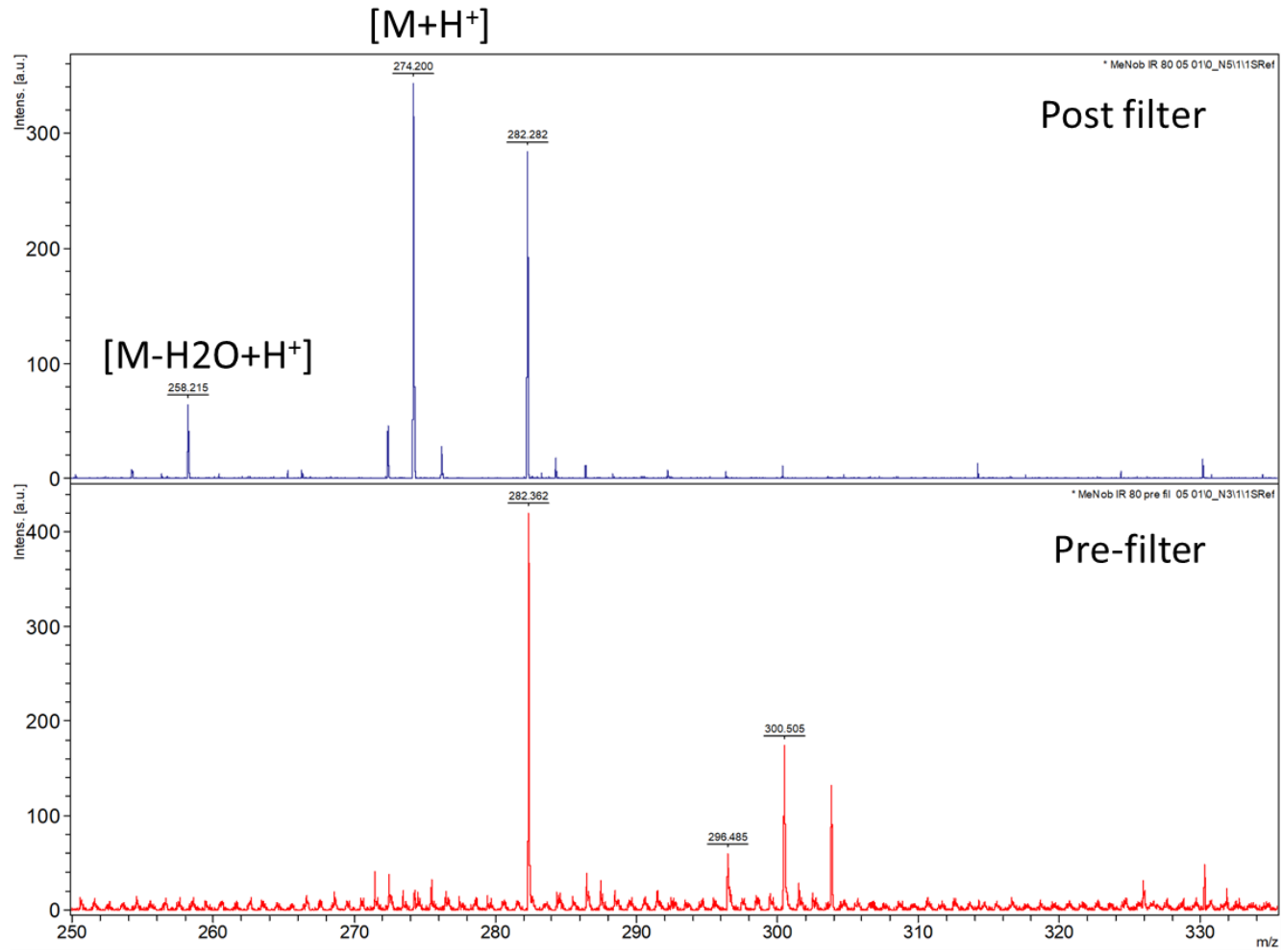

Figure S27: Top: MALDI-ToF analysis of IR-80 reductive amination of isovanillin with tyramine. Bottom: Filtered biotransformation with the residue re-suspended in DMSO<smiles>COc1ccc(CN)cc1O</smiles>

Exact Mass: 153.08

$\left[\mathrm{M}+\mathrm{Na}^{+}\right] 176.07$

$\left[\mathrm{M}+\mathrm{Na}^{+}\right]$

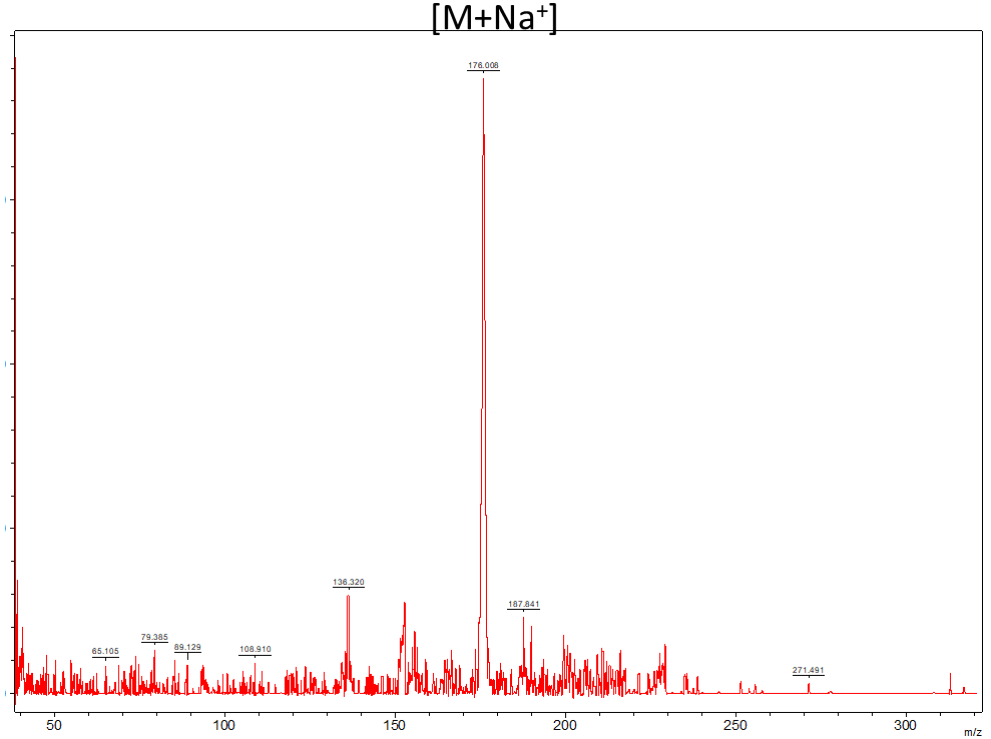

Figure S28: MS2 analysis of m/z 274.2 showing fragmentation of 4-OMethyl norbelladine 


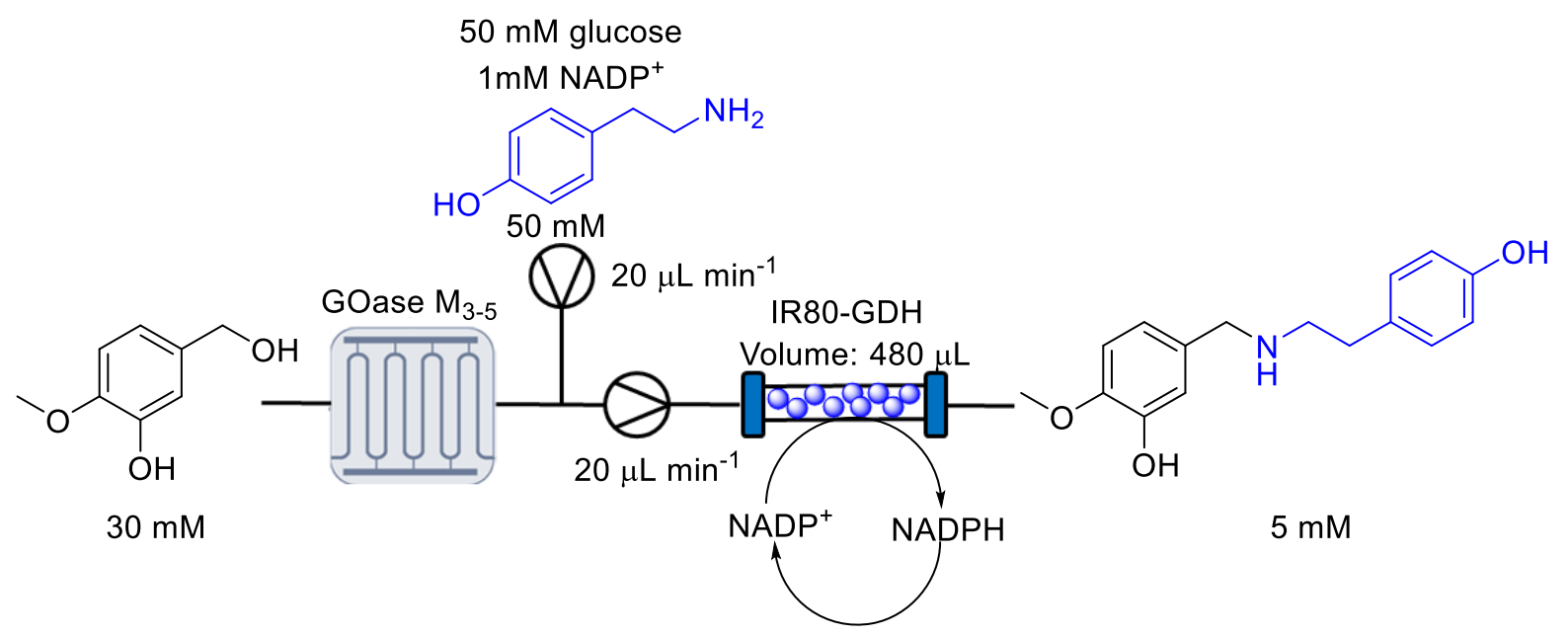

Figure S29: GOase-IR80 MPIR-packed bed system for the continuous production of 4-OMe norbelladine.

MPIR-Packed bed systems were set up as pictured above: The initial bio-oxidation of isovanillnyl alcohol $(30 \mathrm{mM})$ in the MPIR (GOase $\mathrm{M}_{3-5}\left(5 \mathrm{mg} \mathrm{mL}^{-1}\right.$, lysate)) was run for 90 minutes to ensure the system had reached steady state, and the effluent discarded. The reaction mixture was collected until a reservoir of aldehyde solution was formed. A Syrris Asia flow chemistry syringe pump with two modules was then used to pump the flow through from the MPIR and a RedAm substrate reservoir (tyramine $(50 \mathrm{mM}), \mathrm{NADP}^{+}(1 \mathrm{mM})$, glucose (50 $\mathrm{mM})$ ). The effluent was filtered using a 10KDa MWCO Vivaspin column, the filtrate was removed and the residue re-suspended in $\mathrm{H}_{2} \mathrm{O}$ and filtered again. The remaining residue was then re-suspended in $\mathrm{MeOH} / \mathrm{DMSO}$ and filtered. An aliquot of the filtrate was taken for MS analysis with the remaining volume being dried under reduced pressure. 
Standard

Steady state flow reaction pre filtration

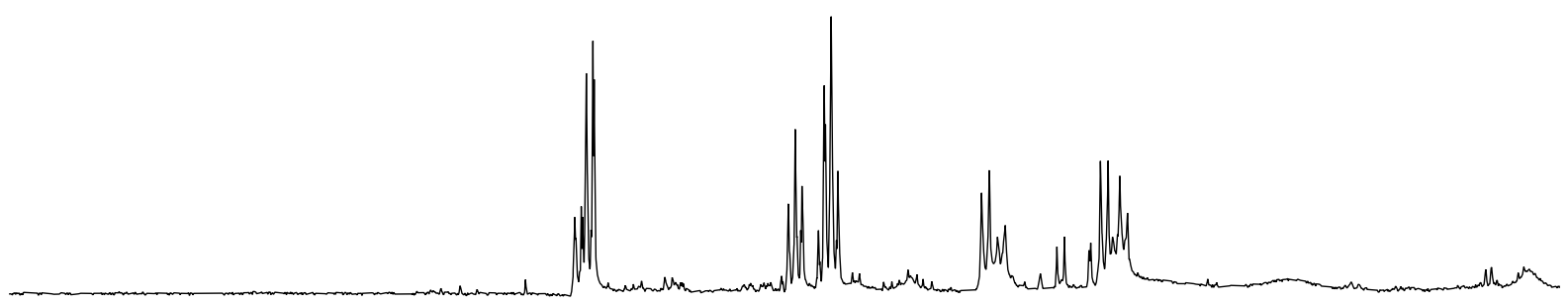

$\begin{array}{lllllllllllllllllllllllll}9.5 & 9.3 & 9.1 & 8.9 & 8.7 & 8.5 & 8.3 & 8.1 & 7.9 & 7.7 & 7.5 & 7.3 & 7.1 & 6.9 & 6.7 & 6.5 & 6.3 & 6.1 & 5.9 & 5.7 & 5 .\end{array}$

Standard

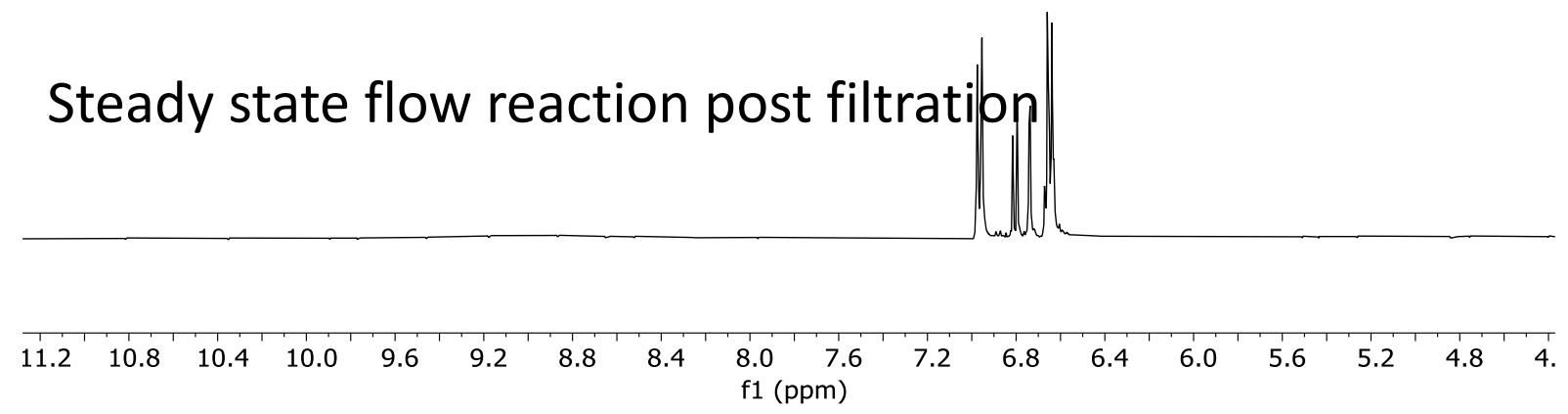


Figure S30: ${ }^{1} \mathrm{H}$ NMR spectra showing standard of 4-OMe norbelladine compared the flow reaction at steady state before and after filtration of the insoluble residue.

\section{GC chromatograms}
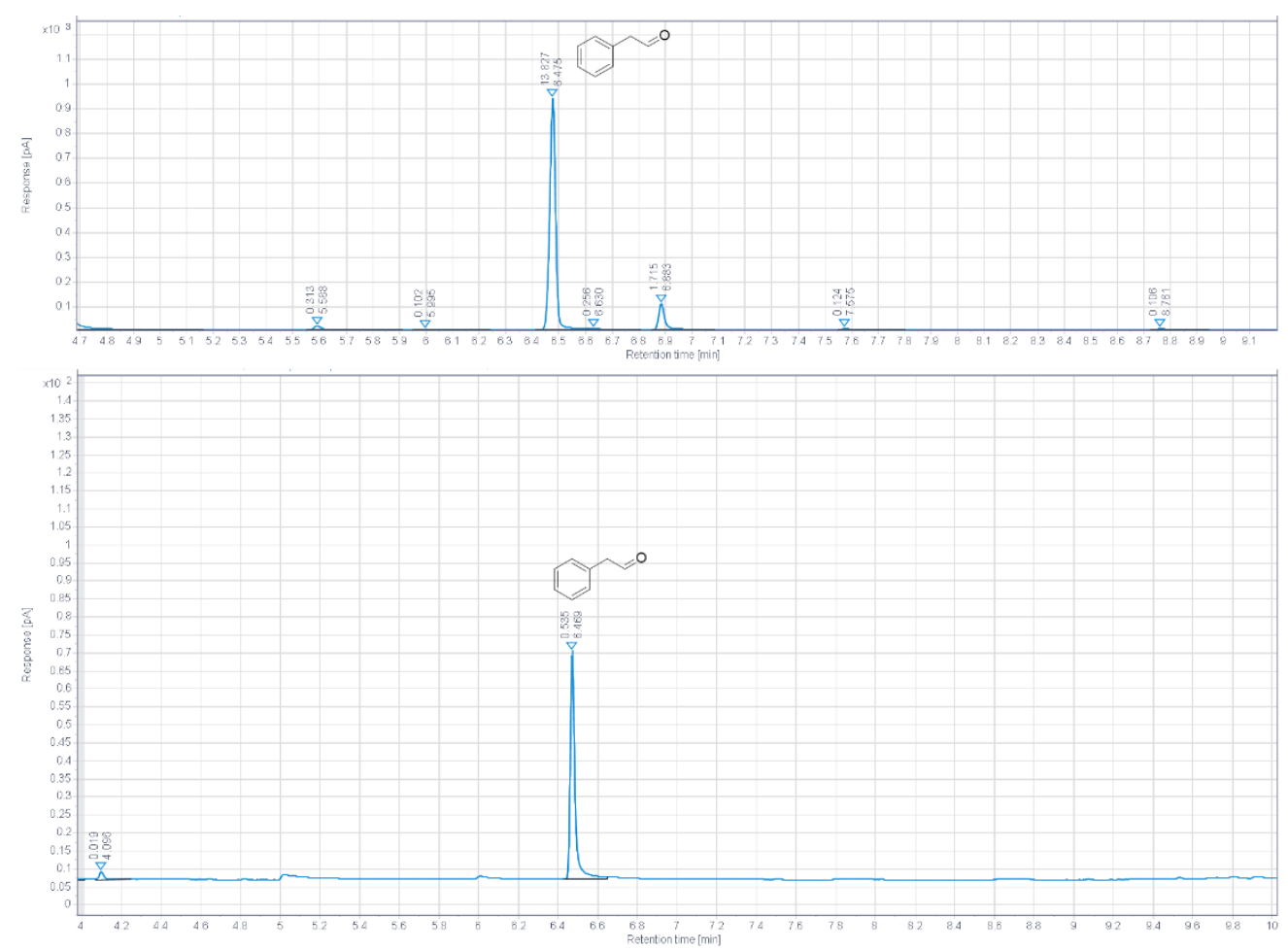

Figure S31: GC-FID spectra of: Top: phenylethanal standard; Bottom: steady state fraction from MPIR biooxdiation of phenylethanol with $\mathrm{AcCO}_{6}$. 


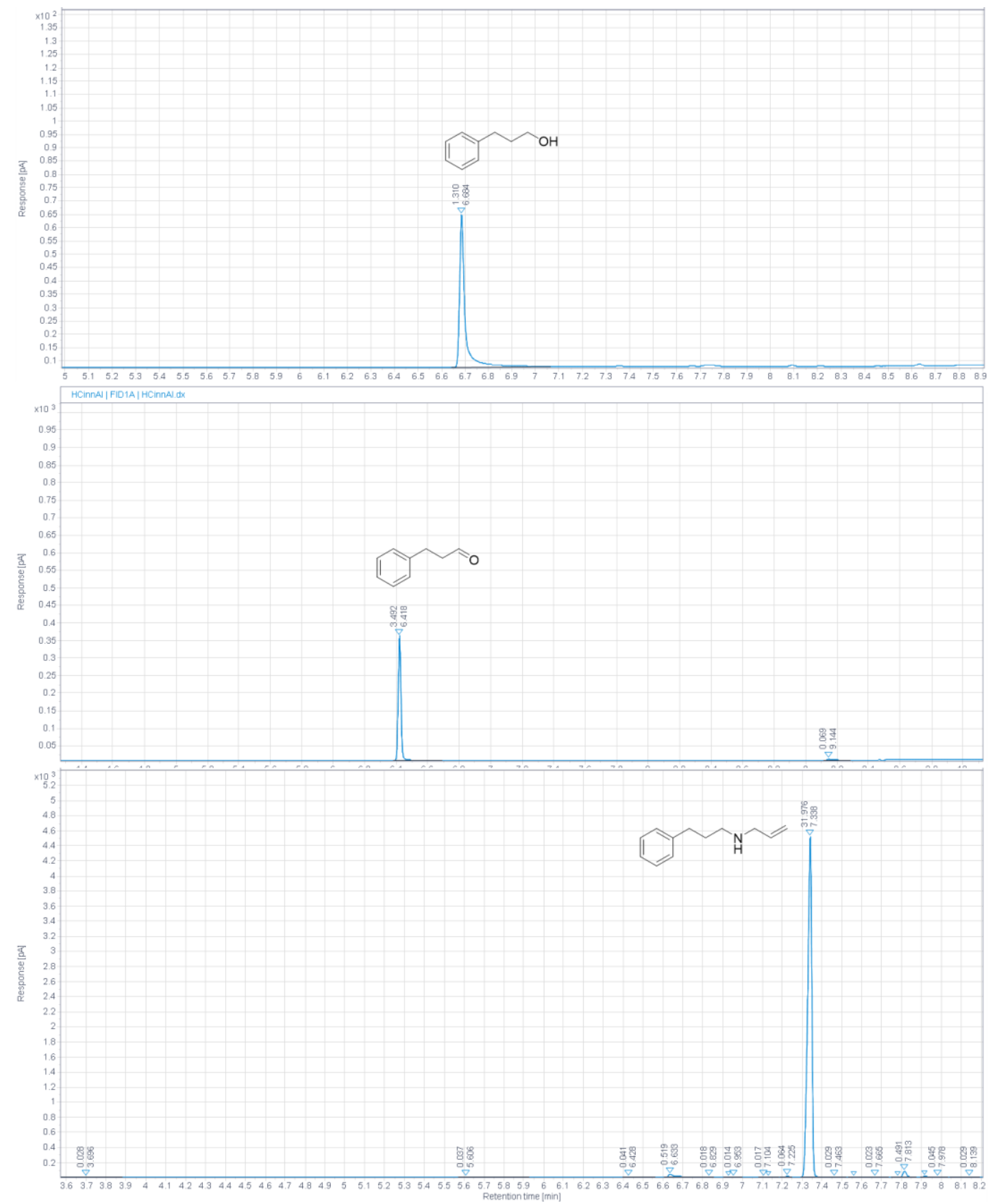

Figure S32: GC-FID spectra of analytical standards: Top: hyrdocinnamylalcohol; Middle: hydrocinnamaldehyde; Bottom: $\mathrm{N}$-Hyrdocinnamylallyl amine. 

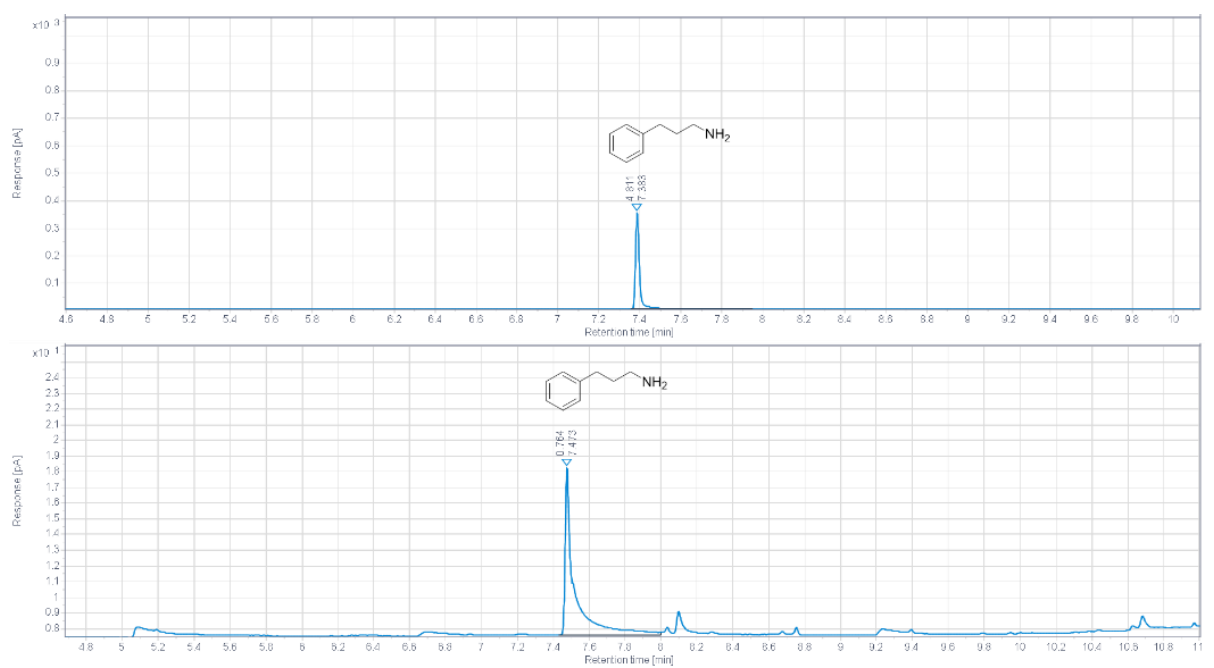

Figure S33: GC-FID spectra of: Top: hydrocinammylamine analytical standard; Bottom: steady state of AcCO6-BmTA MPIR-packed bed flow reaction.

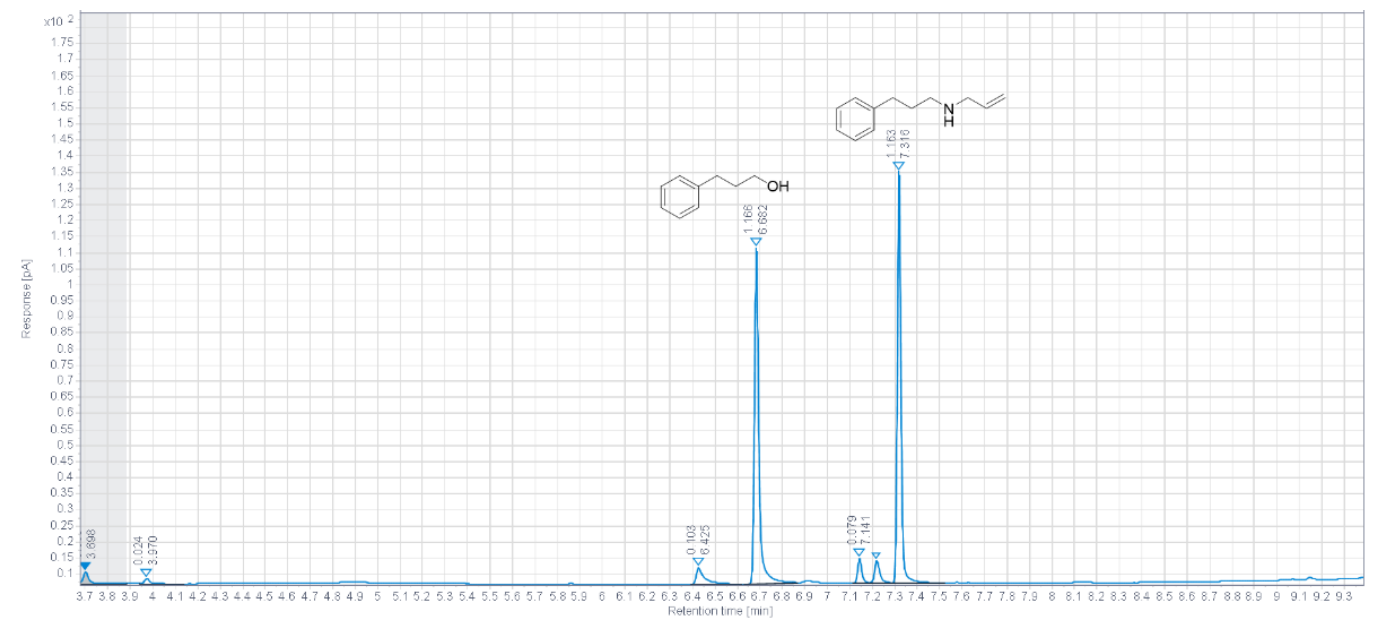

Figure S34: GC-FID spectra of AcCO6-AdRedAm MPIR-packed bed flow reaction. 

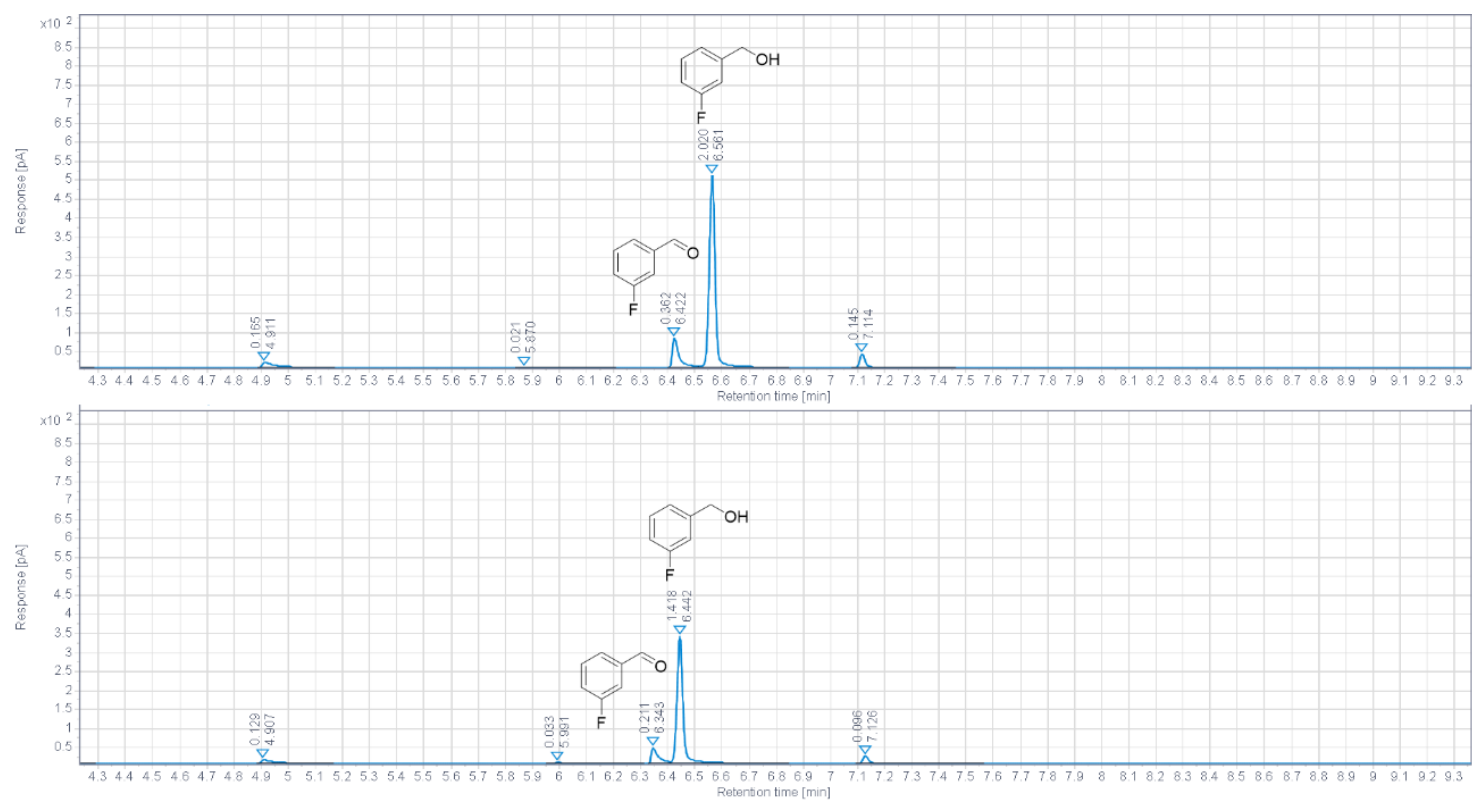

Figure S35: GC-FID spectra of: Top: batch one pot GOase-VfTA with 3-fluoro benzyl alcohol; Bottom: GOase-AdRedAm reaction with 3-fluoro benzyl alcohol.
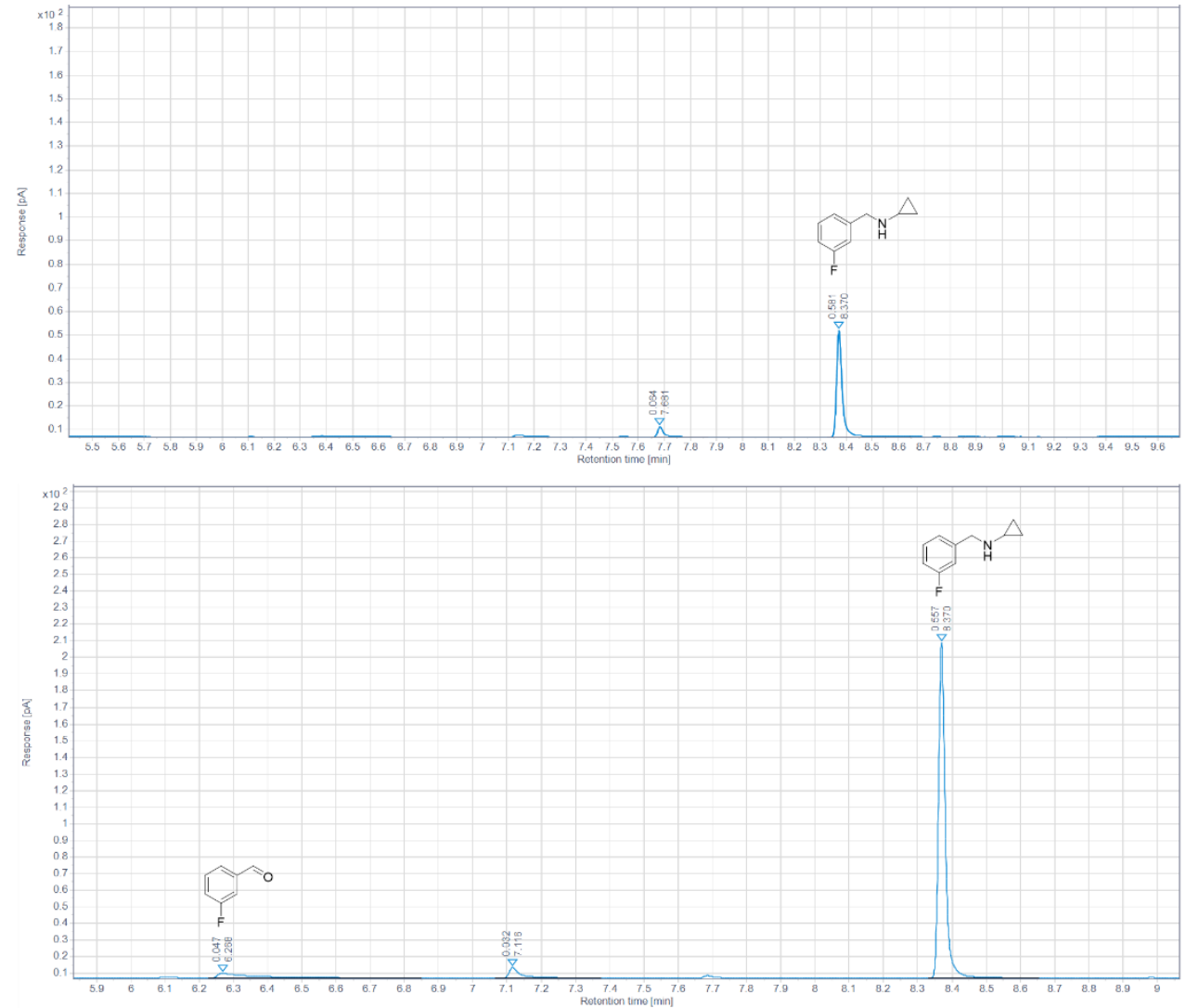

Figure S36: GC-FID spectra of: Top: analytical standard of $\mathrm{N}$-(3fluorobenzyl)cyclopropanamine; Bottom: steady state fractions from GOase-AdRedAm MPIRpacked bed system. 


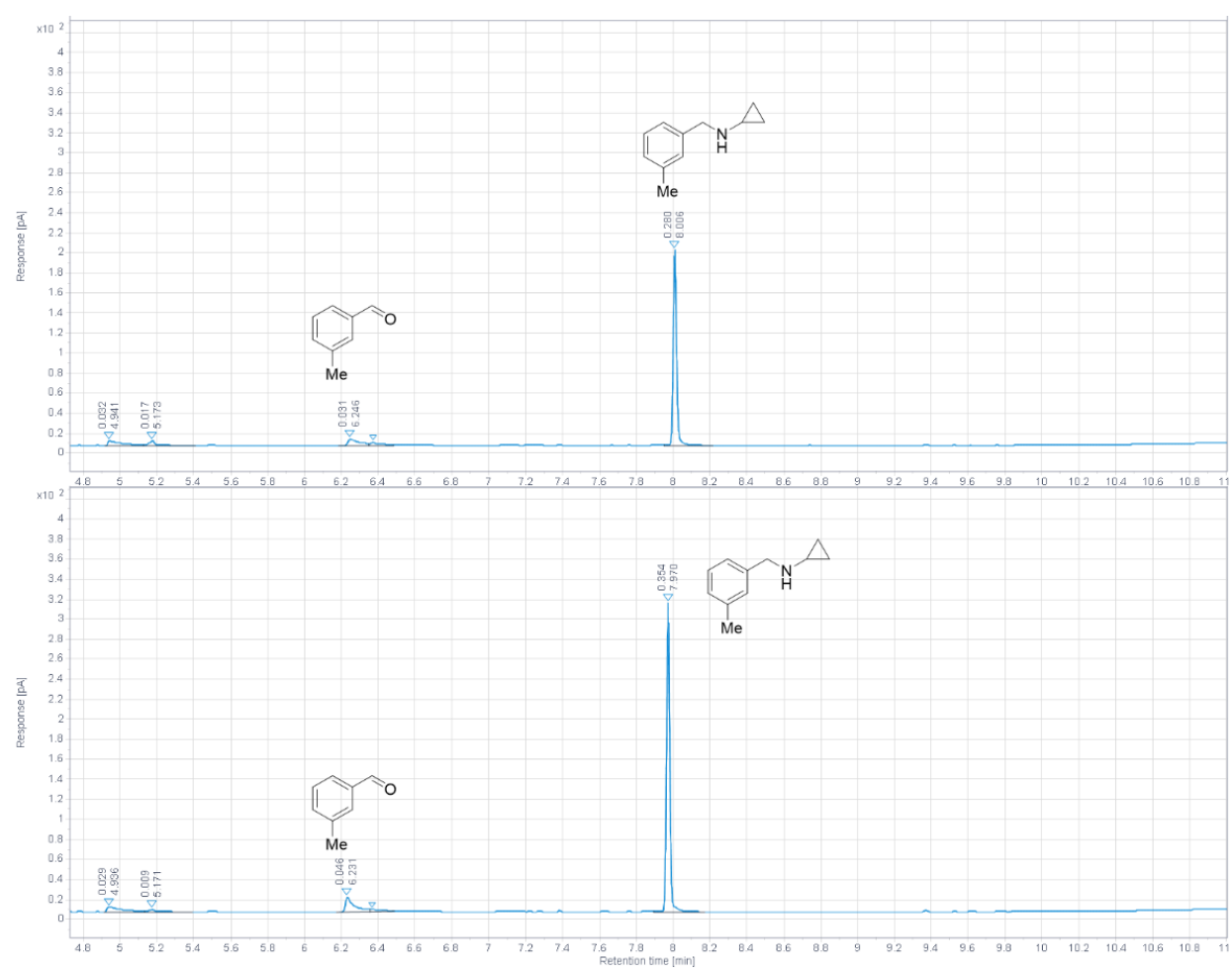

Figure S37: GC-FID spectra of: Top: analytical standard of $N$-(3methylbenzyl)cyclopropanamine; Bottom: steady state fractions from GOase-AdRedAm MPIR-packed bed system.

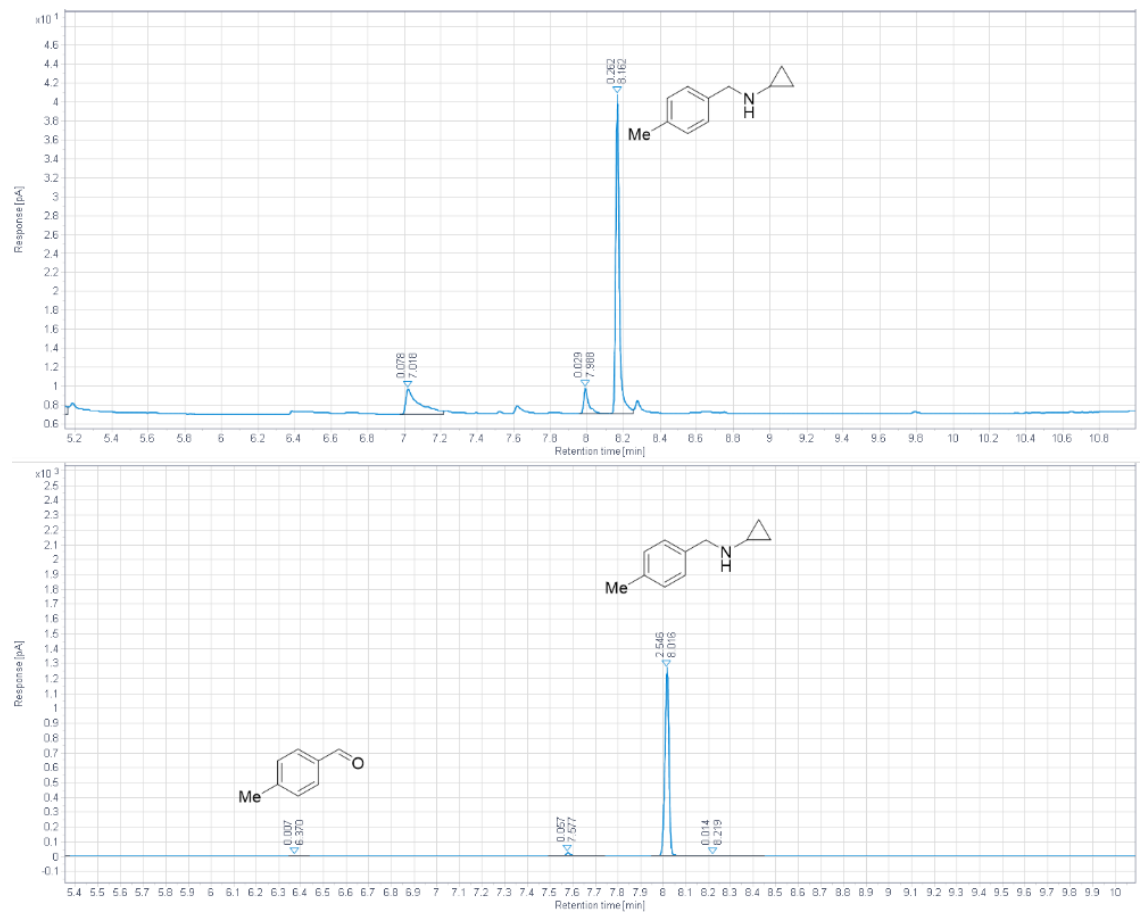

Figure S38: GC-FID spectra of: Top: analytical standard of $\mathrm{N}$-(4methylbenzyl)cyclopropanamine; Bottom: steady state fractions from GOase-AdRedAm MPIR-packed bed system. 


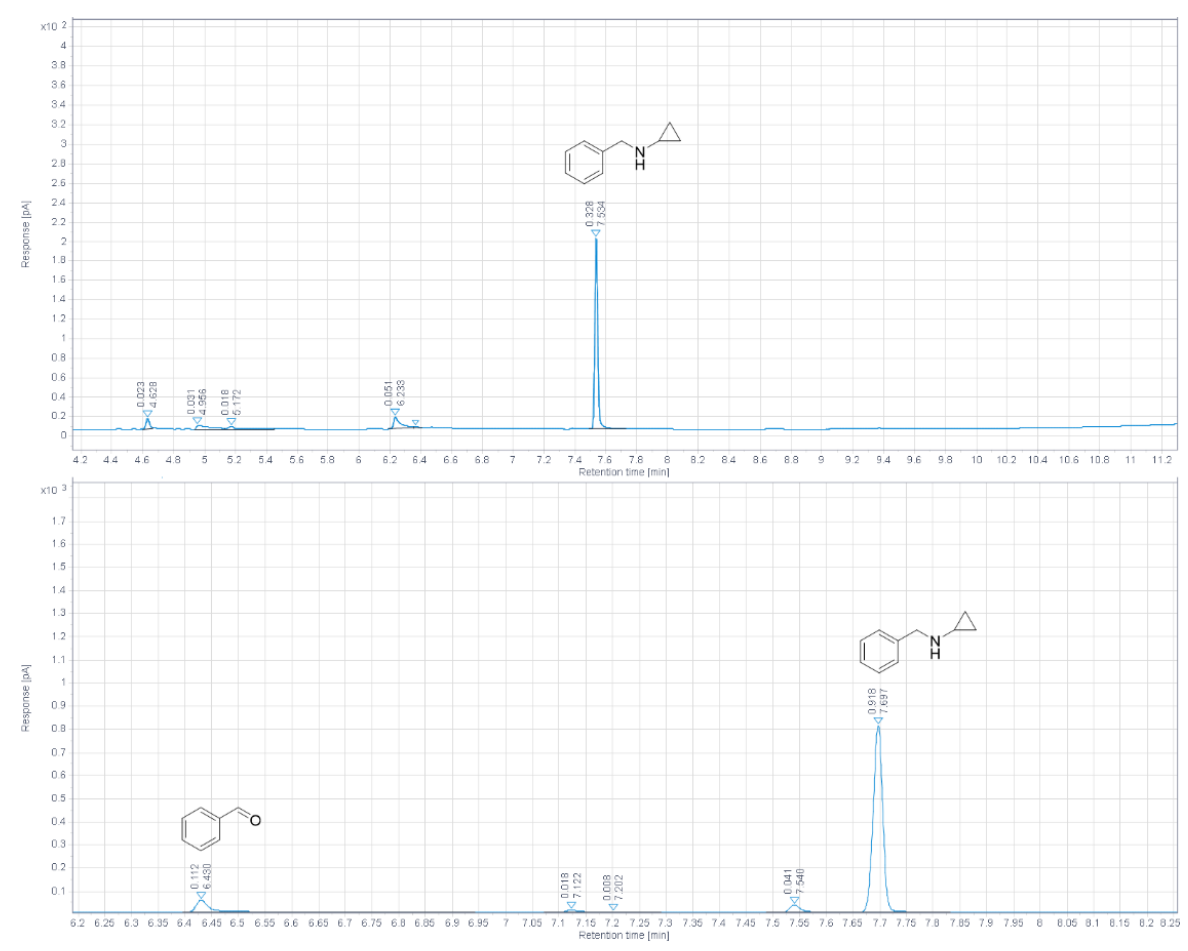

Figure S39: GC-FID spectra of: Top: analytical standard of $\mathrm{N}$-benzylcyclopropanamine; Bottom: steady state fractions from GOase-AdRedAm MPIR-packed bed system.
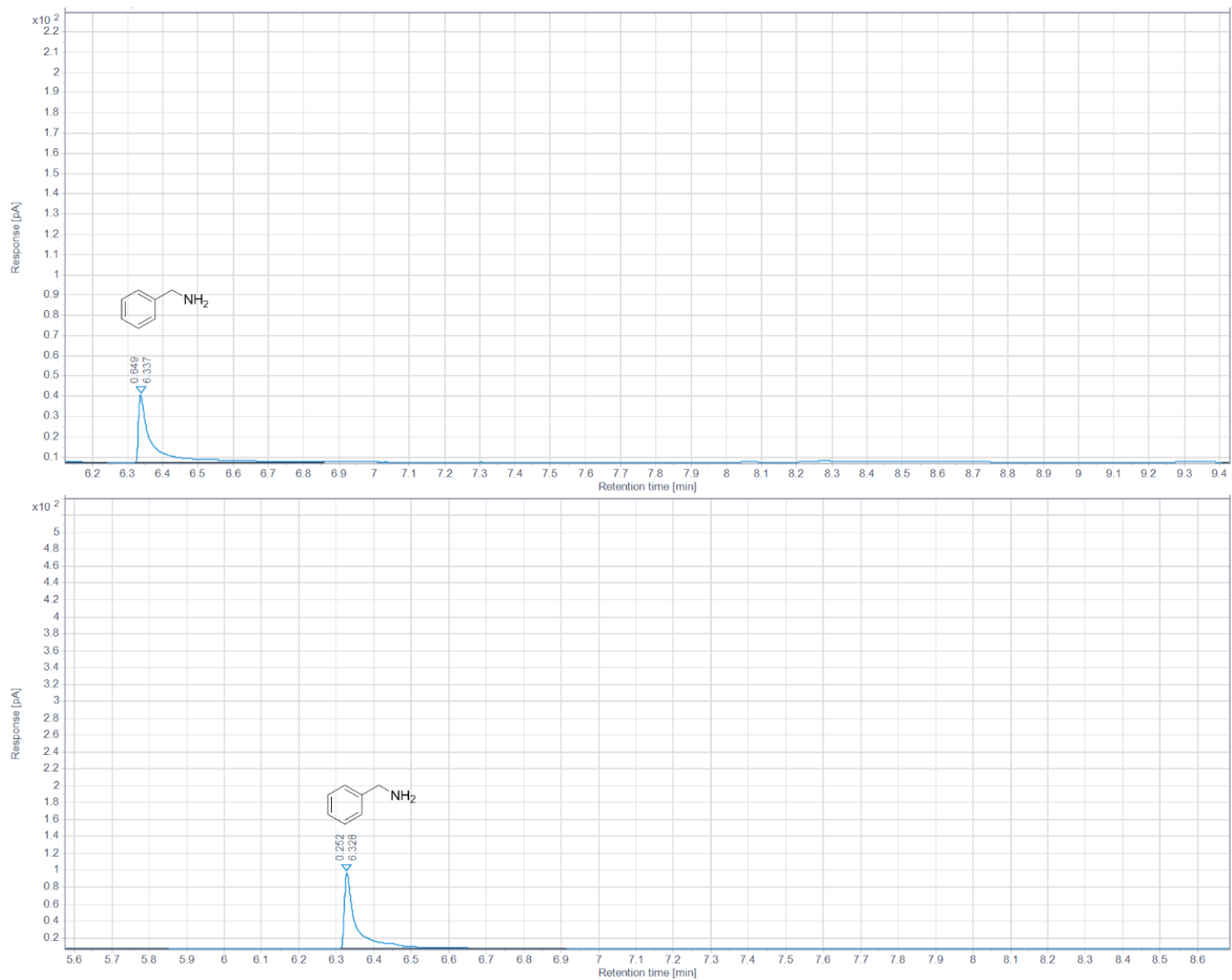

Figure S40: GC-FID spectra of: Top: analytical standard of benzylamine; Bottom: steady state of GOase-VfTA MPIR-Packed bed system. 

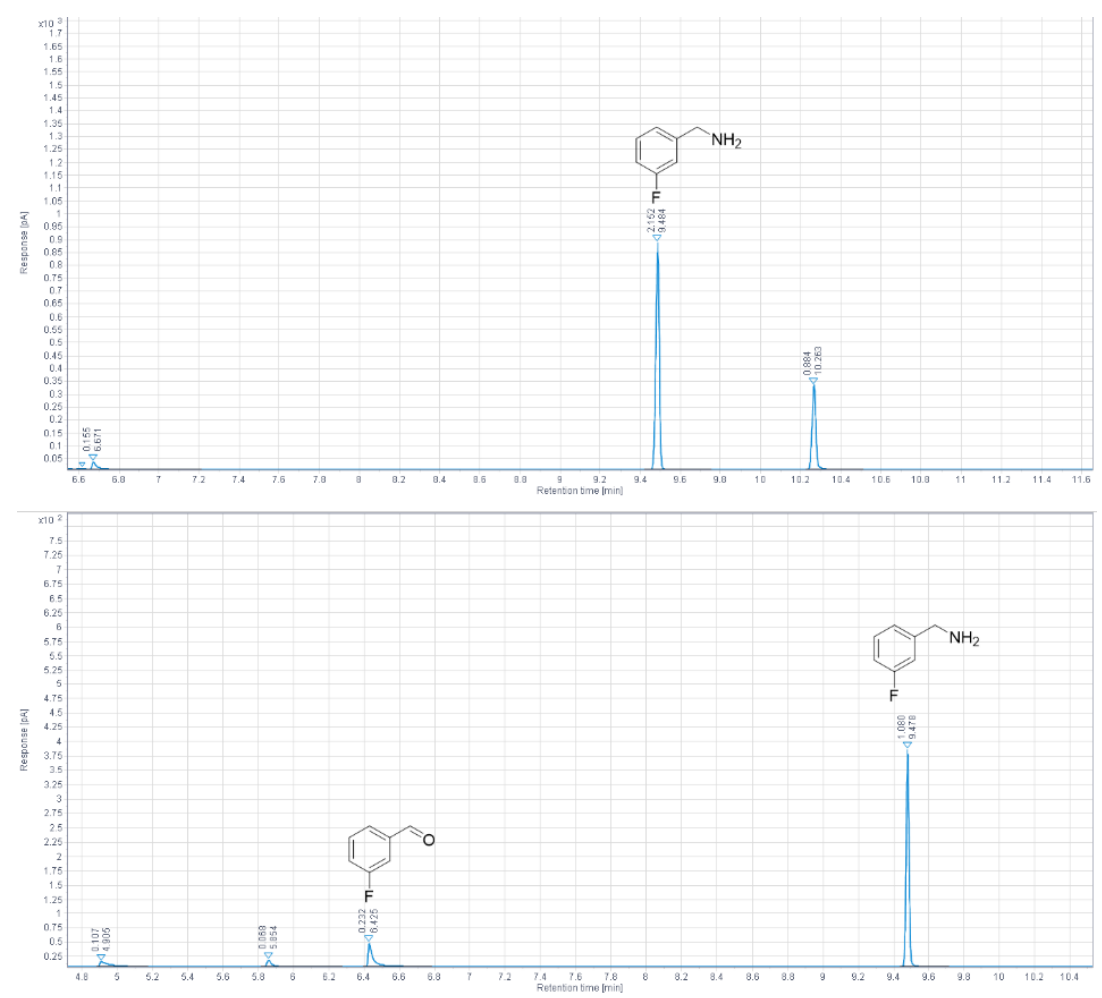

Figure S41: GC-FID spectra of: Top: analytical standard 3-Fluorobenzylamine; Bottom: steady state of GOase-VfTA MPIR-Packed bed flow reaction.
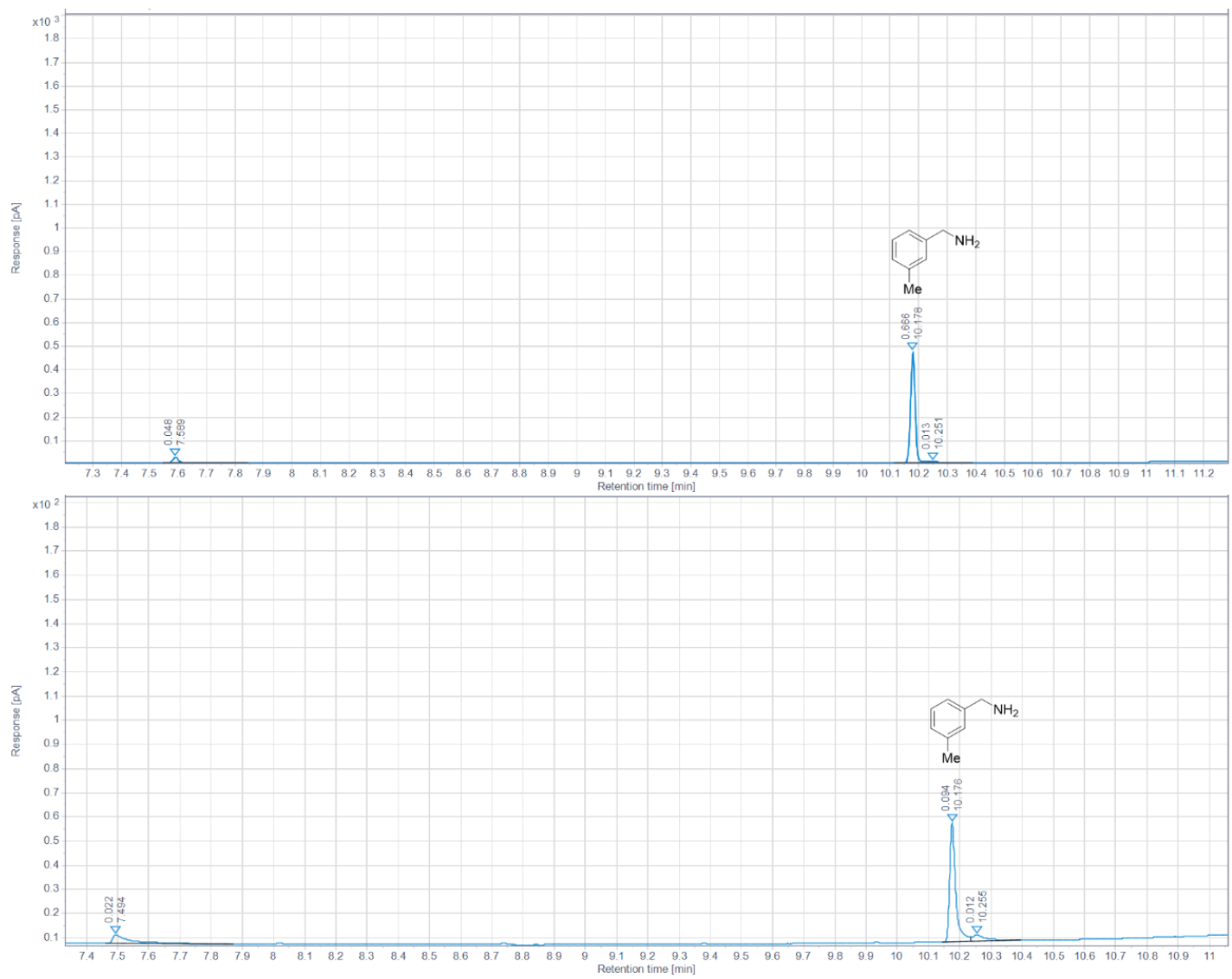

Figure S42: GC-FID spectra of: Top: analytical standard 3-Methylbenzylamine; Bottom: steady state of GOase-VfTA MPIR-Packed bed flow reaction. 

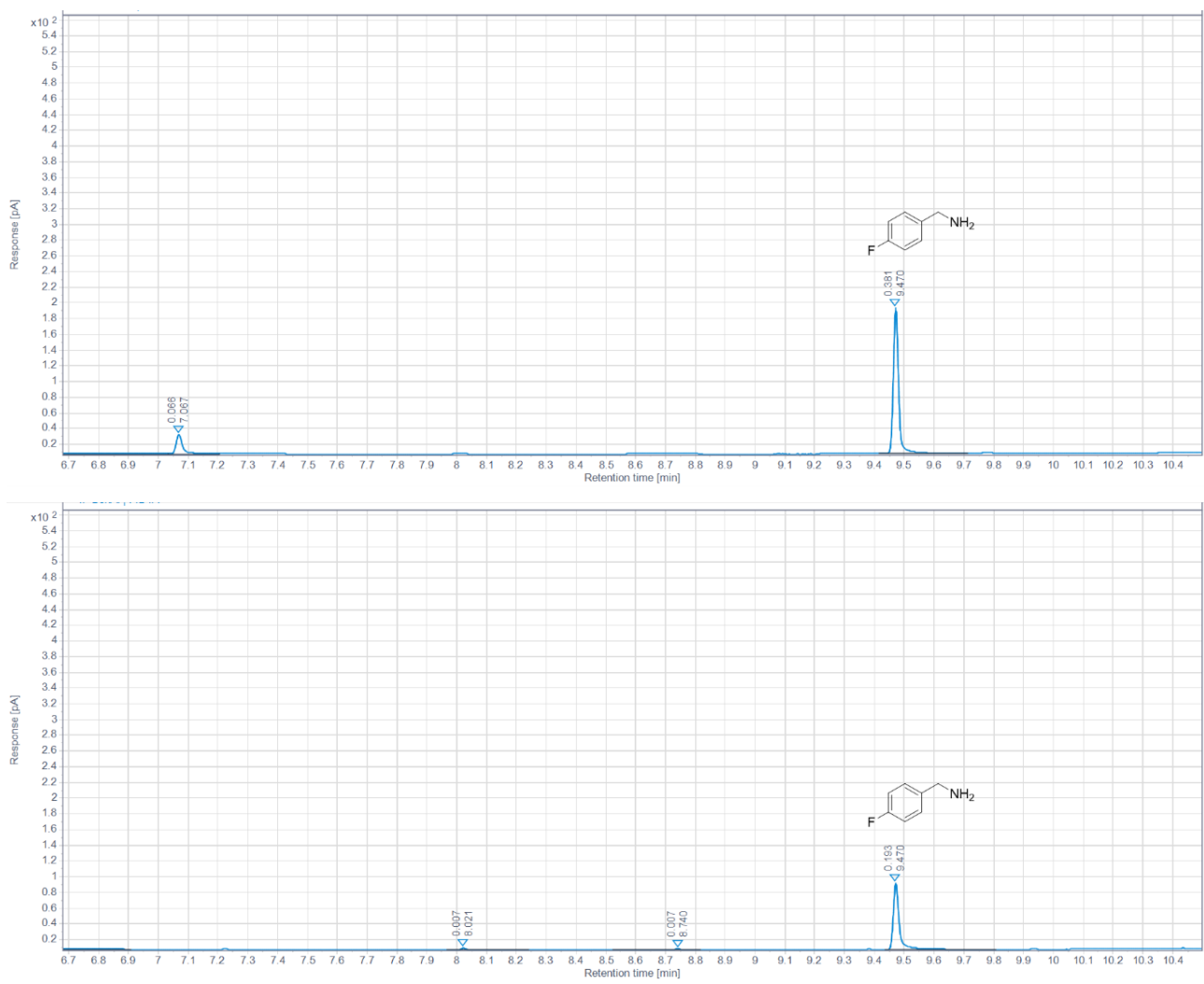

Figure S43: GC-FID spectra of: Top: analytical standard 4-fluorobenzylamine; Bottom: steady state of GOase-VfTA MPIR-Packed bed flow reaction.

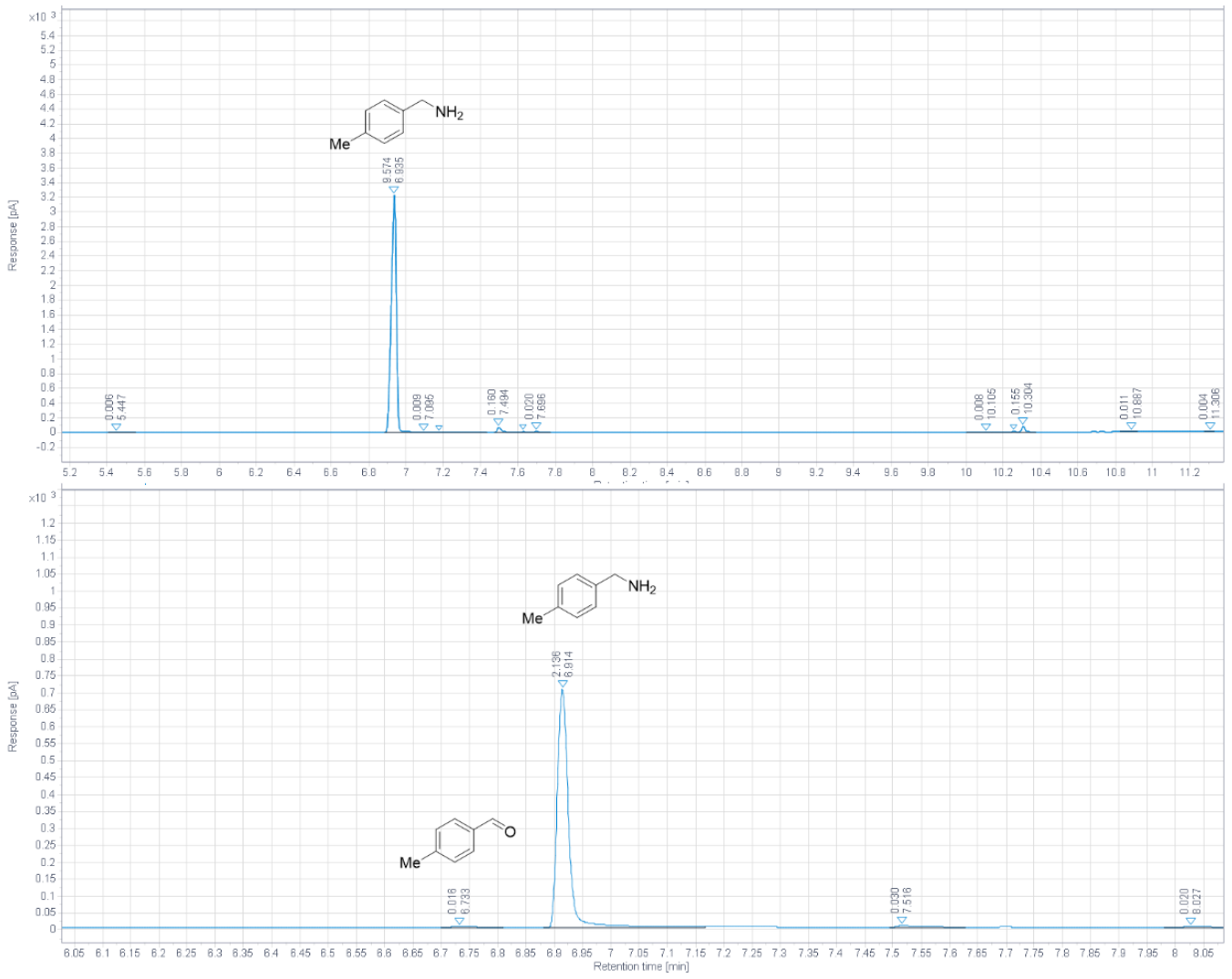

Figure S44: GC-FID spectra of: Top: analytical standard 4-Methylbenzylamine; Bottom: steady state of GOase-VfTA MPIR-Packed bed flow reaction. 

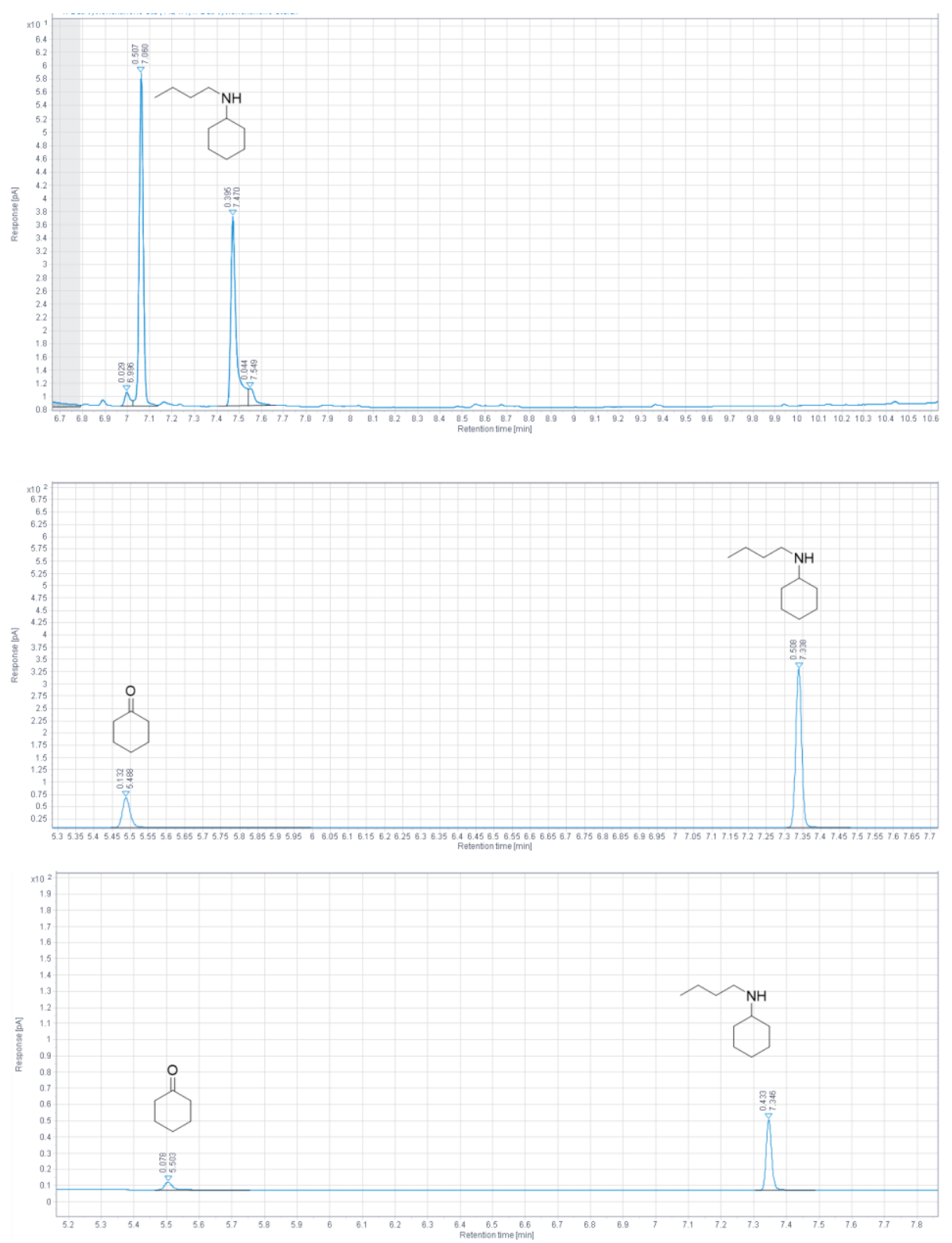

Figure S45: GC-FID spectra of: Top: analytical standard $\mathrm{N}$-butylcyclohexanamine; Middle: steady state of IR-79 single packed bed flow reaction; Bottom: steady state of BmTA-IR79 packed bed packed bed flow reaction.

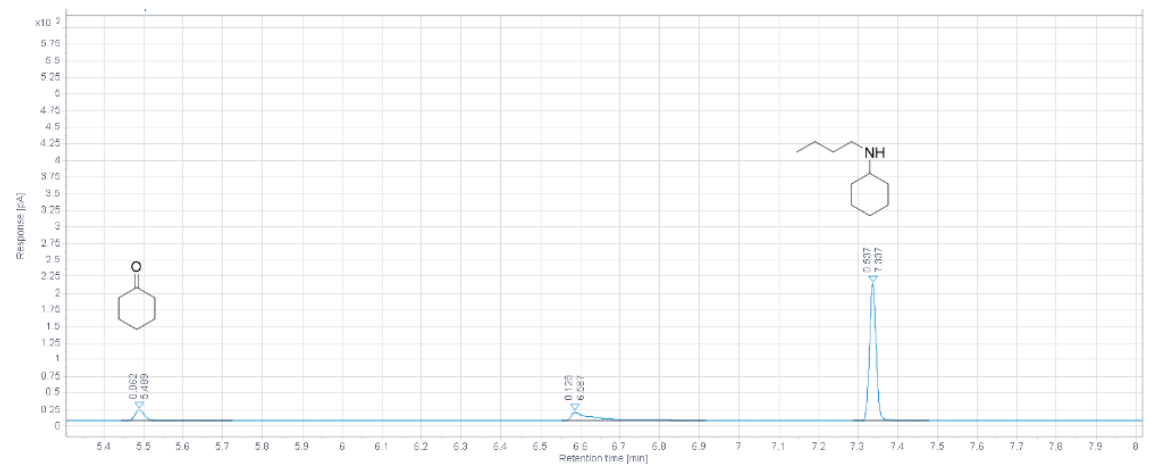

Figure S46: GC-FID spectra of steady state fractions from the $\mathrm{AcCO}_{6}-\mathrm{BmTA}$-IR79 MPIRpacked bed-packed bed system. 

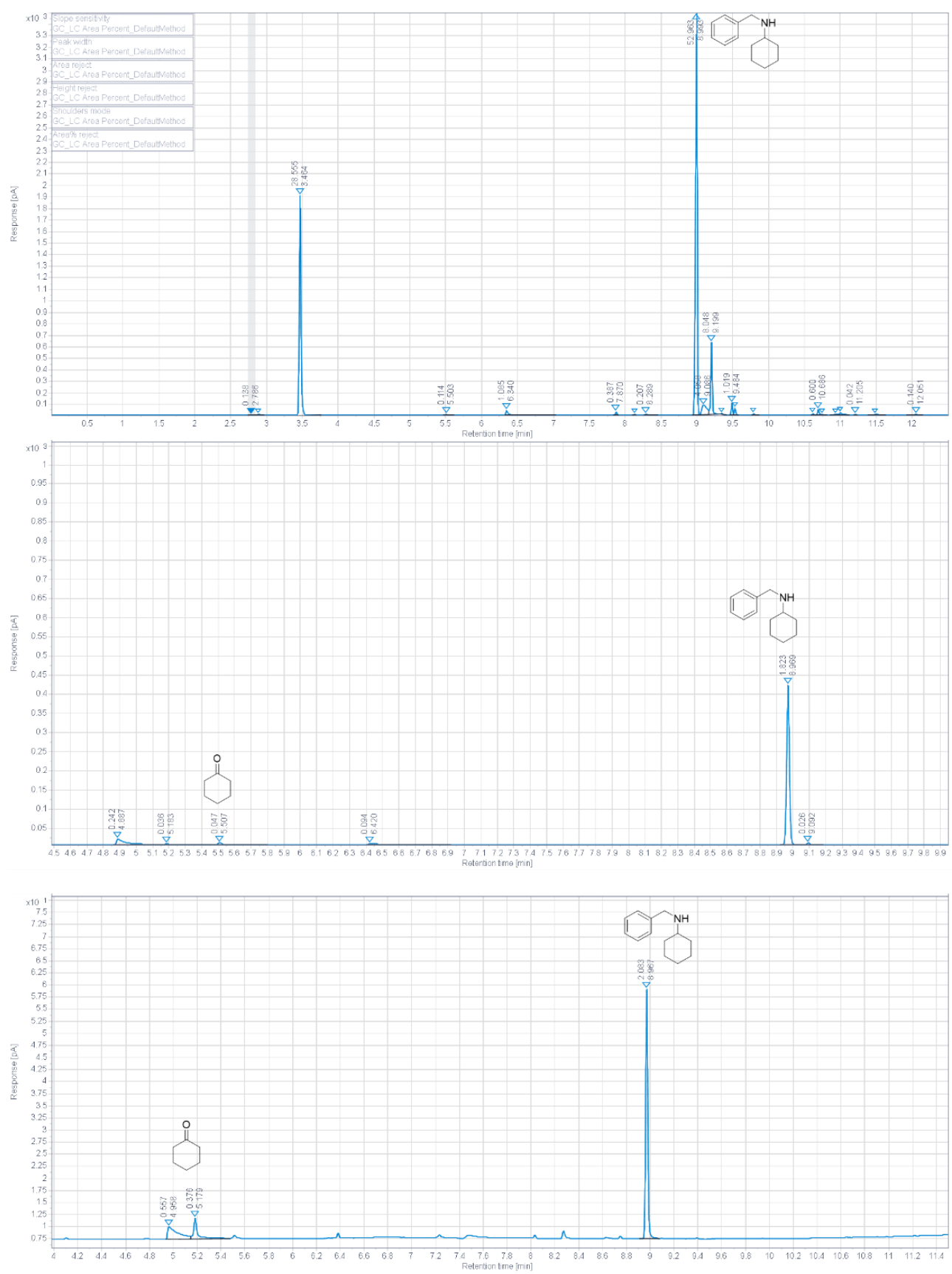

Figure S47: GC-FID spectra of: Top: analytical standard N-benzylcyclohexanamine; Middle: steady state of IR-79 single packed bed flow reaction; Bottom: PpTA-IR79 packed-bed packed-bed flow reaction.

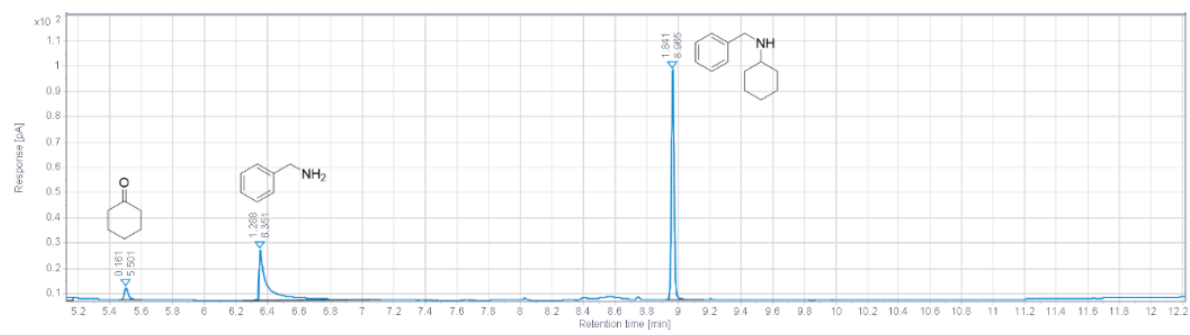

Figure S48: GC-FID spectra of steady state fractions from the GOase-VfTA-IR79 MPIRpacked-bed packed-bed system. 

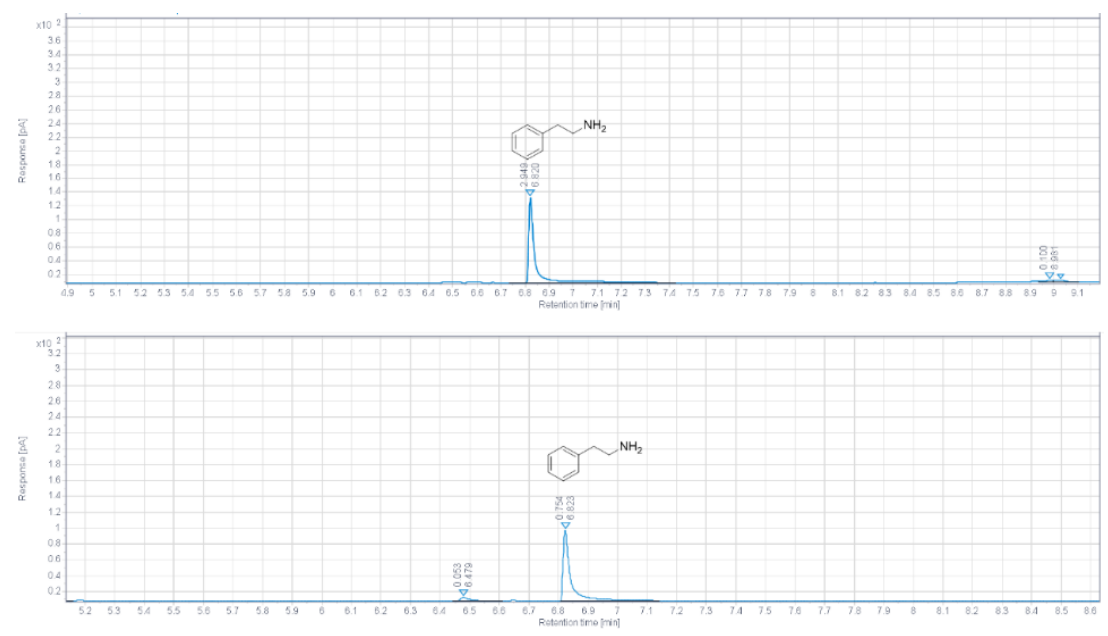

Figure S49: GC-FID spectra of: Top: analytical standard phenylethylamine; Bottom: steady state fractions of BmTA flow amination of phenylethanal. 

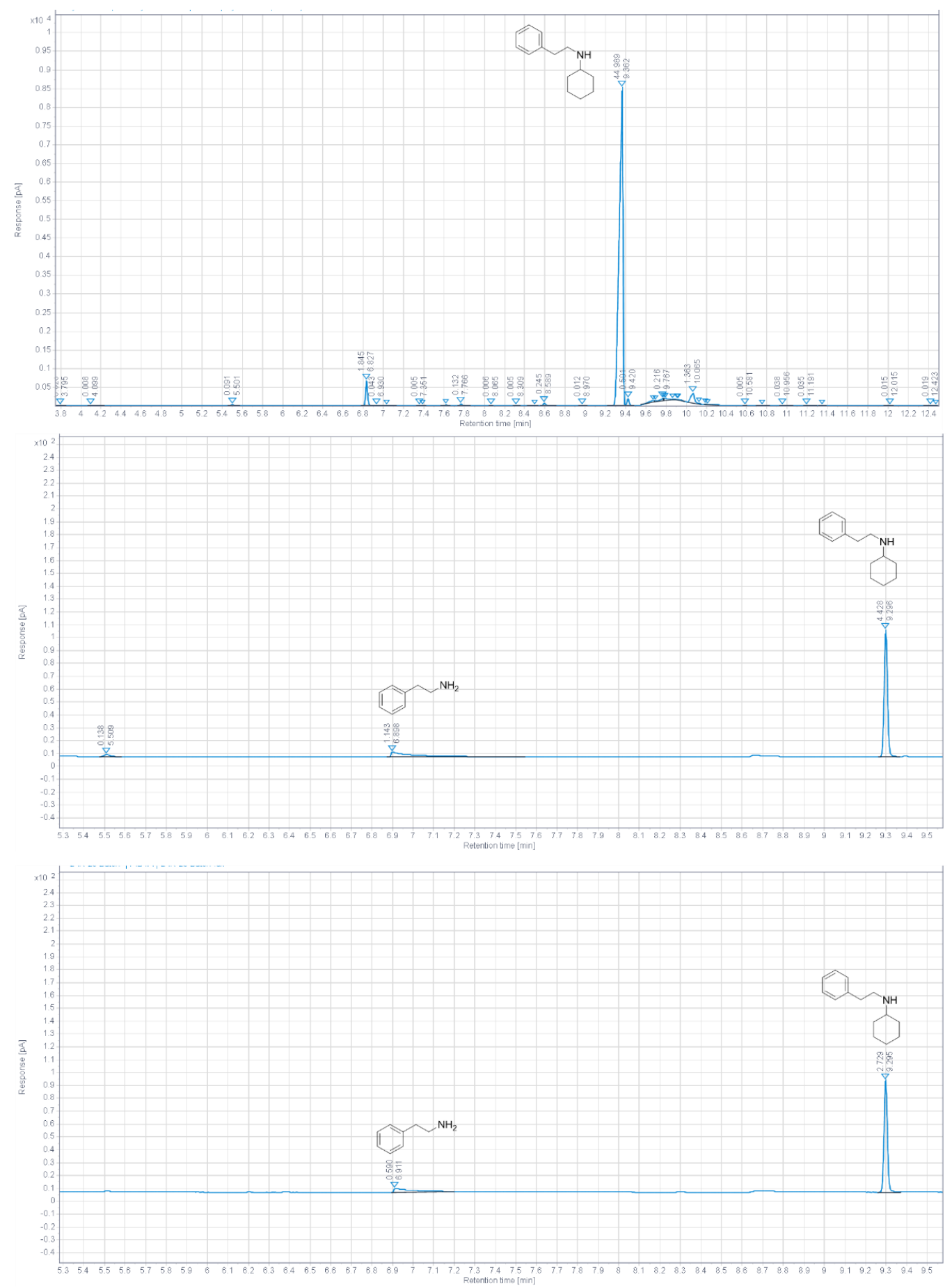

Figure S50: GC-FID spectra of: Top: analytical standard $N$-phenylethyl cyclohexanamine; Middle: steady state of IR-23 single packed bed flow reaction; Bottom: BmTA-IR23 packedbed packed-bed flow reaction. 


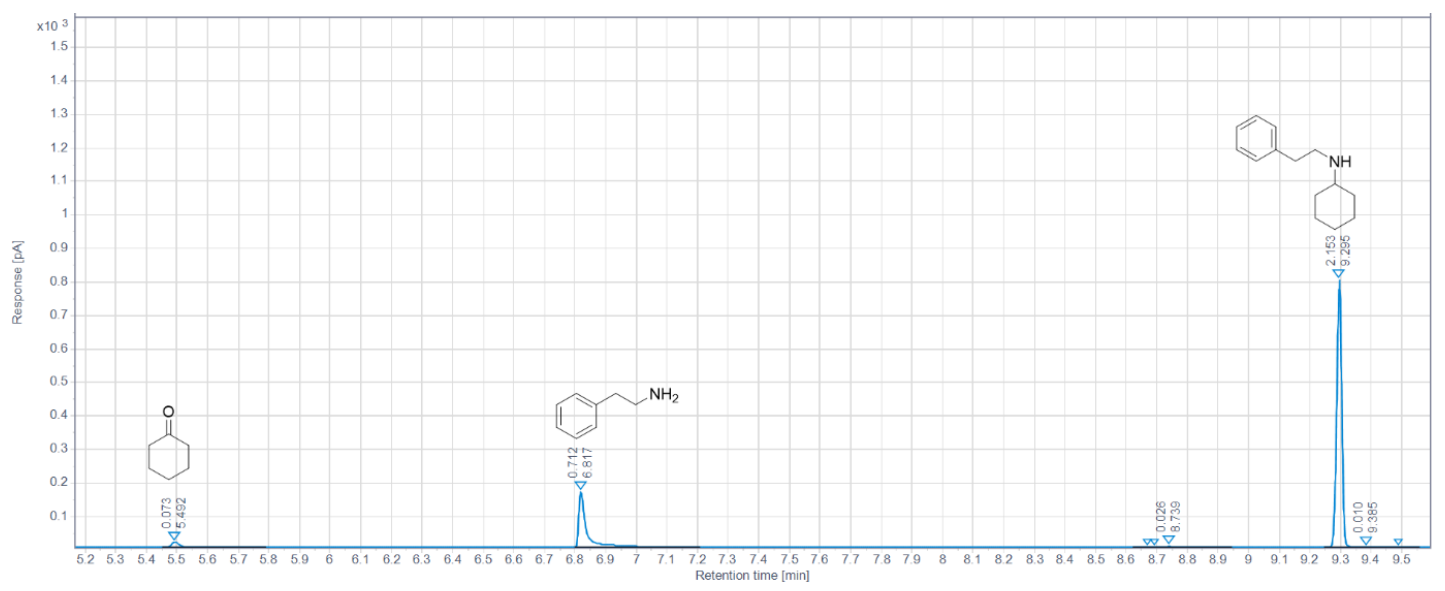

Figure S51: GC-FID spectra of steady state fractions from $\mathrm{AcCO}_{6}-\mathrm{BmTA}$-IR23 MPIR-packed bed packed-bed flow reaction. 


\section{General procedure for synthesis of secondary amines}

To a stirred solution of anhydrous THF $(20 \mathrm{~mL})$ at room temperature under an atmosphere of $\mathrm{N}_{2}$, aldehyde (1 eq.) and amine (1.5 eq.) were added. Glacial acetic acid (1 eq.) and sodium triacetoxyborohydride (1.5 eq.) were added and the mixture was stirred for 24 hours. The reaction mixture was quenched by the addition of saturated $\mathrm{NaHCO}_{3}$ solution $(15 \mathrm{~mL})$ and extracted into EtOAc $(2 \times 15 \mathrm{~mL})$. The combined organic extracts were washed with aqueous $\mathrm{HCl}$ solution ( $1 \mathrm{M}, 3 \times 15 \mathrm{~mL}$ ) and then the combined aqueous extracts were basified to $\mathrm{pH}=$ 12 with $\mathrm{NaOH}$ solution $(5 \mathrm{M})$. The combined aqueous layers were then extracted with EtOAc $(2 \times 15 \mathrm{~mL})$ and then dried over $\mathrm{MgSO}_{4}$. The solvent was removed under reduced pressure to afford the final product.

\section{$N$-benzylcyclopropanamine}

$\mathrm{N}$-benzylcyclopropanamine was prepared as above and matched the literature values (ACS Catal., 2019, 9, 6738).

\section{$N$-(4-methylbenzene)cyclopropylamine}<smiles>Cc1ccc(CNC2CC2)cc1</smiles>

Yellow oil isolated, 59\% yield (191 mg). ${ }^{1} \mathrm{H}$ NMR $\delta_{\mathrm{H}}\left(400 \mathrm{MHz}, \mathrm{CDCl}_{3}\right) 7.21(\mathrm{~d}, \mathrm{~J}=8.0 \mathrm{~Hz}, 2 \mathrm{H})$, $7.14(\mathrm{~d}, \mathrm{~J}=7.8 \mathrm{~Hz}, 2 \mathrm{H}), 3.81(\mathrm{~s}, 2 \mathrm{H}), 2.35(\mathrm{~s}, 3 \mathrm{H}), 2.22-2.12(\mathrm{~m}, 1 \mathrm{H}), 0.51-0.32(\mathrm{~m}, 4 \mathrm{H})$. ${ }^{13} \mathrm{C} \mathrm{NMR} \delta_{\mathrm{C}}\left(101 \mathrm{MHz}, \mathrm{CDCl}_{3}\right) 137.68(\mathrm{C}), 136.48(\mathrm{C}), 129.15(2 \mathrm{CH}), 128.26(2 \mathrm{CH}), 53.52$ $\left(\mathrm{CH}_{2}\right), 30.09(\mathrm{CH}), 21.19\left(\mathrm{CH}_{3}\right), 6.54\left(2 \mathrm{CH}_{2}\right)$; GC-MS: Expected mass [M-H] 160.1, observed mass 160.1 .

\section{$N$-(3-methylbenzene)cyclopropylamine}<smiles>Cc1cccc(CNC2CC2)c1</smiles>

Yellow oil isolated, $68 \%$ yield $(219 \mathrm{mg}) .{ }^{1} \mathrm{H}$ NMR $\delta_{\mathrm{H}}\left(400 \mathrm{MHz}, \mathrm{CDCl}_{3}\right) 7.24(\mathrm{t}, \mathrm{J}=7.5 \mathrm{~Hz}, 1 \mathrm{H})$, $7.17-7.11(\mathrm{~m}, 2 \mathrm{H}), 7.08(\mathrm{~d}, \mathrm{~J}=7.5 \mathrm{~Hz}, 1 \mathrm{H}), 3.83(\mathrm{~s}, 2 \mathrm{H}), 2.37(\mathrm{~s}, 3 \mathrm{H}), 2.18$ (ddd, J = 8.6, 6.6, $3.7 \mathrm{~Hz}, 1 \mathrm{H}), 0.51-0.39(\mathrm{~m}, 4 \mathrm{H}) .{ }^{13} \mathrm{C}$ NMR $\delta_{\mathrm{C}}\left(101 \mathrm{MHz}, \mathrm{CDCl}_{3}\right) 140.60(\mathrm{C}), 138.03(\mathrm{C})$, $129.03(\mathrm{CH}), 128.33(\mathrm{CH}), 127.66(\mathrm{CH}), 125.30(\mathrm{CH}), 53.80\left(\mathrm{CH}_{2}\right), 30.18(\mathrm{CH}), 21.47\left(\mathrm{CH}_{3}\right)$, $6.54\left(2 \mathrm{CH}_{2}\right)$. GC-MS: Expected mass [M-H] 160.1, observed mass 160.1.

\section{$N$-(4-fluorobenzene)cyclopropylamine}<smiles>Fc1ccc(CNC2CC2)cc1</smiles> 
Yellow oil isolated, $55 \%$ yield (182 mg). ${ }^{1} \mathbf{H}$ NMR $\delta_{\mathrm{H}}\left(400 \mathrm{MHz}, \mathrm{CDCl}_{3}\right) 7.31-7.26(\mathrm{~m}, 2 \mathrm{H})$, $7.05-6.98(\mathrm{~m}, 2 \mathrm{H}), 3.82(\mathrm{~s}, 2 \mathrm{H}), 2.20-2.10(\mathrm{~m}, 1 \mathrm{H}), 0.51-0.31(\mathrm{~m}, 4 \mathrm{H}) .{ }^{13} \mathrm{C}$ NMR $\delta_{\mathrm{c}}(101$ $\left.\mathrm{MHz}, \mathrm{CDCl}_{3}\right) 161.98(\mathrm{C}, \mathrm{d}, \mathrm{J}=244.6 \mathrm{~Hz}), 136.46(\mathrm{C}, \mathrm{d}, \mathrm{J}=3.0 \mathrm{~Hz}), 129.83(2 \mathrm{CH}, \mathrm{d}, \mathrm{J}=8.0$ $\mathrm{Hz}), 115.19(2 \mathrm{CH}, \mathrm{d}, \mathrm{J}=21.2 \mathrm{~Hz}), 53.10\left(\mathrm{CH}_{2}\right), 30.13(\mathrm{CH}), 6.55\left(2 \mathrm{CH}_{2}\right)$; GC-MS: Expected mass [M-H] 164.1, observed mass 164.1.

\section{$N$-(3-fluorobenzene)cyclopropylamine}<smiles>Fc1cccc(CNC2CC2)c1</smiles>

Yellow oil isolated, $57 \%(187 \mathrm{mg}) .{ }^{1} \mathrm{H}$ NMR $\delta_{\mathrm{H}}(400 \mathrm{MHz}, \mathrm{CDCl} 3) 7.27$ (td, $\mathrm{J}=7.8,5.9 \mathrm{~Hz}$, $1 \mathrm{H}), 7.08(\mathrm{~d}, \mathrm{~J}=7.6 \mathrm{~Hz}, 1 \mathrm{H}), 7.03(\mathrm{dt}, \mathrm{J}=9.8,2.1 \mathrm{~Hz}, 1 \mathrm{H}), 6.93(\mathrm{td}, \mathrm{J}=8.3,2.3 \mathrm{~Hz}, 1 \mathrm{H}), 3.83$ (s, 2H), $2.18-2.11(\mathrm{~m}, 1 \mathrm{H}), 0.48-0.35(\mathrm{~m}, 4 \mathrm{H}) .{ }^{13} \mathrm{C}$ NMR $\delta_{\mathrm{c}}(101 \mathrm{MHz}, \mathrm{CDCl} 3) 162.97(\mathrm{C}$, d, J = 245.5 Hz), $143.38(\mathrm{C}, \mathrm{d}, \mathrm{J}=6.8 \mathrm{~Hz}), 129.77(\mathrm{CH}, \mathrm{d}, \mathrm{J}=8.3 \mathrm{~Hz}), 123.67(\mathrm{CH}, \mathrm{d}, \mathrm{J}=2.8$ $\mathrm{Hz}), 114.97(\mathrm{CH}, \mathrm{d}, \mathrm{J}=21.0 \mathrm{~Hz}), 113.67(\mathrm{CH}, \mathrm{d}, \mathrm{J}=21.2 \mathrm{~Hz}), 53.21\left(\mathrm{CH}_{2}, \mathrm{~d}, \mathrm{~J}=1.8 \mathrm{~Hz}\right)$, $30.04(\mathrm{CH}), 6.50\left(2 \mathrm{CH}_{2}\right)$; GC-MS: Expected mass [M-H] 164.1, observed mass 164.1. 


\section{NMR Spectra}
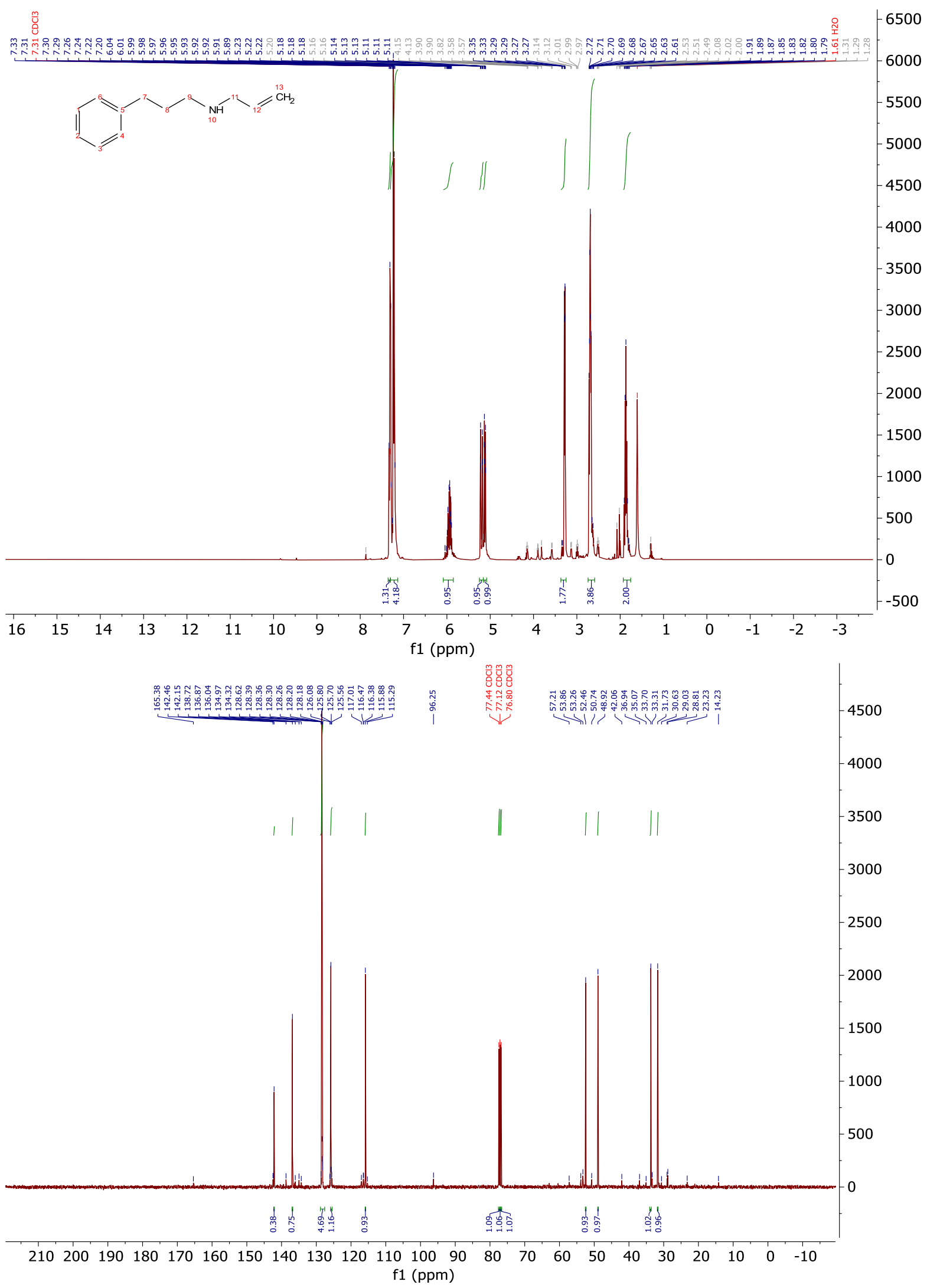

Figure S52: ${ }^{1} \mathrm{H}-\mathrm{NMR}$ spectrum (top) and ${ }^{13} \mathrm{C}-\mathrm{NMR}$ spectrum (bottom) of $\mathrm{N}$ hydrocinnamlyallylamine. 


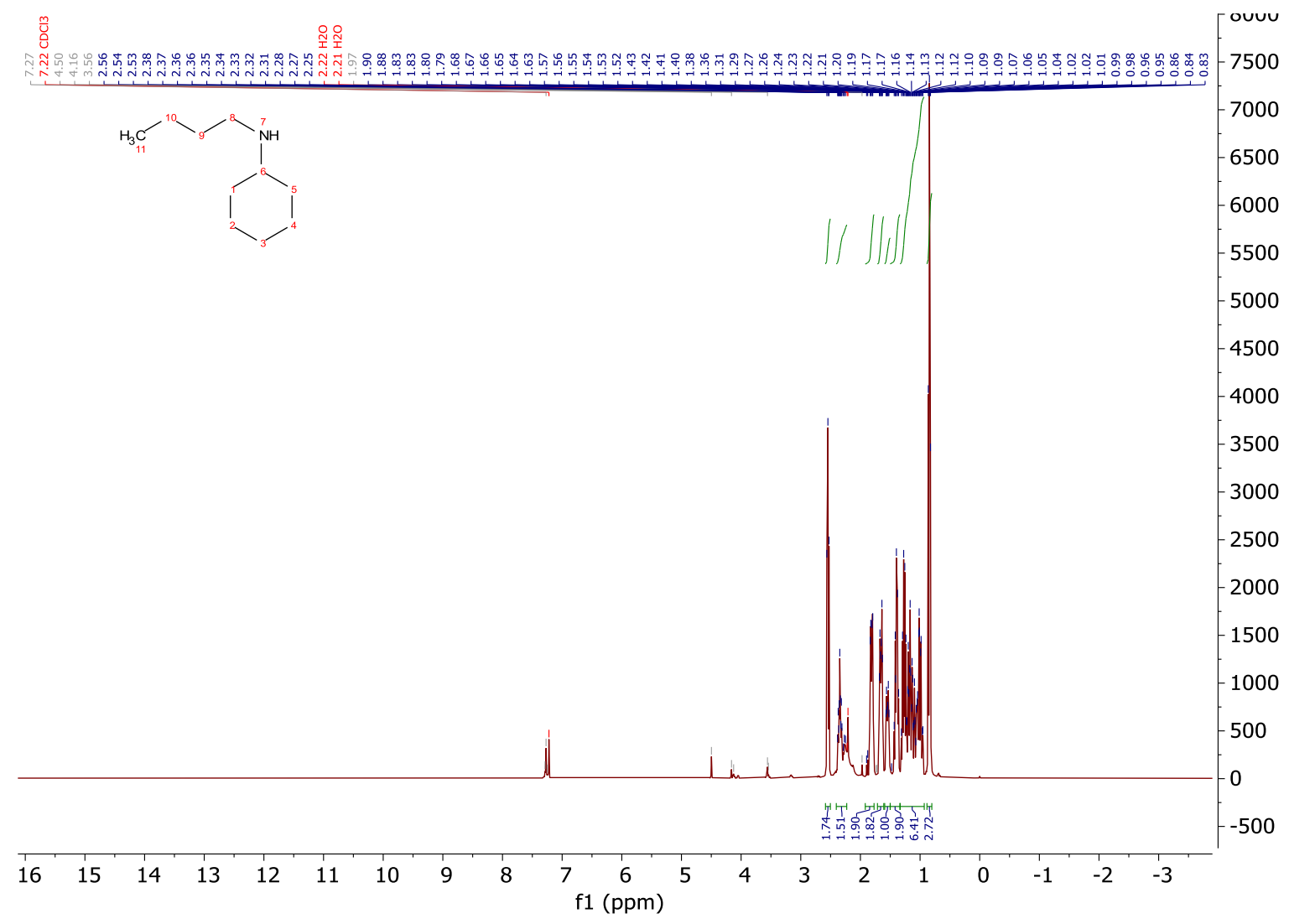

Figure S53: ${ }^{1} \mathrm{H}-\mathrm{NMR}$ spectrum of $\mathrm{N}$-butylcyclohexanamine. 

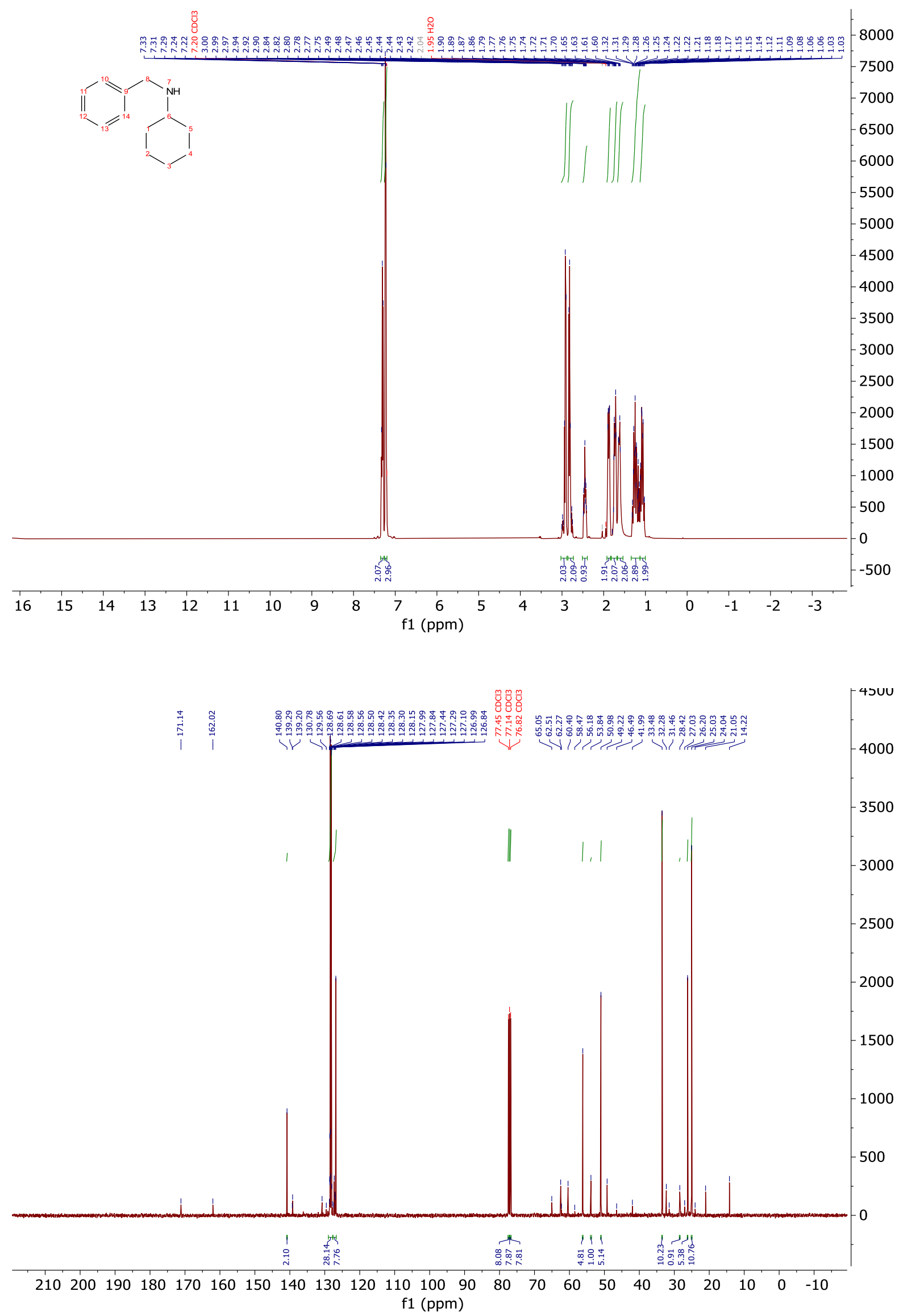
Figure S54: ${ }^{1} \mathrm{H}-\mathrm{NMR}$ spectrum (top) and ${ }^{13} \mathrm{C}-\mathrm{NMR}$ spectrum (bottom) of $\mathrm{N}$-benzyl cyclohexanamine.

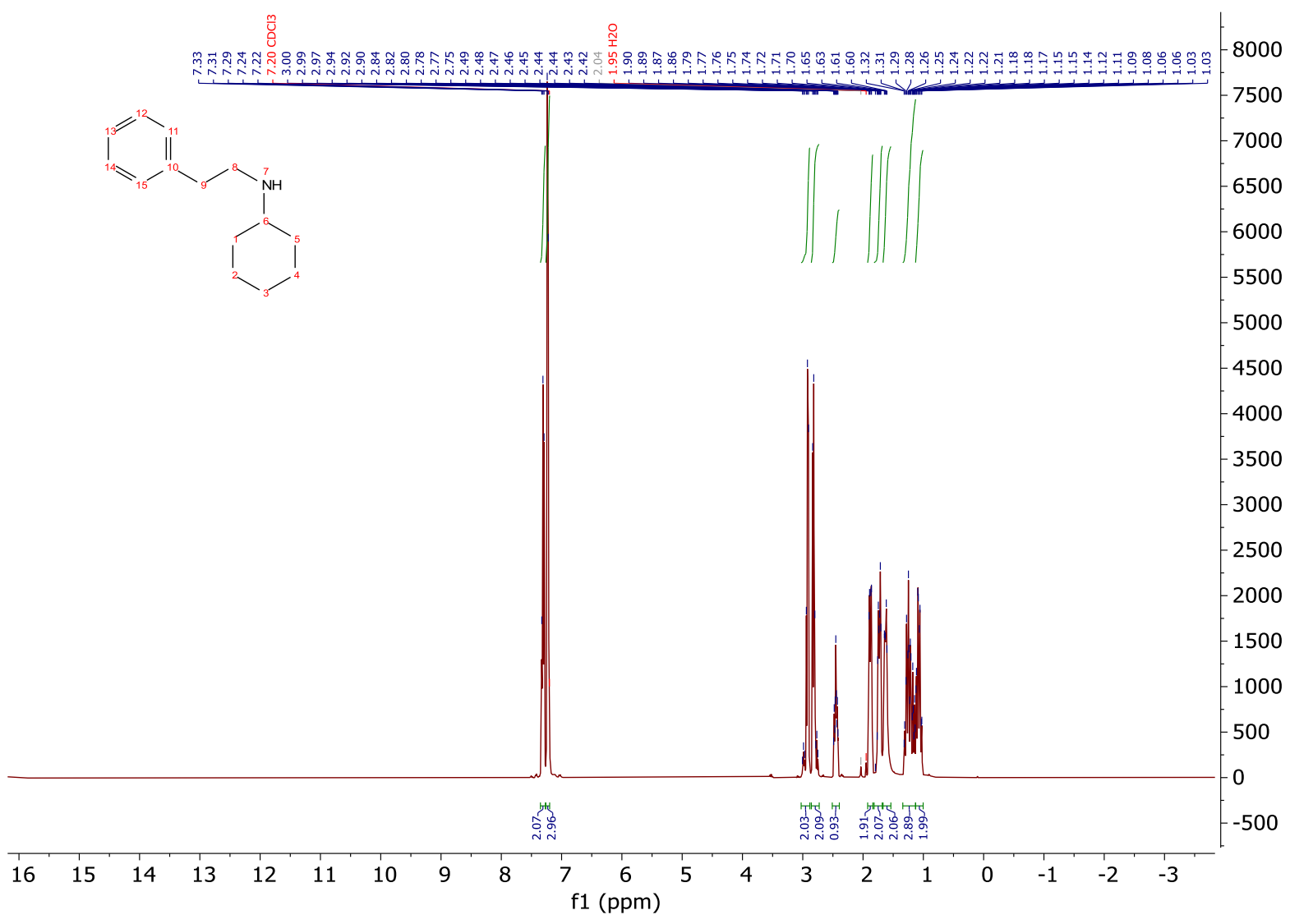




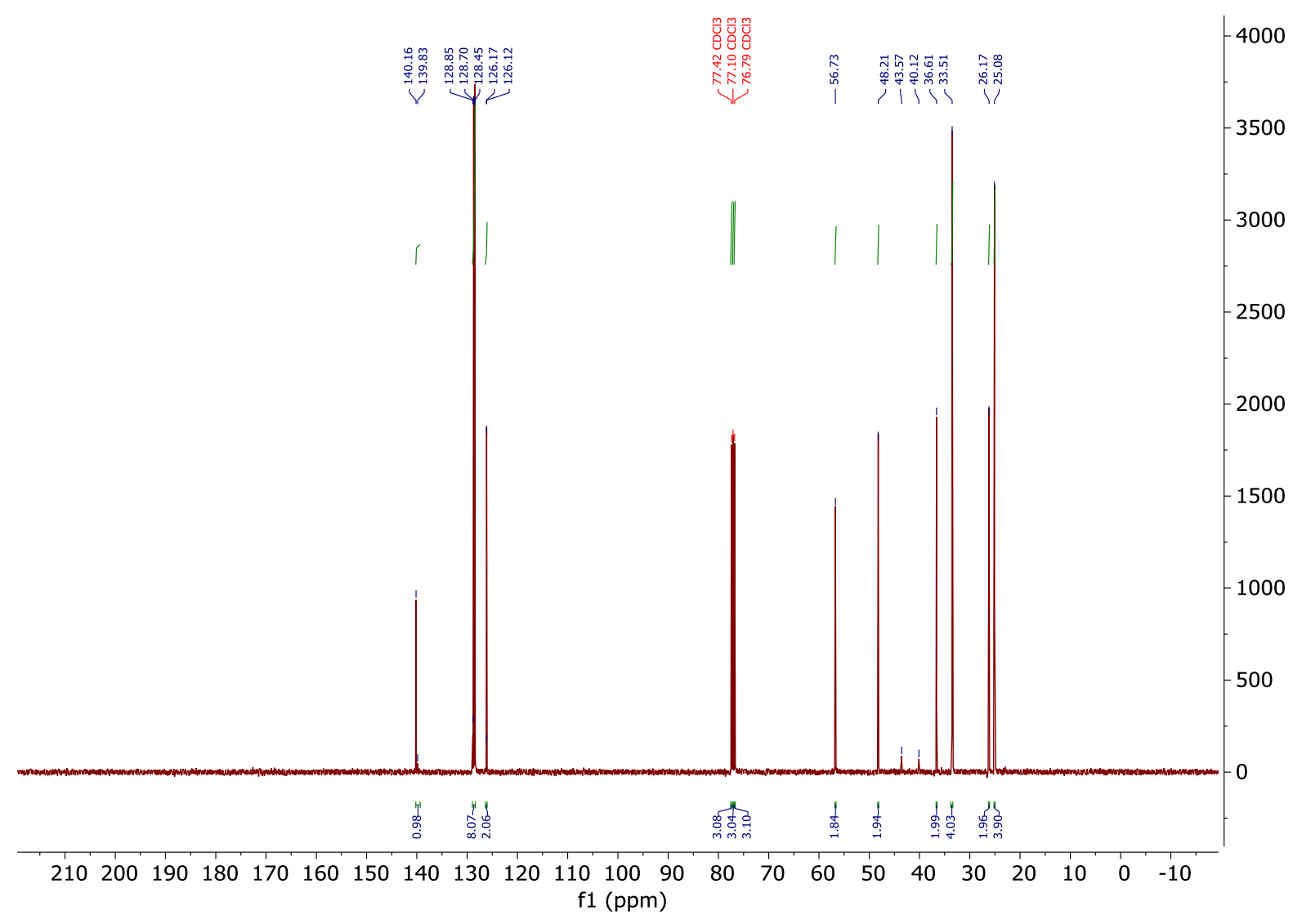

Figure S55: ${ }^{1} \mathrm{H}$-NMR spectrum (top) and ${ }^{13} \mathrm{C}$-NMR spectrum (bottom) of $\mathrm{N}$-phenylethyl cyclohexanamine. 

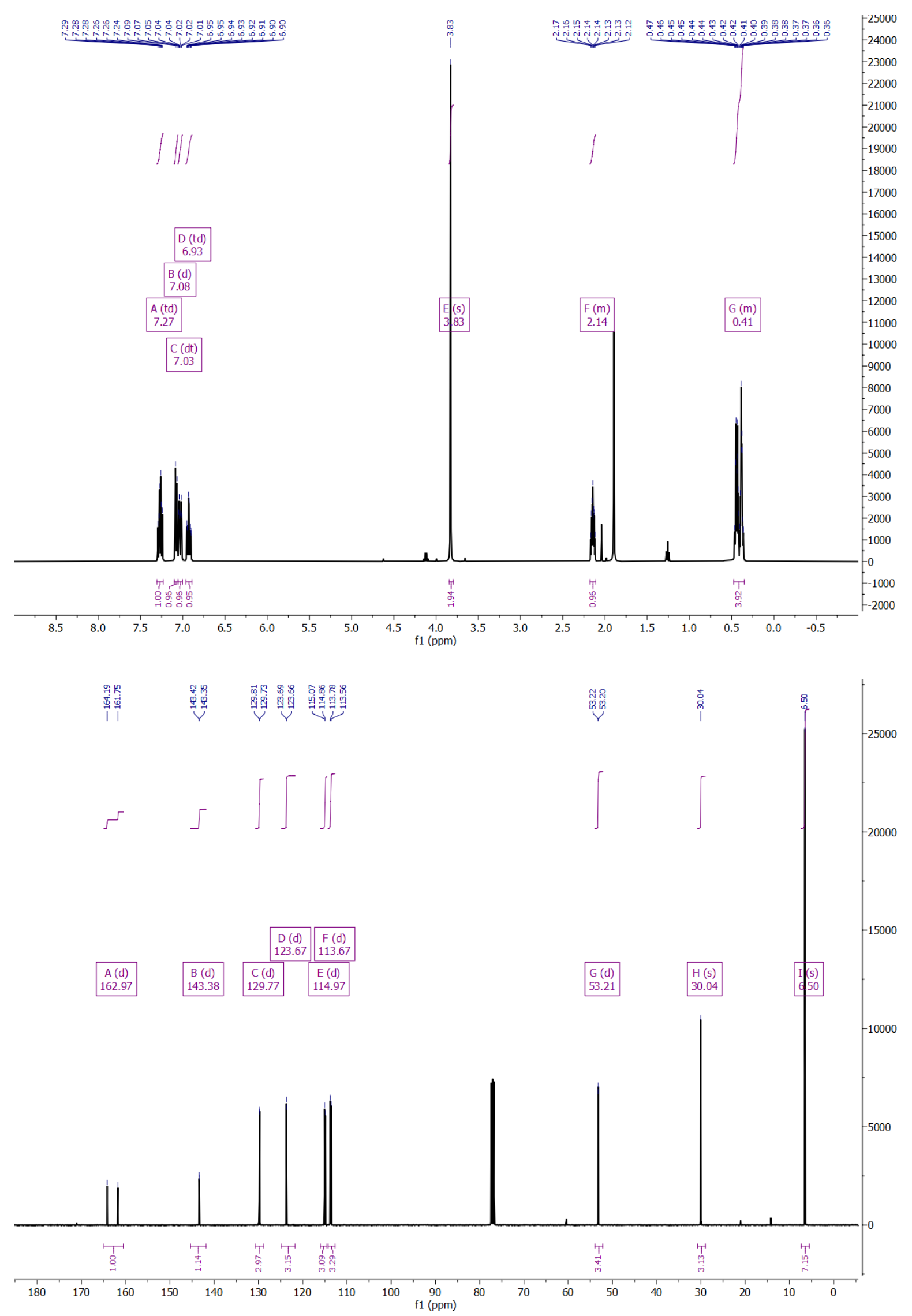

Figure S56: ${ }^{1} \mathrm{H}$ NMR spectrum (top) and ${ }^{13} \mathrm{C}$ NMR spectrum (bottom) of $\mathrm{N}$-(3fluorobenzene)cyclopropylamine. 


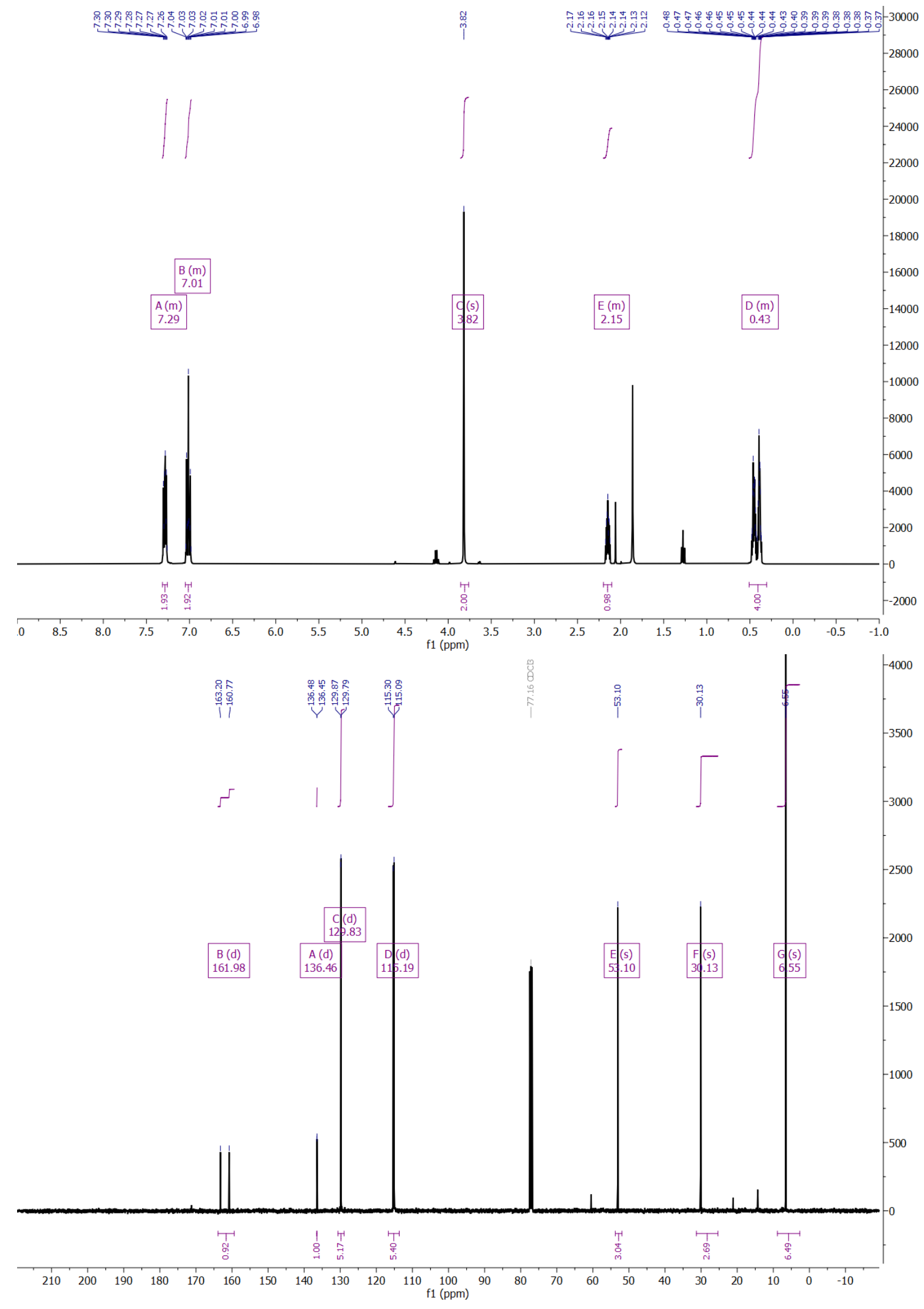

Figure S57: ${ }^{1} \mathrm{H}$ NMR spectrum (top) and ${ }^{13} \mathrm{C}$ NMR spectrum (bottom) of $\mathrm{N}$-(4fluorobenzene)cyclopropylamine. 


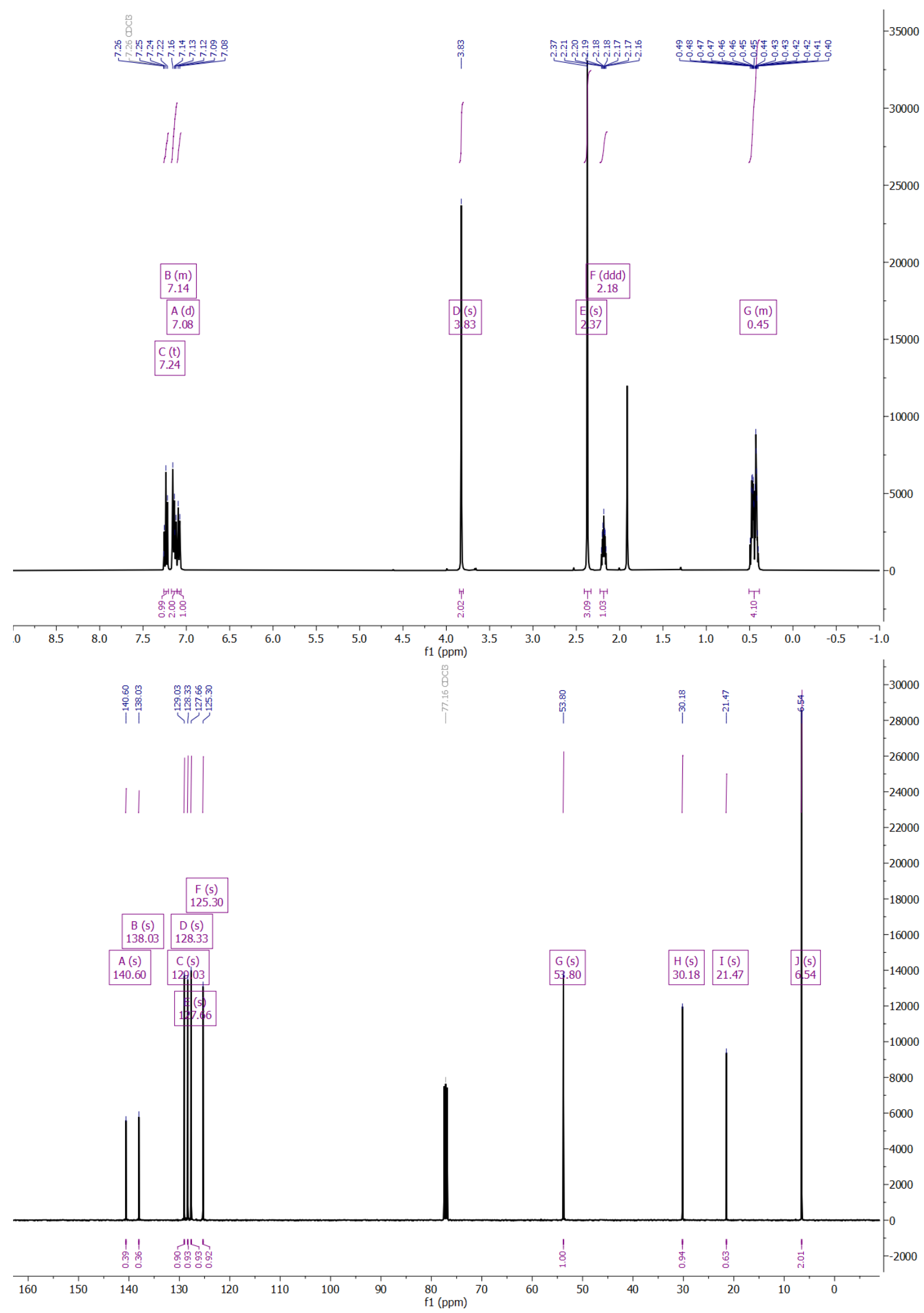

Figure S58: ${ }^{1} \mathrm{H}$ NMR spectrum (top) and ${ }^{13} \mathrm{C}$ NMR spectrum (bottom) of $\mathrm{N}$-(3methylbenzene)cyclopropylamine. 


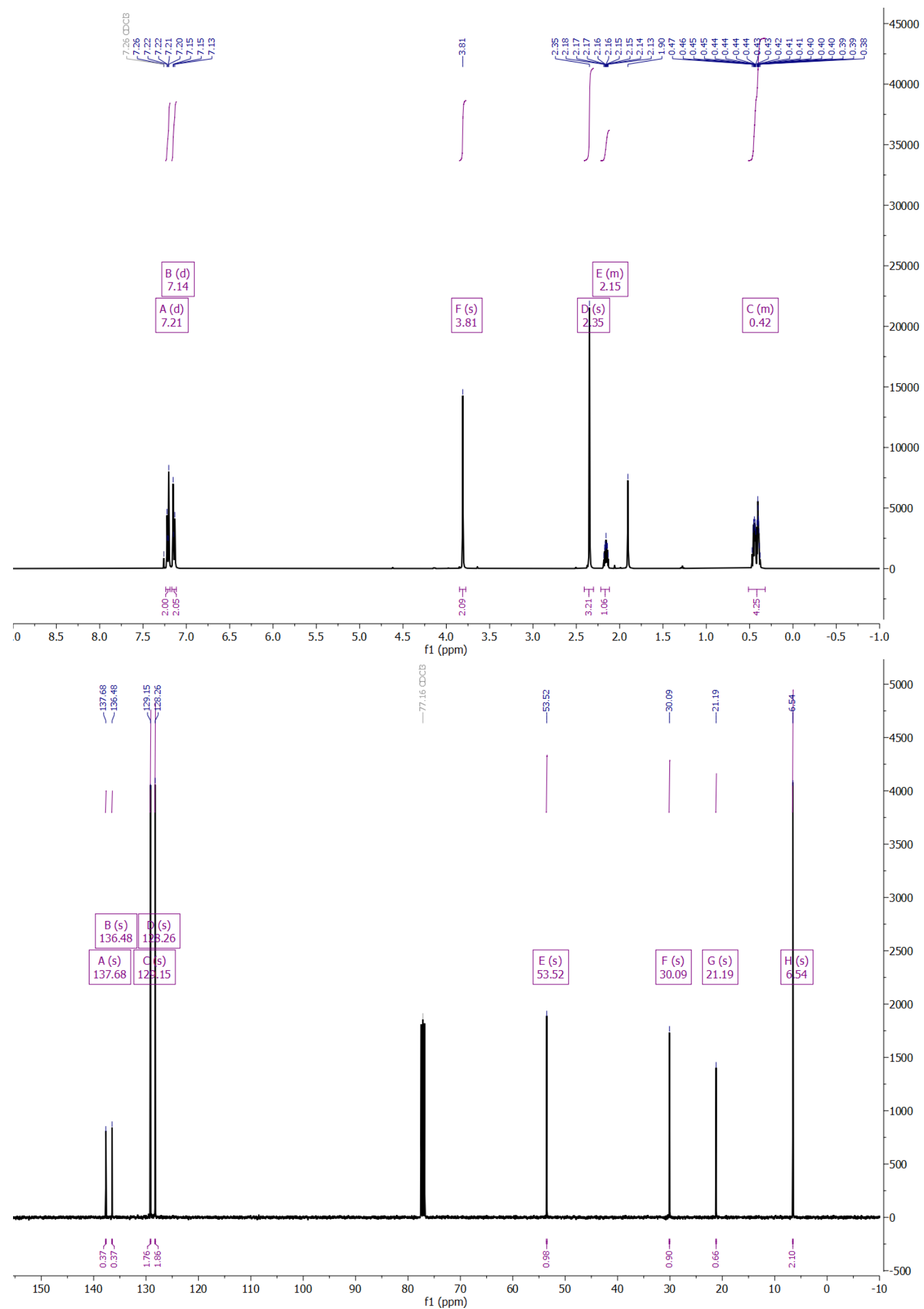

Figure S59: ${ }^{1} \mathrm{H}$ NMR spectrum (top) and ${ }^{13} \mathrm{C}$ NMR spectrum (bottom) of $\mathrm{N}$-(4fluorobenzene)cyclopropylamine. 


\section{Synthesis of 4-OMethylnorbelladine}

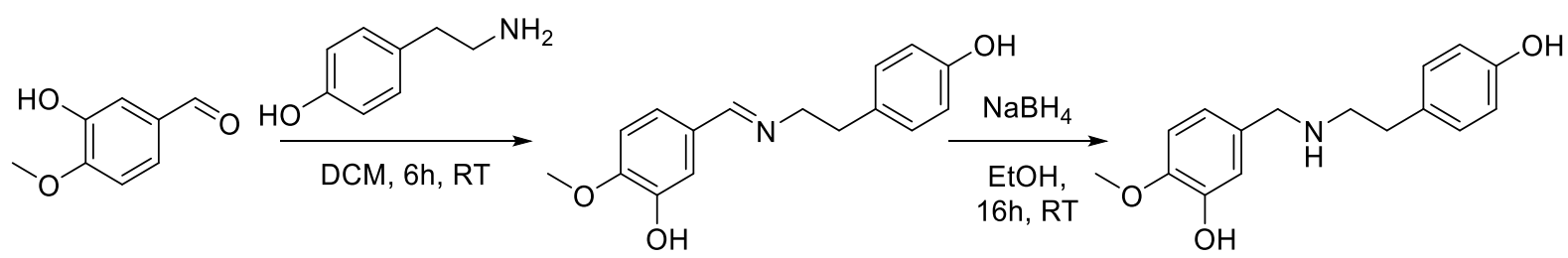

3-hydroxy-4-hydroxymethyl benzaldehyde (304 mg, $2.0 \mathrm{mmol})$ was dissolved in dichloromethane $(8 \mathrm{~mL})$ before addition of tyramine $(274 \mathrm{mg}, 2.0 \mathrm{mmol})$. The solution was stirred at ambient temperature for 6 hours before concentrating in vacuo. The resulting solid was dissolved in methanol $(8 \mathrm{~mL})$ and sodium borohydride $(76 \mathrm{mg}, 2.0 \mathrm{mmol}$ ) was added. The solution was subsequently stirred at ambient temperature for 16 hours. The reaction mixture was concentrated in vacuo and the crude material re-suspended in water $(10 \mathrm{~mL})$. The suspension was filtered and the solid dissolved in methanol before concentrating in vacuo to yield a brown powder (449 mg, 82\%); data consistent with those reported in the literature; ${ }^{4}$ 

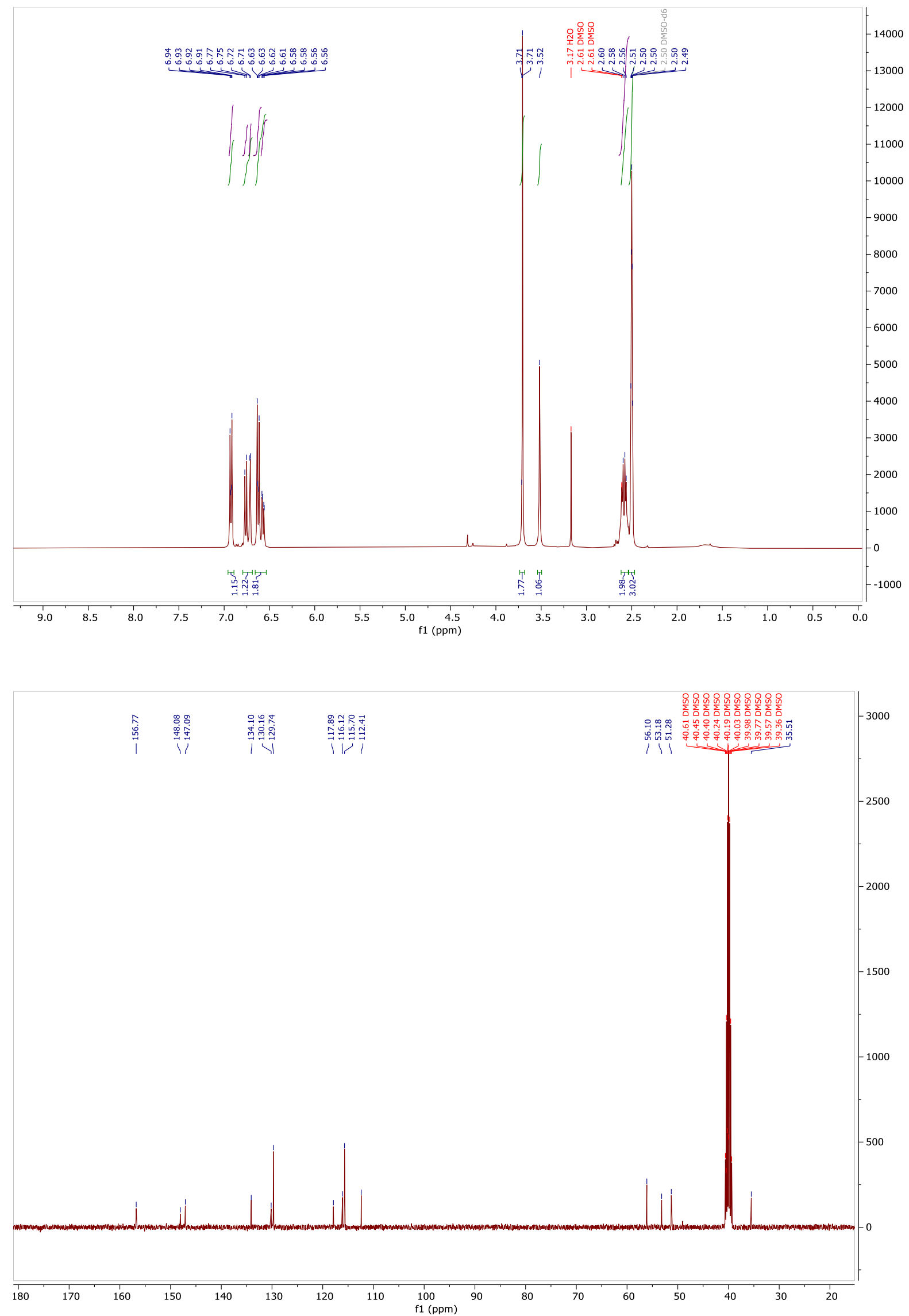
Figure S60: ${ }^{1} \mathrm{H}$-NMR spectrum (top) and ${ }^{13} \mathrm{C}-\mathrm{NMR}$ (bottom) spectrum of 4OMethylmorbelladine.

\section{References}

1. Montgomery, S. L. et al. Characterization of imine reductases in reductive amination for the exploration of structure-activity relationships. Sci. Adv. 6, eaay9320 (2020).

2. Chapman, M. R., Cosgrove, S. C., Turner, N. J., Kapur, N. \& Blacker, A. J. Highly Productive Oxidative Biocatalysis in Continuous Flow by Enhancing the Aqueous Equilibrium Solubility of Oxygen. Angew. Chemie - Int. Ed. 57, 10535-10539 (2018).

3. Marshall, J. R. et al. Screening and characterization of a diverse panel of metagenomic imine reductases for biocatalytic reductive amination. Nat. Chem. (2020) doi:https://doi.org/10.1038/s41557-020-00606-w.

4. Singh, A. et al. Cloning and characterization of norbelladine synthase catalyzing the first committed reaction in Amaryllidaceae alkaloid biosynthesis. BMC Plant Biol. 18, (2018). 